BNWL-SA-5109

\title{
HISTOGENESIS OF FETAL RAT LUNG AND LIVER AFTER X-IRRADIATION IN ORGAN CULTURE AND IN UTERO
}

\author{
JUDITH C. VOGT
}

June 1975 the United States nor the United States Atomic Energy Commission, nor any of their employees, nor any of their contractors, subcontractors, or their employees, makes any warranty, express or implied, or assumes any legal liability or responsibility for the accuracy, completeness or usefulness of any information, apparatus, product or process disclosed, or represents that its use would not infringe privately owned rights. 


\section{DISCLAIMER}

This report was prepared as an account of work sponsored by an agency of the United States Government. Neither the United States Government nor any agency Thereof, nor any of their employees, makes any warranty, express or implied, or assumes any legal liability or responsibility for the accuracy, completeness, or usefulness of any information, apparatus, product, or process disclosed, or represents that its use would not infringe privately owned rights. Reference herein to any specific commercial product, process, or service by trade name, trademark, manufacturer, or otherwise does not necessarily constitute or imply its endorsement, recommendation, or favoring by the United States Government or any agency thereof. The views and opinions of authors expressed herein do not necessarily state or reflect those of the United States Government or any agency thereof. 


\section{DISCLAIMER}

Portions of this document may be illegible in electronic image products. Images are produced from the best available original document. 


\title{
Histogenesis of Fetal Rat Lung and Liver After $\mathrm{X}$-Irradiation in Organ Culture and In Utero \\ by \\ Judith C. Vogt
}

\author{
A THESIS \\ submitted to \\ Oregon State University
}

\author{
in partial fulfillment of \\ the requirements for the \\ degree of \\ Doctor of Philosophy \\ June 1975
}




\section{FOREWORD}

This document is based on a thesis submitted to Oregon State University in partial fulfillment of the requirements for the degree of Doctor of Philosophy. The work described was performed under the direction of Melvin R. Sikov and D. Dennis Mahlum at Battelle, Pacific Northwest Laboratory, supported by a fellowship from the Northwest College and University Association for Science. 


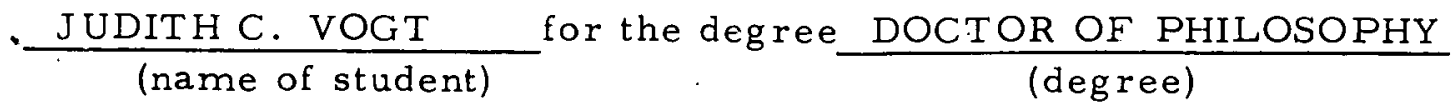
in GENERAL SCIENCE presented on $\frac{\text { AUGUST 13,1974 }}{\text { (Major department) }}$

Title:_HISTOGENESIS OF FETAL RAT LUNG AND LIVER AFTER X-IRRADIATION IN ORGAN CULTURE AND IN UTERO

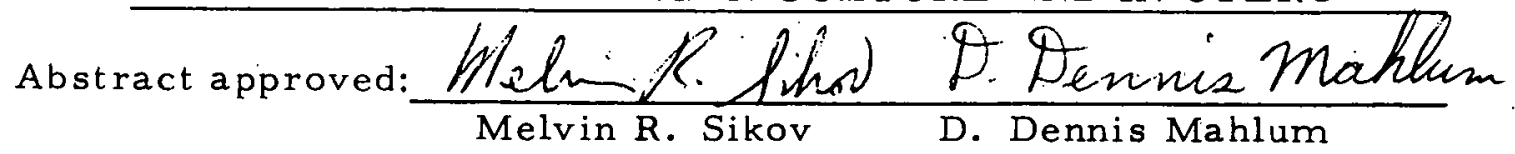

This study compares the effects of exposure to 0 or $435 \mathrm{R}$ of $x$-ray on the in vitro and in vivo development of fetal rat lung and liver when irradiated at $13,15,17$, and 19 days of gestation. In one series of experiments organs were irradiated immediately after explantation and cultured for four hours, one or three days. In a parallel series pregnant females were irradiated and the fetal organs were explanted one and three days post-irradiation and cultured four hours.

The response of liver explants to culture conditions was variable but the presence of necrosis, fibrinogenesis and decreased hematopoiesis was consistently noted. The events associated with culturing of the liver tended to mask the effects of radiation on its organogenesis. 
In the method of culture used, fetal lungs grew and differentiated. There was an initial decrease followed by a resurgence in mitosis between one and three days post-explantation. In vitro morphogenesis did not keep pace with lungs developing in utero. Specific departures from normal development observed in organ culture included degeneration of the epithelial lining of the bronchial tree; deterioration of blood vessels; pycnosis; especially in the mesenchyme; and an initial decrease in mitosis.

In general, radiation accelerated and magnified the changes associated with culturing. In the organ cultures the effects of irradiation were progressive and irreversible for the first three days postirradiation. Recovery was observed between one and three days postirradiation, however in lungs remaining in utero.

Connective tissue deposition is a normal event associated with morphogenesis and is accelerated by culturing and further accelerated by $x$-irradiation. Morphologically the connective tissue synthesized does not appear to be the same between the treatment groups. Biochemical and autoradiographic studies of 15 -day fetal lung confirm these histological observations. 
Effects of X-Irradiation on Biological Systems 2 Embryology of Rat Liver 8 Organogenesis of Fetal Liver 9 Histology of the Liver 12

Characteristics of Liver Culture 14 Biochemical Studies on Developing Liver 20 Metabolic Studies on Liver Organ Culture 22 Embryology of the Fetal Rat Lung 24 Histology of the Lung 26

Studies on the Development of the Lung in Organ Culture

Histochemical Changes During Lung Development 34 Radiation Studies on Lung Cultures 36 Properties of Connective Tissue 38 Properties of Collagen 41 Effect of Radiation on Connective Tissue Scope of These Studies 45

MATERIALS AND METHODS 48

Design of Experiments 48

Method of Culture 49

Histological Procedures 54

$\mathrm{X}$-Irradiation Conditions $\quad 55$

Biochemical Analysis $\quad 56$

Counting Techniques 57

STUDIES ON FETAL LIVER

Results 58

Discussion 93

In Vitro Development of Fetal Kat Liver y.

Effect of Radiation on the Development of

Fetal Rat Liver

$\begin{array}{ll}\text { ST UDIES ON FETA L, LUNG } & 101\end{array}$

Results 101

Histological Studies , 110 
Results and Interpretation of Biochemical

Studies on Fifteen-Day Fetal Lung. 156

Discussion

In Vivo Development of Fetal Rat Lung

In Vitro Development of Fetal Rat Lung

168

Effect of Radiation on Development of Fetal Rat Lung

169

Connective Tissue Biosynthesis

BIB LIOGRA PHY

APPENDIC ES

Appendix I

Appendix II

Appendix III

193

Appendix IV

194

Appendix $V$

197

Appendix VI

198

Appendix VII

200

Appendix VIII

202

Appendix IX

204 


\section{HISTOGENESIS OF FETAL RAT LUNG AND LIVER AFTER}

X-IRRADIATION IN ORGAN CULTURE AND IN UTERO

\section{INT RODUC TION}

Organ culture, as an intermediate between the whole animal and the homogeneous cell population of tissue culture, provides a useful research tool in radiation research. The effects of radiation on fetal organs are obscured in the uterine environment. While studies on tissue culture have contributed to our understanding of cellular response to radiation, they fail to measure its effect on differentiation. The organ culture technique, which has been used to elucidate the mechanisms of organ development, can facilitate the measurement of cellular interactions which are independent of abscopal effects. By comparing both in vivo and in vitro histogenesis after irradiation, mechanisms can be inferred which are unique to the organ.

The objectives of these radiation studies on fetal rat lung and liver are to examine the following responses: 1) The effect of radiation in vitro on fetal organ histogenesis; 2 ) The effect of radiation in utero on subsequent development in organ culture; 3) The effect of radiation in utero on the in utero development of the organ. 


\section{Effects of X-Irradiation on Biological Systems}

Malformations of the embryo are considered to be the result of a series of chemical alterations that lead to net morphological change. Ionizing radiation is recognized as a potent teratogenic agent which also produces alterations of organogenesis. To provide an understanding of the overt manifestations of radiation the effects of ionizing radiation at the molecular, macromolecula $r$ and tissue levels should be considered.

In living tissue, radiation produces both primary events, such as excitations and ionizations, as well as secondary events which may lead to biological damage. One of the most important of the secondary events is the dissociation of water molecules into highly reactive radicals:

$$
\mathrm{H}_{2} \mathrm{O} \stackrel{\mathrm{X}-\mathrm{ray}}{\longrightarrow} \mathrm{H}^{\mathrm{O}}+\mathrm{OH}^{\circ}
$$

In an aqueous biological system, the primary ionization of biologically important molecules per se and the indirect effects of ions or free radicals must be considered. With low LET radiations, increased oxygen tension results in a higher yield of $\mathrm{f}$ ree radicals so that the response of the biological system is increased. 
Chemical structure is altered by ionizing radiation; Iipids and polymers, such as proteins and carbohydrates, may be degraded into smaller units. Breakage of bonds, and the subsequent cross-linking between and within molecules can alter secondary and tertiary structure of molecules and have deleterious effects. The nucleus is the most radiosensitive organelle in the cell ( $\mathrm{Zirkle;} \mathrm{1957)} \mathrm{and} \mathrm{of} \mathrm{the}$ nucleic acid components, pyrimidines a re the most sensitive to radiation. The structure of the nucleic acids can undergo a variety of alterations: change of base or deamination, loss of a base, hydrogen bond fracture, breakage of one or both strands, altered cross-linking within the helix, between helices and other compounds. The stability of nucleic acid-protein bond is decreased after $200 \mathrm{R}$ (Hagen, 1963) and the broken bonds can lead to peroxidation. Radiation results in a decrease in the rate of RNA and DNA synthesis. Unsaturated lipids are also susceptible to radiation damage. With the removal of hydrogen atoms, highly reactive organic peroxides are formed in the presence of oxygen (Casarett, 1968).

Large doses (3000-5000 rads) result in rupture of the plasma membrane, swelling of the endoplasmic reticulum and the disorganization of mitochondrial cristae. The nuclear membrane seems more resistant to rhange. Bacg and Alexander (1961) suggest that 
radiation-induced dis ruption of the lysosomes and the resulting release of enzymes may be the cause of cell death. In embryonic cells undergoing necrosis following irradiation, an accumulation of basophilic, DNAase-sensitive clumps have been observed in the cytoplasm. Hicks and D'Amato (1966) report that the clumps appear in some cells. before abnormal mitosis takes place, suggesting that some lethal radiation effects begin in the cytoplasm.

The doses required to alter constitutive enzymic systems (up to 1 Mrad) are greater than doses which induce chromosomal changes. When an enzyme is bound to a substrate, it is even less susceptible to radiation damage (Casarett, 1968). Moderate doses of radiation $(400 \mathrm{R})$ can inhibit dietary induction of enzyme systems, but induction by steroids, in some instances, are actually enhanced by radiation (Pitot, Peraino, and Lamar, 1965). The alteration in the-quantity or quality of enzymes seems to be a secondary effect of $x$-irradiation due to interrupted transcription of DNA. The messenger RNA undergoes decay by an unknown process (Pollard, 1964).

Radiation has been shown to produce chromosomal damage which can result in cellular death, or persistent chromosomal abnormalities (bridges, rings, fragments), as well as vacuolization of the nucleus and cytoplasm and supression of mitosis. Chromosomal damage is most readily manifested in actively dividing cells. Relatively low doses $(50 \mathrm{R})$ can result in mitotic delay of cultured cells. The mitotic 
delay is prolonged with increased exposure and is due in part to a delay in the breakdown of the nuclear membrane and to chromosomal stickiness. Some cells can synthesize DNA but do not undergo cytokinesis and this leads to polyploidy (Casarett, 1968).

Casarett (1968) has classified cell types in the adult according to their radiosensitivity, based in relation to their rate of proliferation and their state of differentiation. Among the cells most sensitive to radiation are the mature lymphocytes, erythroblasts, endothelial cells of small blood vessels, chondroblasts (ciartilage precursors) and fibroblasts (Casarett, 1968). Fibroblasts have a mean lethal dose of $60 \mathrm{R}$ (Puck et al., 1957). Granulocytes, parenchyma cells; endothelial cells of large blood vessels and red blood cells are léss sensitive to radiation. More radioresistant a re the fibrocytes (connective tissue cells), reticular cells (fixed hematopoietic cells), chondrocytes (cartilage cells) and phagocytes (casarett, 1968). Embryos possess changing proliferative and differentiating cell populations that do not respond alike to radiation (Hicks and D'Amato, 1966). Mesenchymal cells in 12-day rat embryos become necrotic within an hour after $200 \mathrm{R}$, in contrast to differentiated cells, as in the nervous system, in which the process takes longer (Hicks and D'Amato, 1966).

The response of an organ to radiation may be influenced by the response of other irradiated tissues. There is some indirect evidence 
that circulating toxins are produced as a result of radiation damage. There are certain characteristic changes that generally occur in irradiated tissues. Cells may exhibit chromosomal abberations and degenerative changes. The populations of the cells may change as the more radiosensitive deteriorate and are removed by the radioresistant phagocytes. Hemorrhage is common; at moderate doses of radiation, capillaries become occluded and their permeability increases, possibly due to the depolymerization of hyaluronic acid (Casarett, 1968). However, Trowell (1966) believes that organ damage due to radiation is not solely vascular, for chromosomal damage is incurred at lower doses.

The adult lung is quite resistant to ionizing radiation. After large doses, however, the lung initially becomes edematous and hemorrhagic, and later undergoes hyalinization and fibrosis. The response of fetal lung to radiation is largely unknown.

During embryonic development of the rat, the liver is a major hematopoietic tissue. The general structure of the hematopoietic elements is a fibrous network composed of reticular fibers and cells, including fixed macrophages and primitive reticular cells. A wide variety of blood and connective tissue components may be formed by the primitive reticular cells. Of these the macrophages, reticular cells and connective tissue cells a re relatively resistant to radiation; whereas the blood cell precursors, including erythroblasts, 
myelocytes, megakaryocytes, and fibroblasts are sensitive to radiation (Casarett, 1968). Evidence points to a radiosensitivity of the rat hematopoietic system as early as $12-15$ days of gestation (Wilson and Karr, 1951). Izadian and Duplan (1957) found increased hepatic stores of iron 2-4 days after irradiation at 12-14 days of gestation which they attributed to the arrest of erythropoiesis. Hazzard and Budd (1969) reported that a dose of $240 \mathrm{R}$ of $\mathrm{x}$-ray at 15 days of gestation resulted in a decreased concentration of white blood cells, but not of red blood cells, in the newborn. Differentiated (adult) liver cells, which are normally radioresistant, - may exhibit radiation-induced damage as a result of the degenerative changes which occur in the irradiated vascular system. The Küpffer cells are mobilized with the degeneration of tissues (Casarett, 1968). Smith and Shore (1966) exposed rats to $180 \mathrm{rad}$ in utero on the fifteenth day of development. The livers were reduced in size, although the relative proportion of parenchyma and hematopoietic cells was unaltered. The activities of lactic and glycerophosphate dehydrogenases and glucose-6-phosphatase were normal at 20 days of gestation, but the subsequent increase in enzymes after birth was only $30-60 \%$ of that in the controls. The authors suggest that the failure of the organ to develop metabolically may have significance in the decreased survival of irradiated litters.

The above discussion summarizes in vivo radiation effects. To compare the in vivo and in vitro effects is technically difficult for one 
must insure that the intracellular oxygen is the same. Explants undergo biochemical alteration the minute they a re removed from the body and this may alter their radiosensitivity; in addition, the study of radiation effects in organ culture eliminates interactions between organs that may occur in vivo (T rowell, 1966). This will be detailed in a subsequent discussion.

\section{Embryology of Rat Liver}

The tissues comprising the liver are derived from a number of sources: (1) the endoderm of the floor of the foregut differentiates into the parenchymal cells and the cells of the bile drainage system, including the bile ducts; (2) the mesenchyme of the septum transversum ultimately forms the connective tissue of Glisson's capsule and some of the hematopoietic tissue; (3) the lining of major blood vessels that transverse the septum transversum, become the lining cells of the sinusoids; and (4) the blood islands of the yolk sac provide part of the hematopoietic tissue (Wilson, Groat, and Leduc, 1963).

The liver arises as a ventral diverticulum of the foregut which becomes hollow and lined with columnar epithelium (Maximow and Bloom, 1957). In rats, the diverticulum forms at 11 days of gestation and rapid cell proliferation followed by epithelial cord formation . occurs shortly thereafter. By the twelfth day of gestation liver cells can be recognized and $1 / 2$ day later, the organ acquires blood vessels. 
On the thirteenth day of gestation the liver mass surrounds the hepatic artery and contains sinusoids and mesenchyme (Rugh, 1968). The . cranial part of the primitive liver penetrates the septum transversum which, at this stage is essentially composed of the vitelline veins with their surrounding mesenchyme. Now the parenchymal cords are diffuse but they progressively become more compact; the sinusoids become more narrow as the amount of parenchyma increases (Wilson et al. , 1963). Many primitive hematopoietic cells are interspersed with the liver cells on the fourteenth day of gestation (Rugh, 1968).

The parenchyma of the fetal liver is neither morphologically nor physiologically mature (Wilson et al. , 1963.) and the mesenchyme functions as matrix in which these epithelial cells proliferate (C roisille and LeDouarin, 1965).

\section{Organogenesis of Fetal Liver}

Most studies on the organogeny of the liver have used chick embryos because of the ease of manipulation. There are two successive inductive processes in liver differentiation. In the specific primary induction, only the mesoderm of the cardiac area can induce the prehepatic endoderm (C roisille and LeDouarin,. 1965). The second, less specific, induction involves two processes: histological differentiation and the control of metabolic processes (Wolff, 1968). 
The hepatic diverticula degenerates when it is cultivated in vitro in the absence of its mesenchyme. Is olated diverticula give rise to masses of undifferentiated cells when grafted into the coelom of a chick embryo. When the hepatic mesenchyme is placed in close proximity to the diverticulum, hepatic cords will result either in vitro or in vivo. The diverticulum does not have a strict specificity for the hepatic mesenchyme, because mesenchymes of the same embryonic origin (i. e. mesenteric or peritoneal) incite hepatocyte differentiation. However, the hepatic mesenchyme cannot induce other types of endoderm to form hepatocytes (C roisille and LeDouarin, 1965). Thus, the genetic information for the development of liver cells must reside in the diverticula.

Subcellular biochemical changes must occur in the hepatocytes during development since the time at which glycogen can be demonstrated coincides with differentiation (LeDouarin, 1968). With the beginning of glycogen storage there is a large increase in the volume of the cytoplasm and endoplasmic reticulum, while the size of the nucleus (with an enlarged nucleolus) remains unchanged. Mitochondria increase in size and display alterations in form, structure and location. The Golgi apparatus undergoes rapid development towards the end of embryonic development (C roisille and LeDouarin, 1965). Bile pigments are present in the intestine early in.fetal life. In the rat, bile canaliculi and the intrahepatic bile drainage system develop 
at about 14-17 days of gestation (Rugh, 1968). The bile canaliculi, which first appear as networks in the vicinity of the portal vein, a re merely an expansion of intercellular space and their walls are simply a localized specialization of the surface of adjoining hepatic cells (Bloom and Fawcett, 1968). The canaliculi drain into bile tubules, that subsequently differentiate into small bile ducts. In the light microscope, the lumina of the bile tubules appear as a network on the edges of the hepatic parenchyma next to the portal vein (Wilson et al., 1963). The liver cells develop by branching from the primordium and, with the ing rowth of connective tissue, the liver cords nearest the connective tissue a re transformed into ducts. The ing rowth of connective tissue accompanies the development of the portal vein and causes the distance between the endothelium of the circulatory system and the parenchyma to increase and results in the bile tubules becoming completely surrounded by. connective tissue. At this point in their development the bile tubules a re surrounded by 4-8 liver cells. During the differentiation from tubule to bile duct, the side next to the vein is the first to be in intimate contact with the connective tissue and the cells there are the first to transform. As connective tissue surrounds the tubule, the rest of the cells a re transformed. It may be concluded that the connective tissue acts as an inducing agent. Ultimately, the bile caniculi a re limited by two parenchyma 
cells, though the development of bile drainage is not complete at birth (Wilson et al. , 1963).

The formation of blood cells is extravascular and takes place in the mesenchymal islets which are scattered throughout the parenchyma. In the fetal pig megakaryocytes seem to originate from the mesenchyme of the septum transversum (C roisille and LaDourarin, 1965) in contrast to the erythroid series which a re supplied by the yolk sac (Wilson et al., 1963). The large condensed nucleus and nucleolus and the scant ribosome-rich cytoplasm distinguishes the blood stem cells (hemocytoblasts) from the primitive liver cells (hepatoblasts). During differentation of the erythrocyte series the cell diameter decreases, the nucleus disappears and hemoglobin is synthesized. The ferritin granules, which supply iron for the hemoglobin molecule, pass from the hepatoblasts to the primitive erthrocytes (erythroblasts) by a process of pinocytosis. The maturing erythroblasts mig rate between the hepatoblasts and pass through the blood sinusoids. By the twentieth day the liver appears to be functioning primarily as a hematopoietic organ. The hepatic elements increase and liver weight triples between 16 and 22 days of gestation (C roisille and LaDoua rin, 1965).

\section{Histology of the Liver}

The hepatic lobule in the adult rat is shaped like a hexagonal 
prism whose periphery is surrounded by connective tissue. Lobulation is not present in the embryonic rat liver until just prior to birth. In cross section the hepatic vein (which drains the organ) is located in the center of the lobule. This central vein is intralobular and is intercalated to drain into a collecting vein. Cords of liver cells radiate from the central vein and are separated by sinusoids which function as vascular channels. At the corner of each lobule is a portal canal which consists of a small branch of the portal vein (from the intestinal tract), a small branch of the hepatic artery (from the lung) and a bile ductule or cholangiole (from the bile duct), all enclosed in a common connective tissue. The terminal branches of the bile duct leave the portal canal and penetrate the parenchyma between two lobules as ductules (or cholangioles) which have diverticula that expand tightly against the parenchyma. The bile caniculi empty into the lumen of the diverticulum of the ductule. The blood which enters the sinusoids from the interlobula $r$ portal vein and interlobular hepatic artery, flows through the lobule centripetally, and leaves via the central.vein (Bloom and Fawcett, 1968). The hepatic sinusoids are larger and more irregular than capillaries and consist of a thin lining of cells in direct contact with the parenchyma. The end othelium of the sinusoid does not have a basement membrane. Microvilli of the parenchyma project into Disse's space; an area separating the parenchymal cells from the reticuloendothelial lining of sinusoids. 
Some workers feel that there are two types of sinusoidal cells: the endothelial cells with a small dark nucleus and a thin cytoplasm and the stellate cells of Küpfer with a large oval nucleus and a prominent nucleolus. The cytoplasm of Küpffer cells often contains granules of iron or green pigment and engulfed red blood cells. Lipid and glycogen,which are hepatic storage materials, a re removed in routine histological procedures. Special histochemical techniques, however, show that glycogen is deposited in irregular empty spaces and that lipid occurs as round vacuoles in the cytoplasm depending upon the metabolic state of liver. Parenchymal culls are polygonal with six or more sides. They usually contain one large oval nucleus, although binuclear or multinuclear hepatocytes a re sometimes present.

Glisson's capsule is a thin layer of connective tis sue which covers the surface of the liver and extends' into the portal canals. The dense connective tissue forms a common sheath around the branches of the portal veins, the hepatic artery, the bile duct and contains a network of lymphatics that drain lymph from the liver (Bloom and Fawcett, 1968).

\section{Characteristics of Liver Culture}

Liver does not grow consistently well in vitro though there has been more success with fetal tissue than with adult liver. In many of these studies mammalian embryonic liver has been cultúred on 
plasma clots or on agar. The culture method has been found to be of decisive importance in the resulting morphology and growth of liver cells.: Bang and Warwick (19.65) have reviewed the early and of tein futile attempts at culturing liver cells. For instance the main difference between agar cultures and those on plasma clots, is that hematopoiesis persisted on the plasma clot; whereas on agar the blood cells disinteg rated within four days. The plasma clot and agar both limit the rate of disposal of the waste products which may interfere with differentiation.

Chen (1954) used rafts of lens paper floating on serum medium to culture liver explants of 13- and 15-day rat embryos. At 13 and 15 days, the red color of the liver is due to the blood-forming cells in the sinusoids, though the liver cords have not yet been definitely formed. The number of cells which grew from the periphery was small. There was an extrusion of the blood cells into the medium and paper and the explants became progressively paler with time. During the incubation, which lasted 6 to 15 days, there was further differentiation of tissue but this occurred at a slower rate than in vivo. The hepatic cords became more prominent and Klipffer cells appeared in the sinusoids after six days in culture. After eight days in culture, there were fewer blood-forming cells and the amount of glycogen in the parenchymal cells was less than in cells developing in utero at 
the corresponding age. Pigment granules were observed in the macrophages.

Ehrmann and Gey (1956) introduced the use of a collagen substrate which allowed differentiated liver cells to survive for several months. The technique was further improved when Hillis and Bang (1962) studied human embyonic livers in organ culture using rollertube cultures. Outgrowths (cells growing from the periphery) of these cultures consisted of sheets and cords of granular cells, typical of embryonic liver parenchyma. In addition to the parenchyma there were.sheets of squamouslike epithelium, fibroblasts, and numerous scattered macrophages. However Rabes and Jantsch (1971) report that weanling rat liver would proliferate without collagen or cellophane provided there were sufficient growth-promoting substances in the media.

Sandstrom (1965) developed a different approach to cultivation of embryonic liver. In this technique a thin layer of liver was surrounded by two cellophane layers. The lower side was just moistened and the overlying chamber, above the upper cellophane layer which was perforated, was filled with air. A firm attachment to a porous surface with conditions favorable for gas :exchange seemed to be mandato ny for the growth of hepatic cells. Sandström (1965) compared this technique with other methods where embryonic cells are either submerged in media (as in roller tubes) or in fibrin clots. These other methods 
resulted in fibroblast-like cells or clear structureless epithelial cells. Mesenchymal cells can satisfy their energy requirements by glycolysis in vitro and the sinusoid endothelium is able to adapt to anaerobic culture conditions unlike the parenchymal cells which were dead within five hours when the cellophane sandwich was not used. Time-lapse photography showed that fibroblasts grew between the epithelial cells in anaerobic culture techniques. When the liver explants were submerged, there was a transition from the differentiated state to a fibroblastic cell after 10 hours of incubation. The "altered" liver cells seen in culture, concludes Sandstrom (1965), originate in the sinusoidal end othelium and overg row the epithelial cells because of their ability to more readily adapt to anaerobic conditions.

Watanabe (1966) using collagen substrate and roller tubes to culture newborn rat liver, found liver parenchymal cells g rew out over the mesenchymal cells. In electronmic rographs, the most obvious change in cell ultrastructure was a dec reased number of mitochondria in the hepatic cell. He also observed "clear epithelial cells" which are endothelial in origin.

Based on the in vivo $\mathrm{O}_{2}$ consumption of adult liver, Stevens (1965) has calculated that the fluid overlay of in vitro hepatic cells should not exceed $1.7 \mathrm{~mm}$ in $\mathrm{O}_{2}$ or $0.3 \mathrm{~mm}$ in air. The influence of oxygen concentration on the chemical composition of mature rat liver explants was studied by Campbell and Hales (1971). The explants 
were grown on grids floating on chemically defined Eagle's medium. Ideal conditions for mature rat liver were $95 \% \mathrm{O}_{2} / 5 \% \mathrm{CO}_{2} \cdot$ The cultures showed necrotic effects in $95 \%$ air $/ 5 \% \mathrm{CO}_{2}$ within $24-48$ hours. At three atmospheres of oxygen, when the cells should be fully oxygenated, toxic effects could be seen in 24 hours. The nucleus was the last cellular component to undergo degeneration but RNA content was most affected by oxygen tension. Both DNA and RNA content decreased as the oxygen tension was increased. These events were preceded by changes in the ion content; with increased oxygen tension the concentration of the potassium ion was raised and that of the sodium ion, lowered. Glycogen concentration increased when the oxygen tension was increased.

Alexander and Grisham (1970) modified the Sandstrom technique by using a collagen substrate to study the outgrowths which occurred in only $50 \%$ of the neonatal rat livers cultured at 1 - 5 days. Three types of epithelial cells were present in these outgrowths: (1) The predominant cell was similar to the hepatocyte in vivo and had a granular cytoplasm. (2) An unidentified "clear cell" similar to the mesothelium or endothelium, occurred as a closely packed single layer on a basement membrane. Both the "granular" hepatocyte and the "clear" epithelial cell had been previously reported by Sandstrom (1965) and Watanbe (1966). (3) Tubule epithelium cells originated from and were identical to bile ductules in vivo. The following 
mesenchymal cells were found in the outgrowths: (1) Macrophages which were positive for acid phosphatase and were also seen by Bang and Warwick (1955) and Sandstrom (1965). (2) Polymorphonuclear neutrophils and other hematopoietic cells especially in the red blood cell series. (3) Fiber-associated cells which had the appearance of fibroblasts. Using autoradiographic analysis, these fiber-associated cells incorporated tritiated proline which was subsequently found in collagenase-sensitive fibers. Cultured fibroblasts possessed an ultrastructure similar to the fibroblasts in vivo: rough endoplasmic reticulum, prominent Golgi apparatus and an intimate association with collagen fibers. Alexander and Grisham (1970) found that the collagenforming cells were abundant in cultured rat liver.

- Unlike Sandström (1965) who regarded these fibroblast-like cells as transformed macrophages, the authors assumed that this outg rowth was derived from fibroblasts that existed in the normal liver, specifically those in Glisson's capsule and within Disse's space.

Other workers in this area include Rose, Kumegaiva and Catoni (1968) who maintained differentiated hepatocytes of fetal and newborn mouse liver for 120 days in a circumfusion system. This system is a complex in vitro pumping unit incorporating 12 multipurpose chambers through which a serum-supplement fluid nutrient is recirculated at a rate of $4.5 \mathrm{ml} / \mathrm{min}$ per chamber. This method of culturing results in a "hybrid tissue-organ culture." De Belle et al. (1973) have 
reported maintaining fetal rat liver by an undesignated technique for three weeks. Specific hepatocyte functions (i. e. bile acid synthesis and conjugation) were demonstrable.

\section{Biochemical Studies on Developing Liver}

Liver is capable of numerous biochemical reactions and studies have concentrated on the biochemical differentiation during organogenesis. In the rat, the liver starts synthesizing glycogen at about the 16 th day of gestation. The glycogen continues to accumulate until birth when there is a sharp decrease. Hexose units are the source of glycogen in the fetal rat, for the liver is unable to synthesize glycogen from three-C units until after birth (C roisille and Le Douarin, 1965). Burch et al. (1963) observed that as the fetus matures there is a transition from anaerobic glycolysis, glucose utilization and oxidation via the pentose phosphate shunt, to an increased capability for glycogenolysis, lactate utilization and free glucose formation from lactate and glycogen. Hexokinase, phosphof ructokinase and fructose-1,6diphosphate aldolase decrease in fetal liver from the 17 th prenatal day until birth. The embryonic hexokinase is nonspecific but the second glucose-phosphorylating enzyme which develops postnatally, is a specific glucokinase (C roisille and Le Douarin, 1965). Enzymes below fructose diphosphate aldolase in the Embden-Meyerhof pathway (i. e., triosephosphate isomerase, glyceraldehyde dehydrogenase, lactic 
dehydrogenase) increase in activity as maturation progresses. During development, there is a transition in lactic acid dehydrogenase from the muscle isoenzyme to the heart isoenzyme at the time of birth (C roisille and Le Dauarin, 1965). Fructose-1-phosphate aldolase, glycerolphosphate dehydrogenase, glucose-6-phosphatase, glycogen phosphorylase also increase in the process of development.' Uridine diphosphoglucose glycogen transglycosylate activity rises sharply between 17 and 20 days of gestation (Burch et al. , 1963).

Wicks (1968) reported low levels in utero of tyrosine- $\alpha$-ketoglutarate transaminase, for the enzyme is probably repressed during gestation. Immediately upon birth there is a sharp rise, which may be due to the low glucose level which triggers glucagon secretion and. consequently induces synthesis of the transaminase. Alanine-glutamic acid transaminase has $55 \%$ of the activity localized in the mitochondria and $27 \%$ in the supernatant in the embryonic liver; the distribution is reversed in the adult rat liver.

Purine breakdown to uric acid is not significant in the embryonic liver. The formation of urea via the Krebs - Henseleit cycle does not occur until late in gestation. Conjugation reactions with glucuronic acid do not occur in the mammalian liver until after birth (C roisllle and Le Douarin, 1965). 


\section{Metabolic Studies on Liver Organ Culture}

Liver explant undergoes metabolic as well as morphological changes as a result of culturing and these alterations are a reflection

of the incubation conditions. Cultures of fetal rat liver have been used to elucidate the control mechanisms of the metabolic pattern of the organ. Hepatic DNA decreases in the first 24 hours in culture, but renewing the medium causes DNA to exceed its initial level. Paul and Pearson (1957), studying 15-day chick livers in vitro, observed immediate removal of lactate from the medium while hexose and pyruvate were synthesized. After 24 hours in culture the hexose was converted to lactate. The initial rate of oxygen utilization was high but decreased after 24 hours and changing the medium did not restore aerobic metabolism. The authors concluded that an inadequate supply of oxygen or withdrawal from "normal environmental influences" may have caused this metabolic shift. While fibroblasts and central necrosis werepresent in their cultures there were still a large number of hepatocytes.

Organ culture provides a good means to study hepatic glycogen ructabolism in the liver of the near-term fetus. Eisen, Glinsman and Sherline (1973) found that the initial glycogen content was $7.5-12 \%$ of the liver weight and after 40 hours the glycogen stabilized at $1-2 \%$ of its initial value. Insulin caused a net increase in glyoogen which 
was augmented by high glucose concentration. The action of insulin was partially blocked by cycloheximide but not be actinomycin $D$. Epinephrine in the medium caused glycogenolysis.

Wicks (1968) placed liver explants from near-term fetuses and newborns on metal grids which were moistened and placed in a humidified incubator with $98 \%$ air and $2 \% \mathrm{CO}_{2}$ at $37^{\circ} \mathrm{C}$. After 42 hours incubation (when the system was equilibrated), the addition of hydrocortisone induced a three-fold increase in tyrosine- $\alpha$-ketoglutarate transaminase which is immunologically the same in adult and fetal liver. The activity of this enzyme in newborn liver is low when maintained in organ culture. Its activity was elevated by cyclic AMP and those mediators (e.g. glucagon, catecholamines) that stimulate production of cyclic AMP, as well as by hydrocortisone and insulin. The results agree with the hypothesis that cyclic AMP is the mediator in induction of tyrosine transaminase by glucagon (Wicks, 1969). These results contrast with those of Raiha, Schwartz, and Lindroos (1971) who studied explants from 13-day rat fetuses. The activity of tyrosine transaminase was not increased by incubation with hydrocortisone although the addition of glucagon plus cyclic AMP doubled the transaminase activity. The authors concluded that "mammalian liver is not competent to respond to hormone-induced enzyme synthesis before 
a certain developmental stage is reached" and that the mechanism of induction is different depending on the inducer.

\section{Emb ryology of the Fetal Rat Lung}

The vertebrate lung arises from a ventral primitively paired pharyngeal bud. At $101 / 2$ days of gestation the first pharyngeal pouch appears and is followed by a second pouch a day later. A third pouch develops by day 12 as the la ryngotracheal groove extends into a pair of lung buds and the trachea separates from the esophagus (Rugh, 1968). The tips of the lung buds swell and divide; this process is repeated in subsequent generations until a "large arboreous system of tubules is formed" (Sorokin, 1965). At $121 / 2$ days the right lung bud is slightly larger than the left lung bud. By 13 days the bronchi are formed; the left bronchus veers more towards the trachea than the right bronchus (Sorokin, 1965). At $131 / 2$ days the bronchi have 2 or 3 buds and a day later the right bronchus has both secondary and tertiary buds (Rugh, 1968). In the morphogenes is of the lung, the smaller branch diverges more from the parent than the larger branch; thus the conducting volume of the lung is made to occupy as small a volume as possible (Sorokin, 1965).

The primitive bronchial tree is lined with pseudostratified epithelium. Just underlying the respiratory epithelium is a relatively cellular mesencinyme that originates next to the laryngotracheal groove. 
This mesenchyme, which is destined to form the connective tissue, accompanies the epithelium as it migrates from the pharyngeal floor into a relatively acellular mesenchyme (Sorokin, Padykula, and Herman, 1959). A continuous basement membrane separates the epithelium from the mesenchyme throughout development. Extracellular fibers are deposited in the tissue space that separates the basement memb.ranes of the epithelium and the endothelium. This connective tissue increases in amount with age well into the adult stage (Sorokin, 1965). The invaded mesenchyme, which earlier migrated from the median coelomic walls, condenses a round the bronchial tree and differentiates into the blood vessels, lymphatics, pulmonary pleura, interlobular septa and cartilage (Sorokin et al. , 1959). Both the epithelium and the mesenchyme which lags behind, differentiate in a "wave-like manner" in a proximal to a distal direction. In Sorokin's (1965) opinion, the mitotic ratio between the epithelium and the stroma determine the form of the lung more than any other factor. With unequal cell division favoring the epithelium and the basement membrane (binding the epithelium and the stroma), it may be expected that a branched tubular structure would result. Sorokin and his coworkers (1959) found twice as many mitotic cells in the epithelium as compared to the stroma in fetal rat lung. The greatest mitotic activity occurred in the distal air sacs and the maximum 
ratio of 2.65 mitotic cells in the epithelium for every mitotic cell in the stroma occurred at 15 days gestation.

At $161 / 2$ days in development, the normal rat fetus possesses a branched bronchial tree, lobed, vascularized lungs and a diaphragm that separates the peritoneal and pleural cavities. Alveoli are formed on about the 19 th prenatal day. By day 21 , the nares are open so that the lung passage is complete and the organ is now potentially functional (Rugh, 1968). The lung of the newborn rat (normally in the 22 nd day after conception) is at a stage in development comparable to a seven month human fetus. Though birth causes the inflation of the organ, it does not inter rupt the development which continues postnatally (Sorokin, 1965).

\section{Histology of the Lung}

As the bronchi subdivide there is a transition from cartilage rings to cartilage plates to muscular layers. The mucosa of the bronchi consists of a small amount of reticula $\mathbf{r}$ and collagenous connective tissue and many elastic fibers. Adjacent to the mucosa is a layer of smooth muscle which contains a dense network of blood vessels and many elastic fibers. The outermost layer of the bronchial wall is a dense connective tissue containing numerous elastic fibers (Maximow and Bloom, 1957). The pseudostratified epithelium of the trachea and bronchi is composed of four cell types: ciliated, goblet, 
non-ciliated (brush) and short (basal) cells. In the bronchioles, the columnar epithelium is differentiated into ciliated cells or cells containing apical secretory droplets. The smaller respiratory tubules are lined with a cuboidal epithelium which extends and is transformed into the flattened cells which line the alveoli. The walls of alveolar ducts are composed of strands of elastic and collagenous fibers (Sorokin, 1965). The alveolar sac is a cluster of 2-4 alveoli opening into a central, slightly larger chamber (Leeson and Leeson, 1966). The mouth of the alveolar sac is completely surrounded by a wavy wreath of collagenous and elastic fibers which are continuous from one sac to the next (Maximow and Bloom, 1957). Alveoli are polyhedral with one wall missing to permit the diffusion of air and are lined by a thin squamous epithelium in which only the nuclei can be resolved by the light microscope. The alveoli are separated by an interalveolar septum, a framework comprised primarily of reticular and elastic fibers with a little collagen. Endothelial cells, with their diminished cytoplas $m$, line the capillaries which are a predominant structure in the interalveolar septum (Leeson and Leeson, 1966).

\section{Studies on the Development of the Lung in Organ Culture}

Sorokin (1961) describes the three levels of development of explants of fetal rat lung. grown anaerobically on nutrients in agar. Shortly after lunge are cultivated, damaged epithelium 
surrounds the explant, torn ends of the bronchi are sloughed off and the pre-existing bronchial branching begins to expand. In the second level of development, there is infolding of branch tips to form new bronchial branches. The "adult-like" third stage is characterized by "many saccular chambers enclosed by delicate walls." Lungs from 12-day embryos never reach this stage and instead form cysts from expanded bronchi. A development of thin walled sacs is observed in lungs from 14-day and older embryos after about nine days in culture. In such explants, bronchial contractions are observed after two or three days in culture and ciliary waves a re seen after five days in vitro.

The presence or absence of epithelial glycogen may be used to distinguish between terminal buds and mature epithelium; mesenchymal glycogen is absent in both cases. A 14-day explant, after one week in culture, has a bronchial pseudostratified epithelium which contains secreting goblet cells and ciliated elements. Cartilage, smooth muscle layers and blood vessels are observed in bronchial walls at this time. Stromal cells elaborate networks of reticular, collagenous and elastic fibers. The histochemical localization of enzymes and triglycerides parallels the development of lungs in vivo.

Organ culture cannot simulate the conditions of the uterine environment. However, because the conditions of the isolated organ in culturecan be carefully regulated, it is a technique which has 
facilitated our understanding of organogenesis. It has shown the lung to be a "self-developing entity" for "once started development seems to go on as a matter of course" and rudiments of the lung appear to differentiate in vitro by the same mechanism as their in utero counterparts (Sorokin, 1961). Initially the organ cultures appear to develop at the same rate as the organs do in vivo; after a few days, however, even the best cultures fall behind (Sorokin, 1965). In explanted lungs the epithelium divides more frequently than the stroma, but the epithelium to stroma mitotic ratio is below the mitotic ratio in the in vivo control. As a consequence, the lung cultures branch less often than the lung in vivo. The lung organ culture shows other disparities with the fetal lung developing in vivo: it lacks mesenchymal glycogen in the terminal buds and because of disuse, blood vessels do not develop to the same extent (Sorokin, 1961).

The mesenchyme has the ability to induce the budding of pulmonary tissue. Dameron (1961) found that the epithelium of chick lung isolated in vitro, is incapable of morphogenesis and instead forms spherical aggregations or spreads over the culturing surface. Histogenesis in culture requires a proper balance between epithelium and mesenchyme. Alescio and Cassini (1962) observed that isolated pulmonary mesenchyme migrated over a plasma clot to the epithelium of the tracheobronchial tree and condensed around it; once this association was established, epithelial branching followed. Irradiation of 
either the mesenchyme or epithelium results in inhibition of this recognition; however, irradiation of the mesenchyme is more effective than irradiation of epithelium alone and less effective than irradiation of both.

Alescio and Cassini (1962) found if a section of mesenchyme from the tracheal bud was removed and replaced by mesenchyme taken from a bronchial bud, a supernumerary bud grew from the epithelium beneath the graft. Normally the trachea produces no extra branches but grafted mesenchyme resulted in an elongated bud that eventually branched. The donor bronchus deprived of its mesenchyme was slower to branch than the controls. However, Wessels (1970) found that tracheal mesenchyme did not incite bronchial budding. The pulmonary mesenchyme along the bronchial tree has different capabilities to stimulate epithelial budding; usually the mesenchyme normally closest to the site of normal undisturbed budding is most efficient, (Alescio and Cassini, 1962) though mesenchyme derived from different organs and species varies in its ability to cause epithelial morphogenesis (Taderera, 1967). As Sorokin (1965) summarizes, "... supplied in the right amount and at a certain stage in its maturity, the nulmonary mesenchyme is suited to promote branching of the rudimentary bronchial tree and depending on its state of differentiation possesses the capacity to limit branching as well." This morphogenic response of the epithellum to the riteserichyme may be made 
through epithelial cell division. How the more mature mesenchyme prevents the budding of the trachea is not known. Possibly, the production of the stimulating chemicals is lowered, or the extracellular material which allows the diffusion of these chemicals between the mesenchyme and epithelium is altered. With maturation the amount of connective tissue increases between the mesenchymal cells and the epithelium (Sorokin, 1965). Pulmonary mesenchyme can evoke budding from epithelia that does not normally bud (i. e. trachea and gut) (Taderera, 1967).

Alescio and Dani (1971) state that there are three experimentally distinguishable effects operating in epithelio-mesenchymal interaic-. tions: (1) Regulation of specific metabolic patterns of the epithelial cells by the mesenchyme. This is exemplified by the reappearance of glycogen in tracheal epithelium coincident with bud formation caused by bronchial mesenchyme. On the other hand metanephrogenic mesenchyme fails to incite tracheal budding or glycogen formation. (2) The growth rate along the entire bronchial (epithelial) tree which is controlled by the mesenchymal factors. When the relative amount of mesenchyme is increased, there is an enhancement in epithelial proliferation (Alescio and Colombo Piperno, 1967). Alescio and de Michele (1968) have concluded that ove rall growth and budding activity of the epithelial tree depends on its cell divison. (3) Localized control of the morphogenetic pattern which determines the 
precise time and sites of the appearance of secondary buds.

Collagen biosynthesis seems to be one of the mechanisms by which the mesenchyme controls the spatial organization of the epithelial tree. This type of control appears to be relatively independent of the actual rate of the replication of epithelial cells (Alescio, 1973). Kallman and Grobstein (1965), using autoradiog raphy after administration of tritiated proline, found that collagenous proteins synthesized in the mesenchyme were transported across a membrane filter to the epithelium. Wessels and Cohen (1968) reported that in vitro morphogenesis of lung was altered by collagenase treatment. This may be contrasted with pancreatic epithelium which does not have a specific mesenchymal requi rement and was not altered by collagenase treatments. They conclude that collagenase-sensitive materials may be essential to morphogenesis where epithelial development is highly dependent upon a specific mesenchyme and where epithelial branching is predominant.

From radioactive tracer studies in which salivary epithelium was cultured on membrane filters across from salivary and mammary mesenchyme, Bernfield (1970) also obtained evidence that the mesenchyme is a major source of epithelial collagen. In this study both the tritiated hydroxyproline content and labelled hydroxyproline/proline ratios were the same whether the salivary epithelium was incubated across the salivary mesenchyme which incited morphogenes is or 
across the mammary mesenchyme which did not induce morphogenesis. Thus epithelial development is not required for the passage of collagen across the filter because inducing as well as non-inducing mesenchyme can transfer collagen and the morphogenetic effect of the mesenchyme is probably not exclusively mediated via collagen. While the epithelial morphogenesis appears to be independent of the quantity of epithelial collagen, it may be dependent upon the localization or arrangement of the fibrils. The reciprocal interaction is the apparent ability of the epithelium to increase collagen in the mesenchyme, for salivary and pancreatic mesenchymes cultured across from salivary epithelium, hydroxylated substantially more labeled proline than did mesenchymes cultured alone (Bernfield, 1970).

Alescio (1973) using the proline analogue, azetidine-2-carboxylic acid in cultures of 11 -day fetal mouse lungs, found budding sharply declined, but glycogen distribution did not change. Wessels (1970) described the influence of collagen on the morphogenetic growth of lung cultures in vitro. An oriented deposition of collagen, as seen in bronchi in electronmicrographs, leaves open spaces which a re available for mesenchyme induction and hence budding. However "more helpful information may come from the knowledge of individual responses of the epithelium and mesenchyme and of possible modifications of the patterns of macromolecular synthesis in both tissues" (Alescio, 1973). 


\section{Histochemical Changes During Lung Development}

Sorokin and his coworkers (1959) monitored developing embryonic a.t ling for histochemical changes. They found glycogen and neutral fats to be the principle storage products. Glycogen was deposited in the epithelium as new cells were formed. The presence of epithelial glycogen has been correlated with the development of lung buds (Alescio and Dani, 1971). It disappeared after the cells matured and as a consequence, most epithelial glycogen was concentrated in the terminal buds. On the 14 th day in utero, the rat lung had abundant glycogen in the secondary bronchi, though it was absent.in the primary bronchi (Sorokin et al., 1959). Coarse glycogen granules were present in mesenchymal layers removed from the epithelial tree (Sorokin, 1965). Mesenchymal glycogen, which is not present in all species of vertebrate lung, was also absent when explants are grown in lung culture (Sorokin, 1961).

Of the pulmonary lipids, the triglycerides undergo the greatest fluctuation during development. Accumulation of the triglycerides in fetal rat lungs begins about the 17 th day of gestation and continues through the first postnatal week. Triglycerides accumulate in the connective tissue and the cytoplasm of the cuboidal epithelial cells and displace one-third to one-fourth the cellular volume (Sorokin et al., 1959). 
Rat lung is capable of development in an anaerobic environment for cultures of embryonic lung in the absence of air or the presence of metabolic inhibitors grow about as well as the controls (Sorokin, 1961). Ninety-five percent oxygen inhibits normal bronchiogenesis in fetal mouse lung cultures (Resnick, Brown, and Venier, $1973)$.

The histochemical presence of enzymes varies among species. The mere histochemical presence of an enzyme does not necessarily mean it is in an active state nor that it is significant to pulmonary development. Despite these reservations, Sorokin (1965) has proposed the following metabolic scheme for development.

Early differentiation promotes glycogen storage and rapid cell division in the epithelium. During the early period of development, when a branching bronchial tree is under construction, the glycogenrich organ derives most of its energy through glycolysis. The energy derived from glycolysis is spent largely for the synthesis of protoplasm and for cell division. With maturation, this glycogen storage decreases, and there is an increase in the activities of the citric acid cycle (as indicated by the appearance of succinic dehydrogenase), the cytochrome system (indicated by the presence of indophenol oxidase) and the hexose monophosphate shunt (determined histochemically by glucose-6-phosphate dehydrogenase), and energy is diverted to operate the newly synthesized differentiated cells. Since the 
epithelium contains these enzymes it would be more affected than the mesenchyme by a decline in mitotic activity. Branching would no longer occur in the more differentiated spots; although it would continue in the undifferentiated terminal buds. Earlier in development the epithelium would increase relative to the mesenchyme but later on, the mesenchyme would increase relative to the epithelium.

\section{Radiation Studies on Lung Cultures}

Borghese (1961) irradiated lung explants and fetal mice in utero during the twelfth day of development with $818 \mathrm{R}$ of $\gamma$-rays. Four days later when the fetuses were removed, no alteration could be detected in lung development. The explants showed marked morphogenetic change which were subsequently described in more detail by Alescio and Ladu (1962). During the first 12 hours post-irradiation, a wave of degeneration was noted in the epithelial tree proceeding in the proximal to distal direction. No mitosis was observed in the epithelium or the mesenchyme. From 12-48 hours post-irradiation, the epithelial tree regenerated and cells began to proliferate although the mesenchyme exhibited pycnotic degeneration and did not regenerate.

Alescio (1966) irradiated explants of 12 -day fetal mouse lung in air with gracled doses of $\mathrm{x}$-ray up to $400 \mathrm{R}$. Immediately after irradiation, cultures were washed with Tyrodes and cultured in a 
hanging drop on a plasma clot made up of equal amounts of chicken plasma and chick embryo extract. In the first 24 hours following irradiation the nuclei of the epithelial cells became pycnotic; the degenerated epithelial cells detached from the epithelial surface and were sloughed into the lumen. The extent of the damage was proportional to the dose. During the next day further necrosis and a decrease in the cell population in the mesenchymal mantle which paralleled the radiation dose was seen. While the bronchial epithelial tree was intact it was surrounded by reduced mesenchyme and the degree of branching was less than that in the control. "Peristalictype contractions" were sometimes observed in irradiated lung rudiments progressing in a proximal to distal direction. Three days after exposure both the epithelium and mesenchyme had degenerated to an extent that was proportional to the dose; however only a small number of pycnotic cells were observed in the mesenchymal mantle as though the dead debris had been cleared from the mesenchyme. Initially all irradiated cultures exhibited depressed growth rates, but cultures irradiated at 50,100 or $175 \mathrm{R}$ had a recovery of the growth rate which paralleled the control cultures after 30-60 hours. The selective depletion of the mesenchymal cell population following irradiation had an effect on the epithelial cell proliferation as well as budding (Alescio, 1966). 


\section{Properties of Connective Tissue}

From the early work in tis sue and organ culture it was recognized that collagen is formed in vitro by fibroblasts derived from many different sources including lung and liver. As these fibroblasts migrate from the explant a reticulum develops around the cells, sometimes within 24 hours (Fell, 1951). Fibrinogenesis and the resulting structure of connective tissue in vitro is similar to synthesis in vivo (Eitton Jackson, 1953). Since lung and liver both respond to injury by increased synthesis of connective tissue, the nature and properties of connective tissue will be considered.

The origin of the connective tissue cells is the mesenchyme which gives rise to the cells, fibroblasts and fibrocytes, which are responsible for the development and the maintenance of the connective tissue. Fitton Jackson (1964) described fibroblasts as elongated and somewhat irregularly stellate cells with an ovoid nucleus surrounded by a thin sheath of cytoplasm; several cytoplasmic processes radiate and form networks of multiple branches in which collagen fibers interwind. In vitro, fibroblasts accumulate small cytoplasmic granules of glycoprotein and possessaprominent Golgi apparatus, Fibrocytes which llaintair the connective tissuc arc smaller and flatter than fibroblasts. The cells per se and their products combine in specific ways to form various types of connective tissue. The nature of the 
connective tissue is dependent upon the relative proportions of its four constituent phases: the cells; the ground substance or matrix; the fibrous components (collagen, reticulum and elastin); and the interstitial fluid and free electrolytes (Fitton Jackson, 1964). Two factors determine the character and function of the connective tissue: (1) "the synthetic balance between the various components of the extracellular material, (2) the precise structural relationship between the fibrous constituents and ground substance" (Fitton Jackson, 1964). The assumption is that the fibroblast is capable of making all the constituents of the connective tissue but the regulatory processes are not understood. This implies that the connective tissue cells have required genetic information for diverse specialities but the functional state is dependent on the environmental requirements. Evidence is accumulating that the ground substance may control fibrinogenesis in vivo and form an integral part of the fibrous material (Fitton Jackson, 1964). It may be significant that there is correspondingly less ground substance present with age (Fitton Jackson, 1953).

There are three major extracellular constituents of connective tissue: (1) Interstitial fluid which bathes the extracellular compartment and contains plasma proteins, free electrolytes, hormones, amino acids, simple sugars, peptides, precursor and degradation products; (2) Glycoproteins such as sialic acid, which are present in small but significant quantities, and may be one of the factors 
stabilizing the collagen fibers; (3) Acid mucopolysaccharides constituents such as hyaluronic acid and the chond roitin sulfates (tracheal cartilage). Mucopolysaccharides are linear unbranched polymers of consisting of a hexamine(glucosamine or galactosamine) and either a uronic acid or a galactose unit. The chondroitin sulfates contain sulfate esters which vary in the degree of sulfation. The acid mucopolysaccharides, which combine with small amounts of non-collagenous protein, carry a high negative charge and form reversible linkages with other compounds; thus they play an important role in diffusion and inorganic ion metabolism (Fitton Jackson, 1964).

The fibrous components of connective tissue are: (1) Collagen, which will be discussed in more detail in the next section; (2) Elastin, which is often formed in close association with collagen. The histology, amino acid content and extensibility of elastin are different from collagen through still poorly defined. (3) Reticular fibers whose structure is similar to that of collagen and appear to consist of two types of fibers: (a) Immature fibers found in embryonic and regenerating connective tissue which appear to be incorporated within the collagen fibers; (b) Fibers present in the basement membrane which are stable (Fitton Jackson, 1964).

Basement membranes constitute a distinct group of extracellular matrices. They are complex: structures composed of dissimilar protein units rich in carbohydrate. 'One component of the triple helix 
is collagen which has a higher proportion of hydroxyproline and hydroxylysine compared to interstitial collagen. Basement membranes appear to be synthesized by endothelial cells (derived from mesenchyme) in the lung and glandular organs. While the function of these membranes is not yet proven, it is thought the membranes function as filter barriers to molecules moving across capillary walls (Kefalides, 1973). The epithelial basement membrane may polymerize soluble collagen (from the mesenchyme) and thus be a component in fibrinogenesis (Grobstein, 1967).

\section{- Properties of Collagen}

Collagen is the major constituent of connective tissue and is composed of about equal" portions of glycine, hydroxyproline and hydroxylysine. Fibroblasts secrete a small tropocollagen unit into the extracellular matrix. The tropocollagen fibril is a triple chain helix. These kinked chains a re held together by hydrogen bonds between carbonyl and amino groups which keeps collagen stable and resistant to stretch (Lehninger, 1970). The fibrils aggregate head to tail and a re staggered to give a larger fiber with a banded appea rance and a periodicity of 600-700 A (Wilson, 1972).

Chvapil and Hurych (1968) have summarized the control of collagen biosynthes is in detail. Because hydroxyproline and hydroxylysine fail to form an activated complexes with ATP, the proline and 
lysine are incorporated into the polypeptide and are subsequently hydroxylated in collagen biosynthesis. This is followed by glycosylation of specific hydroxylysine residues (Kefalides, 1973). Atmospheric oxygen and the presence of an electron donor are essential for the hydroxylation of proline and lysine. The ferrous ion is the major electron donor used in the in vitro studies of this reaction. The mechanism for collagen hydroxylase is: peptidyl-proline + ascorbate $+\mathrm{O}_{2} \underset{\mathrm{Fe}^{2+}}{\stackrel{\text { ketoglutarate }}{2+}}$ peptidyl-hydroxyproline + dehydroascorbate + $\mathrm{H}_{2} \mathrm{O}$. The ascorbate acid probably acts in two ways: It reduces $\mathrm{Fe}^{3+}$ and converts $\mathrm{H}_{2} \mathrm{O}_{2}$ to further radicals (Chvapil and Hurych, 1968).

$$
\begin{gathered}
\mathrm{AAH}^{-}+\mathrm{H}_{2} \mathrm{O}_{2} \longrightarrow \cdot \mathrm{AAH}+\cdot \mathrm{OH}+\mathrm{OH}^{-} \\
\cdot \mathrm{AAH}+\cdot \mathrm{OH} \longrightarrow \mathrm{AA}+\mathrm{H}_{2} \mathrm{O}
\end{gathered}
$$

In excess, ascorbic acid can inhibit collagen synthesis.

Collagen synthesis is inhibited in the presence of iodoacetate (a glycolytic inhibitor); since fluoroacetate does not inhibit collagen biosynthesis however there is no direct connection between the Krebs Cycle and hydroxyproline production. As long as ATP is present, uncoupling of the electron transport system by 2,4 dinitrophenol or cyanide, does not affect collagenous protein production. In vitro synthesis of collagen is very sensitive to the presence of electrolytes. It has been reported that the collagen synthesis of rat uterine slices is decreased $90 \%$ if $\mathrm{NaCl}$ is absent from the medium. The electrolyte 
requirement varies with the various systems and may reflect differences in membrane permeability. When increased proline is included in the diet of rats, there is increased systemic free hydroxyproline but no increase in collagen. On the other hand, excess hydroxyproline can inhibit collagen synthesis. Under stressed conditions (without metal ion, oxygen, or ascorbic acid), an atypical collagen, free of hydroxyproline or hydroxylysine, forms (Chvapil and Hurych, 1968). The synthesis of collagen is summarized as follows:

$$
\begin{aligned}
& \text { Pro }+ \text { ATP } \longrightarrow \text { Pro-AMP } \longrightarrow \text { Pro - t-RNA } \\
& \downarrow 50 \% \\
& \text { Gly-Pro-Pro-X } \\
& \downarrow \begin{array}{l}
\mathrm{Fe}^{2+} \\
\mathrm{pO}_{2} \quad 10 \% \\
\text { ascorbic acid }
\end{array} \\
& \text { Gly-Pro-Hyp-X } \\
& \downarrow_{\text {Tropocollagen }} \\
& \text { maturation } \\
& \downarrow \begin{array}{l}
\mathrm{pO}_{2} \\
\text { Intermediate metabolism }
\end{array} \\
& \text { C.ollagen fiber } \\
& \text { (modified from Chvapil and } \\
& \text { Hurych, 1968). }
\end{aligned}
$$

Interstitial fluid may provide organic and/or enzymic substances essential for the transformation of the collagen precursors for the formation of the extracellular material (Fitton Jackson, 1964) and a 
polymerizing enzyme has been isolated from liver (Chvapil and Hurych, 1968).

The mechanism of the hepatic fibrogenic effect is not known although ascorbic acid and iron in the form of ferritin, accumulates in the fibroblasts and ground substance in this inflammatory response. -Ferritin may be indirectly involved in the formation of collagen in that it is phagocytized by macrophages and accelerates their breakdown. This increased macrophage breakdow $n$ is coincident with the release of "fibrosis-stimulating" substances which stimulate the fibroblasts to form collagen (Chvapil and Hurych, 1968). Hepatic mesenchymal cells produce a mucopolysaccharide-protein complex which has a great affinity for iron. Large doses of colloidal iron inhibit collagen formation through the blockage of the reticuloendothelial system and small amounts stimulate its formation. Pulmonary fibrosis may be induced with the inhalation of iron oxides and quartz. Hypoxia favors the growth of fibrogenic cells and this is reflected in increased collagen biosynthesis. Silicosis results in localized hypoxia of tissue and stimulates fibroblastic activity (Chvapil and Huyrch, 1968).

\section{Effect of Radiation on Connective Tissue}

Connective tissue in vivo is among the most resistant to radiation of all body tissues. After in vitro irradiation at very high doses (5. $4 \mathrm{Mrads}$ ); collagen loses its banded appearance in the $\mathrm{x}$-ray 
diffraction pattern presumably due to the rupture of the covalent bonds in the protein chain. This process also causes the breakage of the hydrogen bonds and facilitates the entry of water into the collagen molecule. When collagen is irradiated in the wet state, there is a net decrease in the solubility as a result of two competing reactions. Solubility is decreased because of the increased crosslinking produced as a result of free radicals formed in the water. On the other hand, the splitting of the peptide chains produced by the direct action of radiation on the collagen tends to increase solubility (Bailey, 1968). At doses of 100 kilorads irradiation of tropocollagen solution leads to gel formation due to the formation of intramolecular crosslinks by radicals, thereby increasing the viscosity. At 50 kilorads, elastin shows swelling, decreased elasticity and intrafibrillar debris (Bailey, $1968)$

In view of the very large doses required to alter the fibrous elements of connective tissue; the connective tissue cell response to radiation is more likely due to nucleic acid damage and/or a change in enzyme balance caused by rupture of cell membranes with the formation of abnormal metabolites.

\section{Scope of These Studies}

The basic purpose of these experiments was to measure the alLeralivis that $x$-irradiation can subscquently causc in the in vivo and 
in vitro development of two fetal organs, the lung and liver. These two organs were chosen for their diversity in function and anatomy. The liver, a glandular organ contains enzymes capable of catalyzing many biochemical reactions, and of regeneration. The lung has a better defined and more compartmentalized anatomy which facilitates the study of its organogenesis. In this study the following questions a re being asked: 1) What is the pattern of in vivo development in fetal liver and lung? 2) What is the effect of culturing on the development of an organ explant; i. e. what is the pattern of in vitro development? 3) What effects does in vivo or in vitro exposures to $x$-ray have on the development of the organ culture? 4) And, finally, what effect does $x$-irradiation have on histogenesis in utero?

Answers to these questions were approached in the following ways. In vivo development was ascertained from the study of explants of control lungs which were cultured for four hours. The pattern of in vitro development was elucidated by observing explants which were incubated for one or three days and then comparing their development to that of their counterparts developing in utero. The effect of radiation in vivo or in vitro development was studied by culturing explants immediately after irradiation of the pregnant female, for four hours, one day or three days. Irradiation of organ explants which were incubated for four hours, one day or three days, provided a measure for the effect of radialiui in vitro on in vitro 
development. The effect of irradiation on organ histogenesis in utero was assessed by irradiating the pregnant females and allowing the organs to remain intact for one or three days prior to their explantation. and subsequent four hour incubation.

The effect of $x$-irradiation on the histogenesis of fetal rat lung and liver as well as the feasibility of the organ culture technique were evaluated by comparing these patterns of development. 
MATERIALS AND METHODS

In Experiment 1, fetuses at 13, 15, 17 and 19 days of gestation were exposed in vivo to 0 or $435 \mathrm{R}$ of $\mathrm{x}$-ray. Based on the histological observations, it was determined that a more concentrated study (Experiment II) should be confined to the development of fetal organs at 13 and 15 days of gestation following in vivo as well as in vitro exposure to 0 or $435 \mathrm{R}$. All sacrifices in Experiment II were done in triplicate:

\section{Design of Experiments}

Diagram 1 outlines the protocol for the study of 13-day fetal lung and liver. As discussed previously, organs at other stages in development were studied simultaneously. In the "A" series of experiments, the organ was explanted, ir radiated immediately with

o or $435 \mathrm{R}$ of $\mathrm{x}$-ray and incubated at $37^{\circ} \mathrm{C}$. The cultures were terminated by placing them in Bouin's fixative after four hours, one day and three days. The "A" series of determinations were performed only in Experiment II. In the " $B$ " series of treatments, the pregnant animals were irradiated with 0 or $435 \mathrm{R}$ and the fetal organs were explanted immediately and, again, cultured for four hours, one day and three days. The "B" series of sacrifices was part of both Experiment I and II. In the "C" series of experiments the animals were 
exposed to 0 or $435 \mathrm{R}$ and the organs were allowed to develop in utero for one or three days after exposure to the $x$-ray. These organswere explanted and cultured for four hours before termination. The biochemical analysis on fetal lung development was performed on 15-day fetal lung in the " $\mathrm{B}$ " and " $\mathrm{C}$ " series of experiments. Each treatment and time was repeated a minimum of three times.

\section{Method of Culture}

Wistar rats (Hilltop Lab Animals, Inc., Chatsworth, CA) were fed and watered ad libitum. Young males (about three to six months old) were placed in cages with four females (two to four months old) at 4:00 p.m. At 7:30 a.m. vaginal smears were taken and examined; those containing sperm were assumed to be pregnant. This was taken as day zero of gestation. Fertilization was assumed to have occurred at 9:00 a.m.; hence, exposures to $x$-ray and the culturing of organs were carried out between 7:00 and 11:00 a. m.

At the designated day in gestation the females were anesthesized with ether and the uterus was quickly removed, washed in sterile saline and placed on a paraffin wax block wrapped in sterile aluminum fnil. Then the block with the uterus was transferred to a bench top hood with a filtered blower (Germfree Lab, Inc.), the interior of which had been sterilized with ultraviolet light overnight. The embryos were then removed from the uterus and placed in chilled L-15 medium 
Diagram 1. Experimental design for the study of the characteristics of development of fetal rat liver and lung after exposure to 0 or $435 \mathrm{R}$ of $\mathrm{x}$-ray. It is shown for the organs at 13 days of gestation, but identical protocol was used at other times in development. 
A. IN VITRO RADIATION - IN VITRO DEVELOPMENT

Day of development 13

14

15

16

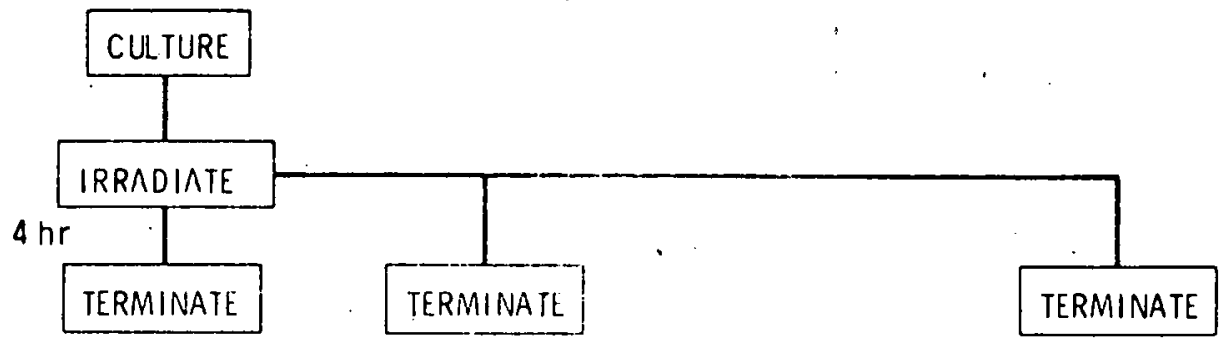

B. IN UTERO RADIATION - IN VITRO DEVËIOPAIENT

Day of development 13

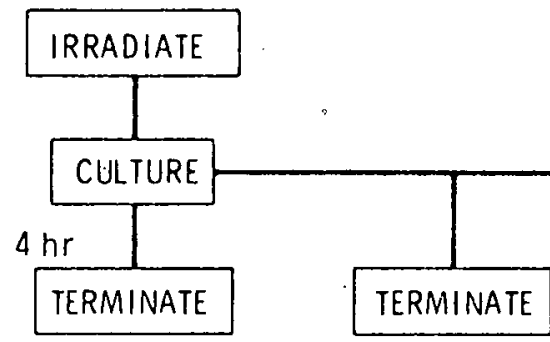

15

16

C. IN UTERO RADIATION - IN UTERO DEVELOPMENT

Day of development

14

15

16

TERMINATE

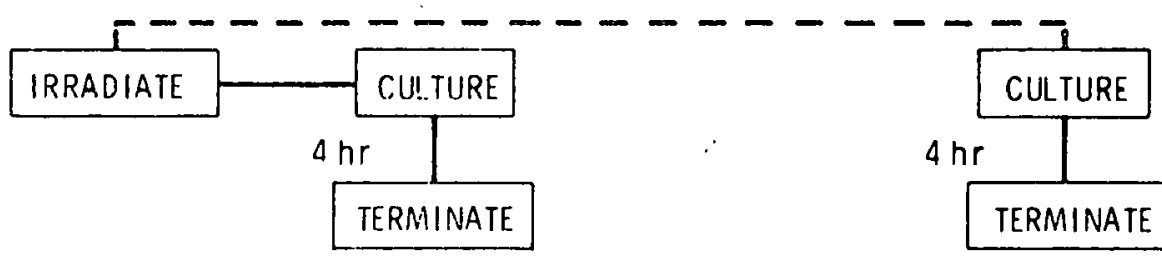


(Grand Island Biologics, Grand Island, IL) (See Appendix 1). After all the embryos were removed, the lung and liver were removed from each embryo. An attempt was made to make the organ explants. less than $2 \mathrm{~mm}$ in their greatest dimension; consequently, the entire lung was removed from the 13 -day embryo, whereas pieces from the tip of the lobe of 19-day lungs were explanted. Organ explants were placed on small iriangles of Millipore filter (SMWP 02500) of $5 *$ pore size and $25 \mathrm{~mm}$ in diameter. The pieces of Milliporefilter were placed on metal grids which were inserted into the filled center well of the organ culture dish which was filled with organ culture medium. Care was taken to moisten but not submerge the Millipore filter. The organ culture medium consisted of $20 \%$ fetal calf. serum (Immunoprecipitin Tested Fetal Calf Serum, Grand Island Biological Co., Berkeley, CA) and $80 \%$ L-15 medium (Leibovitz) with glutamine and without antibiotics which were mixed aseptically in sterile vaccine bottles. Culture dishes were $60 \times 15 \mathrm{~mm}$ and contained an absorbent ring (Falcon plastics No. 3011). A triangular metal grid about $13 \mathrm{~mm}$ from the center to a corner (Falcon plastics No. 3016) supported the Millipore filter over the center well. The outer disc was moistened with $3 \mathrm{cc}$ of sterile distilled water and $0.8 \mathrm{cc}$ of cultúre medium was added to the inner compartment.

These culture plates were placed in a $37^{\circ} \mathrm{C}$ incubator having a thermal jacket (National Appliance Co., Portland, Oregon) with 
$100 \%$ humidity and $5 \% \mathrm{CO}_{2}(0.308$ liter per minute) and $95 \%$ air $(5.8$ liter per minute) flowing over the surface of the cultures.

The culture medium was replaced by warmed, fresh medium every 48 hours. In the first experiment cultures were exposed to medium containing $1 \mu \mathrm{C}$ i of ${ }^{3} \mathrm{H}$-thymidine (New England Nuclear Co.) per cc for 30 minutes before termination. In the second experiment cultures were labeled with medium containing $50 \mu \mathrm{Ci}$ of ${ }^{3} \mathrm{H}$-proline (New England Nuclear Co.) per cc for four hours before being placed in Bouin's fixative.

The cultures were periodically photographed using a Zeiss stereomicroscope with an attached Zeiss camera containing High Speed Ektachrome (Kodak) film. Cultures were terminated by placement in Bouin's fixative (Appendix II) and fixed overnight. They were washed in flowing water for several hours after being wrapped in lens paper and tissue holders. The tissue holders were stored in $70 \%$ alcohol until embedded.

Prior to use all instruments and glassware were soaked in Microsolv detergent (Microbiological Associates, Inc., Albany, CA), rinsed five times in tap water and three times in distilled water. All disserting instruments were wrapped individually and autoclaved for 20 min at 15 lbs per square inch pressure. 


\section{Histological Procedures}

The first experiment (Experiment I) included studies of fetal organs irradiated at 13,15, 17, and 19 days of gestation. After fixation, these organs were dehydrated by hand (Appendix III) and embedded into paraffin. Sections were cut on an $A O / S p e n c e r$ microtome and allowed to dry overnight. After one hour in an oven at $74^{\circ} \mathrm{C}$, the cooled slides were deparaffinized in xylene, and rehydrated and stained with Van de Grift's modification of the Masson's trichrome stain. (See Appendix IV). Additional sections were cut and ${ }^{3} \mathrm{H}$-thymidine autoradiographs were prepared (Appendix VI). The autoradiographs were inadvertantly contaminated with plutonium.

Experiment II was confined to 13 and 15 -day fetal lungs. After fixation these organs were dehydrated and embedded in methacrylate (See Appendix V). Sections $2 \mu$ in thíckness were cut on a JB-4 microtome (Sorvall). These were stained using a modification of the Van de Grift's stain (See Appendix IV). Many of the autoradiographs of 3 H-proline incorporation (Appendix VI) were contaminated with plutonium, but the few successful attempts will be discussed in the following sections.

Sections were photographed on a Leiss photomicroscope using Ektachrome or Panatomic-X (Kodak) film. 


\section{$\underline{X-I r r a d i a t i o n ~ C o n d i t i o n s ~}$}

\section{All animals were exposed to $x$-ray generated by (General}

Electric) Maxitron 250 unit operating at $250 \mathrm{kVp}$ and $30 \mathrm{~m}$. a. The output was calibrated using a Victoreen dosimeter with $100 \mathrm{R}$ and 250

$R$ chambers. In the initial studies, animals were exposed to 250 , 345, and $435 \mathrm{R}$, and on the basis of the results, $435 \mathrm{R}$ was selected for the subsequent experiments. The animals were placed in a lucite carousel which rotated at $1 \mathrm{rpm}$ at a target-mid line distance of 105 $\mathrm{cm}$. The beam was filtered by $0.5 \mathrm{~mm} \mathrm{Cu}$ and $1.00 \mathrm{~mm} \mathrm{Al}$ (HVL $1.5 \mathrm{~mm} \mathrm{Cu}$, giving an average exposure rate of $30-32 \mathrm{R} / \mathrm{min}$. Control animals were rotated in the carousel for 15 minutes. Organ cultures ("A" series") were exposed in vitro to $435 \mathrm{R}$ using the same apparatus. The moistened Millipore filter was placed on porous filter paper (Whatman No. 1) saturated with the culture medium in a sterile plastic petridish. The dish was placed $34 \mathrm{~cm}$ from the target of the Maxitron 250 and the beam was filtered by $0.25 \mathrm{~mm} \mathrm{Cu}$ and $1.0 \mathrm{~mm} \mathrm{Al} \mathrm{(HVL} 0.88 \mathrm{~mm} \mathrm{Cu}$ ). The exposure rate was $219-222 \mathrm{R} / \mathrm{min}$. The controls were treated the same, except they were left outside the $\mathrm{X}$-ray room while the cultures were exposed. All organ cultures were transferred to incubated organ culture plates immediately after treatment. 


\section{Biochemical Analysis}

The chemical analyses were performed on 15-day fetal lung which had been irradiated in vivo (" $B$ " and " $C$ " series). In the preliminary studies, 10,25 and $50 \mu \mathrm{Ci}$ of ${ }^{3} \mathrm{H}$-proline (New England Nuc lear Co.) per cc of culture medium were used to measureincorporation. The highest concentration was found to provide satisfactory count rates. In these studies the 15 -day lung cultures were prepared as described previously. They were incubated with $0.8 \mathrm{cc}$ of culture

medium containing $50 \mu \mathrm{Ci}$ of ${ }^{3} \mathrm{H}$-proline (pro) and $10 \mu \mathrm{Ci}$ of ${ }^{14} \mathrm{C}$-leucine (leu) per cc for four hours prior to termination. At the end of the four hours the Millipore filters were washed two times in L-15 medium and blotted on absorbent paper. The cultures were carefully scraped off, placed in a glass homogenizer, frozen and stored until they could be analyzed. An average of 30 cultures made up one sample.

The fruzen samples were thawed and homogcnizcd in $2 \mathrm{cc}$ of $5 \%$ TCA. The homogenates were placed in a $90^{\circ} \mathrm{C}$ water bath for 20 minutes. The homogenates were centrifuged in a table top centrifuge for 10 minutes and the supernatant was decanted into a clean vial. DNA content in the supernatant was determined (Appendix VII) and activity in $0.5 \mathrm{cc}$ aliquots of ${ }^{3} \mathrm{H}$ and ${ }^{14} \mathrm{C}$ were measured. The precipitate (ppt) was washed with $1 \mathrm{cc}$ of $5 \%$ TCA and centrifuged again. 
The resulting supernatant was discarded. The precipitate was dissolved in $1.0 \mathrm{cc}$ of $0.1 \mathrm{~N} \mathrm{NaOH}$ and left at room temperature overnight. Aliquots of $0.2 \mathrm{cc}$ were removed and counted for ${ }^{3} \mathrm{H}$ and ${ }^{14} \mathrm{C}$ and the remainder was used for the protein determination (Appendix VIII).

Prior to use, all glassware was soaked in dilute nitric acid overnight and washed in Haemo-sol (Haemo-sol Inc, Baltimore, $\mathrm{MD)}$, rinsed in tap water five times and distilled water three times.

\section{Counting Techniques}

Aliquots of $0.5 \mathrm{cc}$ of supernatant or $0.2 \mathrm{cc}$ of dissolved precipitate were transferred to glass scintillation vials and $10 \mathrm{cc}$ of liquid scintillation fluid (Appendix IX) was added to each vial. All vialswere counted for five minutes in a Mark II (G. D. Searle \& Co., Des Plaines, IL) liquid scintillation counter using the dual channel method. 


\section{STUDIES ON FETAL LIVER}

\section{$\underline{\text { Results }}$}

Throughout these experiments it was noted that the livers of embryos which were irradiated at 13 days of gestation and removed one day later were malformed and were smaller than those of the controls. When the fetuses were removed at three days after exposure the reduction in liver size was even more pronounced. Livers of fetuses exposed at 15 days of gestation and removed one or three days later were slightly hemorrhagic. No gross abnormalities of the liver were observed in the fetuses irradiated at 17 or 19 days of gestation. The loss of pigment and blood cells was the most evident macroscopic change that occurred in fetal liver explants subsequent to culturing and/or radiation.

When the dimension of control explants exceeded $2 \mathrm{~mm}$, a central zone of necrosis, which was devoid of pigment, became visible after 24 hours and increased in size with time. Radiation accelerated the development and enlarged the size of the central zone of necrosis. Even in pieces of liver less than $2 \mathrm{~mm}$, however, there was often an extrusion of blood cells and a progressive decrease in pigment which paralleled the time in culture. Radiation also accelerated the depigmentation process, and organs exposed in vivo to $435 \mathrm{R}$ during the 
thirteenth day and the fifteenth day in gestation were completely devoid of color after two days in culture.

Experiment I was performed to establish the techniques and to determine optimal conditions and stages of development for subsequent, more definitive studies. The initial experiment yielded inconsistent results until it was established that the explant size had to be kept below $2 \mathrm{~mm}$. During the learning process, some of the histological sections embedded in paraffin were lost and some were cut too thick which reduced the number of observations. As indicated in the previous section, this experiment included a wider range of development stages and radiation doses than did the subsequent studies.

Experiment II was limited to the study of embryos at 13 and 15 days of gestation and to a single radiation dose. In addition, the tissue taken for culture was consistently less than $2 \mathrm{~mm}$ in its largest dimension. In this experiment methacrylate embedding permitted one to see the tissue, thus reducing the loss and allowing the preparation of thinner sections. The change to methacrylate embedding led to minor differences in the histological appearance between the two experiments. but did not affect the criteria or the scoring system to be described subsequently.

On the basis of the histology of the sections prepared from liver cultures and the relevant literature, classification criteria were 
developed for the non-hematopoietic cells:

1) "Granular epithelium" is composed of cells which closely resemble the functional adult parenchymal cells and are polygonal with a granular, slightly acidóphilic cytoplasm. These cells have a large nucleus containing one to two prominent nucleoli (Figure i).

2) "Clear epithelium" resembles the granular epithelium with the exception that the periphery or all the cytoplasm was clear and unstained (Figure 22).

3) "Fibrinogenic epithelium" which was only seen in culture, tended to form a web around zones of necrosis (Figure 2 a and $2 \mathrm{~b})$. These cells were often poorly stained and seemed to adhere to one another with interspersed red-stainingfibers.

4) "Fibroblastic-like" cells had a light staining oval nucleus and an elongated, usually basophilic, cytoplasm (Figure 9).

Blood cells occur in the sinusoids and this permitted the size and distribution of the sinusoids to be assessed on the basis of hematopoietic elements (Figure 14). The predominant hematopoietic cells possessed condensed nuclei with a small amount of cytoplasm. Megakaryocytes, large multinucleate, green-staining cells were also present (Figure 28). The blood vessels were well-defined and lined with green-staining connective tissue. These were readily 
Figure 1. (Top) Photomicrograph showing a mosaic of cell types in a single section along the periphery. Note the fibroblasts (left), a rea of pycnotic cells (center) and granular epithelium (right). Section was obtained from fetal rat liver irradiated in vivo with $435 \mathrm{R}$ on the fifteenth day of gestation, cultured immediately and terminated after three days in vitro $(225 \mathrm{x})$.

Figure 2a. (Lower left) Photomicrograph showing a web of fibrinogenic epithelium surrounding zones of necrosis. Section was obtained from a different fetus whose liver was treated the same as the one in Figure $1(90 \mathrm{x})$.

Figure $2 b$. Higher power of a rea at lower right of Figure 2a. Note cytoplasmic vacuoles $(225 \mathrm{x})$. 

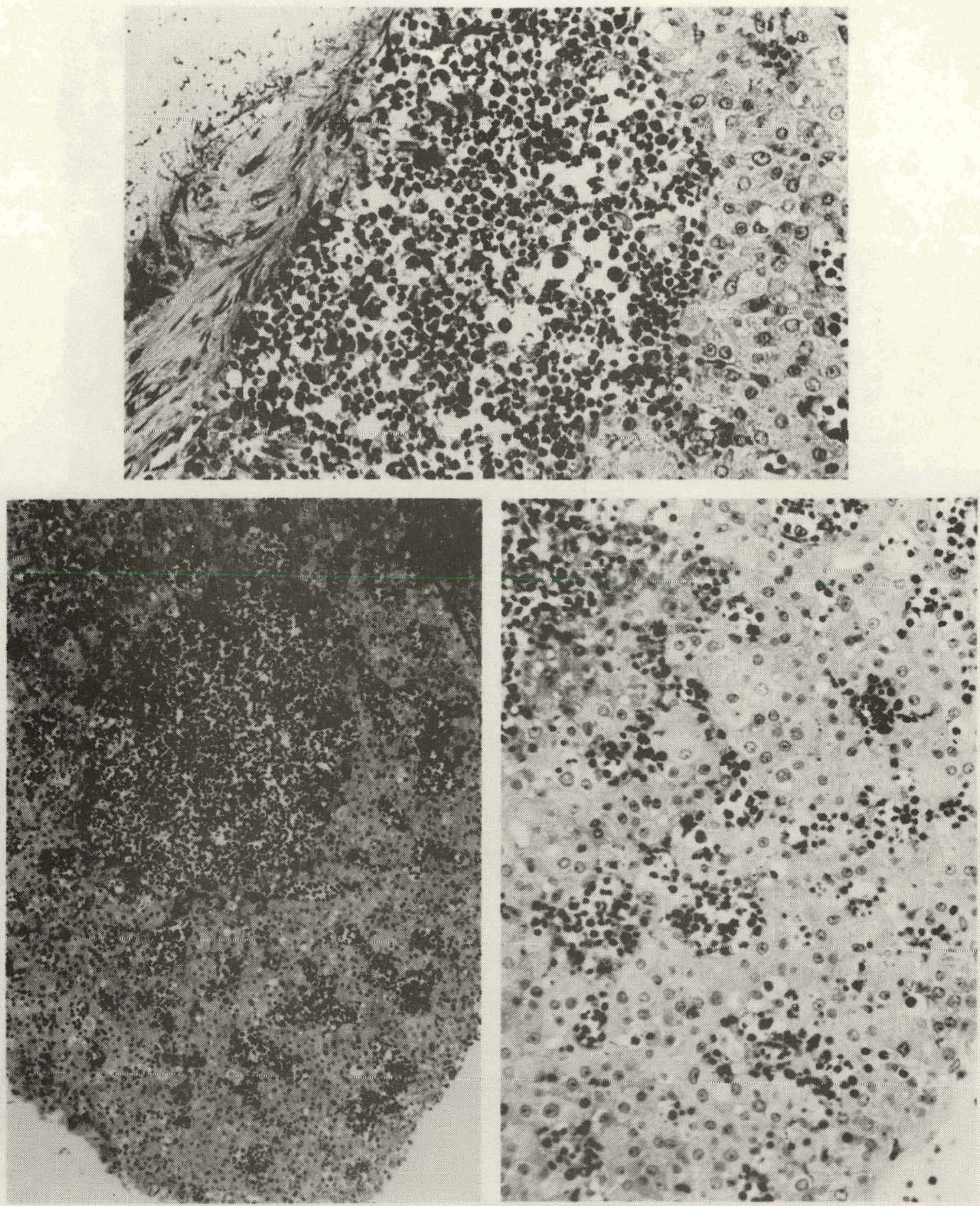
differentiated from the small spaces between the parenchymal cells which were taken to be bile caniculi. Cytoplasmic vacuoles were circular spaces occurring within the cytoplasm of the parenchymal cells, and while special staining is required, it is assumed that these were lipid droplets.

The sections were examined and an evaluation system was evolved to provide a semiquantitative and consistent method for comparison. The sections were subsequently reexamined and a relative assessment of the various characteristics was established. This system is equally applicablefor size and f'requency determinations but does not involve actual enumeration.

$$
\begin{aligned}
& 0=\text { none } \\
& \pm=\text { minimal number or size } \\
& 1=\text { few or small size } \\
& 2=\text { moderate number or size } \\
& 3=\text { la rge number or size } \\
& 4=\text { maximum number or size }
\end{aligned}
$$

On thesebases, it was possible to examine the patterns of 1) in vivo development 2) in vitro development, 3) in vitro development after exposure to $x$-ray, 4) in vivo development after exposure to $x$-ray. The seven tables in this section are arranged to present these patterns in the above sequence. 
The in vivo development of fetal rat liver, as observed in Experiment I and II are shown in Tables 1 and 2 , respectively. These explants were incubated for four hours which provided sufficient time for flattening to occur so as to make them comparable to the in vitro material. This four hour incubation also allowed some deterioration to occur.

It was observed that the "cords" of the parenchymal cells became thinner as did the width of the sinusoids which became progressively more numerous. The staining reaction of the parenchymal cells became more basophilic with maturation. The sections from the first experiment were so thick that the bile caniculi were obscured; however the bile caniculi were visible in the thinner sections from the second experiment. The mitotic frequency decreased with hepatic organogenesis. Hematopoiesis peaked on the seventeenth to eighteenth day of gestation with the frequency of megakaryocytes nearly paralleling this pattern. The fetal nucleated, acidophilic red blood cells ( $\left.R B C^{\prime} s\right)$ were seen at earlier times in gestation; mature $R B C^{\prime} s$. first were apparent on the fifteenth to sixteenth day of gestation and became progressively more prevalent. The relative number of blood vessels and the amount of associated connective tissue increased with the development of the liver. The prevalence of vacuoles in the cytoplasm increased with maturation. By the day of birth ( 22 days) the parenchymal cells near the periphery had enlarged cytoplasmic areas 
Table 1. Characteristics of Fetal Rat Liver Developing in Vivo as Observed at Four Hours after Explantation - Expt. I. a

\begin{tabular}{|c|c|c|c|c|c|c|c|}
\hline \multirow[b]{2}{*}{ Characteristics } & \multicolumn{7}{|c|}{ Days of Gestation } \\
\hline & 13 & 16 & 17 & 18 & 19 & 20 & 22 \\
\hline \multicolumn{8}{|l|}{ Parenchymal cells } \\
\hline Relative frequency & 4 & 3 & 3 & 3 & 2 & 2 & 1 \\
\hline \multicolumn{8}{|l|}{ Sinusoids } \\
\hline Relative frequency & 0 & 3 & 3 & 4 & 4 & 4 & 4 \\
\hline Size & - & 3 & 3 & 2 & 2 & 1 & 1 \\
\hline \multicolumn{8}{|l|}{ Blood vessels } \\
\hline Relative frequency & 0 & 1 & 1 & 2 & 4 & 4 & 4 \\
\hline Connective tissue & 0 & 1 & 1 & 2 & 3 & 4 & 4 \\
\hline \multicolumn{8}{|l|}{ Mitotic frequency } \\
\hline Parenchyma & 3 & 2 & 1 & 1 & 1 & 0 & 0 \\
\hline Hematopoiet & 1 & \pm & 0 & 0 & 0 & 0 & 0 \\
\hline \multicolumn{8}{|l|}{ Hematopoietic tissue } \\
\hline Relative amount & \pm & 3 & 4 & 4 & 3 & 3 & 1 \\
\hline \multicolumn{8}{|l|}{ Megaka ryocytes } \\
\hline Relative number & 0 & 2 & 3 & 4 & 4 & 3 & 2 \\
\hline Size & - & 2 & 3 & 4 & 4 & 4 & 4 \\
\hline \multicolumn{8}{|l|}{ Mature blood cells } \\
\hline Relative number & 0 & 1 & 1 & 2 & 3 & 4 & 4 \\
\hline \multicolumn{8}{|l|}{ Gytoplasmic vacuoles } \\
\hline Relative frequency & 1 & 1 & 2 & 3 & 3 & 3 & 4 \\
\hline Size & \pm & 1 & 2 & 3 & 3 & 3 & 4 \\
\hline
\end{tabular}

$\mathrm{a}_{\text {For a description of the numerical values, see text p. } 63 .}$ 
Table 2. Characteristics of Fetal Rat Liver Developing In Vivo as Observed at Four Hours after. Explaniation - Expt. II. a

\begin{tabular}{|c|c|c|c|c|c|}
\hline \multirow[b]{2}{*}{ Characteristics } & \multirow[b]{2}{*}{13} & \multicolumn{3}{|c|}{ Days of Gestation } & \multirow[b]{2}{*}{18} \\
\hline & & 14 & 15 & 16 & \\
\hline \multicolumn{6}{|l|}{ Parenchymal cells } \\
\hline Relative frequency & 4 & 4 & 3 & 2 & 2 \\
\hline \multicolumn{6}{|l|}{ Sinusoids } \\
\hline Rëlative frequency & \pm & 2 & 3 & 3 & 4 \\
\hline Size & 2 & 1 & 2 & 1 & 1 \\
\hline \multicolumn{6}{|l|}{ "Bile caniculi" } \\
\hline Relative frequency & 0 & 0 & 1 . & 3 & 4 \\
\hline Size & 0 & 0 & 1 & 2 & 2 \\
\hline \multicolumn{6}{|l|}{ Blood vessels } \\
\hline Relative frequency & 0 & 0 & 1 & 1 & 2 \\
\hline Connective tissue & 0 & 0 & 1 & 1 & 4 \\
\hline \multicolumn{6}{|l|}{ Mitotic frequency } \\
\hline Parenchyma & 4 & 3 & 3 & 2 & 3 \\
\hline Hematopoietic elements & 1 & 2 & 3 & 2 & 1 \\
\hline \multicolumn{6}{|l|}{ Hematopoieti: tissue } \\
\hline Relative amount & 1 & 2 & 3 & 4 & 4 \\
\hline \multicolumn{6}{|l|}{ Megaka ryocy tes } \\
\hline Relative number & 1 & 3 & 3 & 4 & 4 \\
\hline Size & 1 & 2 & 3 & 4 & 4 \\
\hline \multicolumn{6}{|l|}{ Mature blood cells } \\
\hline Relative number & 0 & 0 & \pm & 1 & 3 \\
\hline \multicolumn{6}{|l|}{ Cytoplasmic vacuoles } \\
\hline Relative frequency & \pm & 1 & 2 & 2 & 3 \\
\hline Size. & 1 & 1 & 2 & 2 & 2 \\
\hline
\end{tabular}

aFor a description of the numerical values, see text p. 63. 
filled with non-staining granules. The granules were presumed to be glycogen and this observation may represent cells of differing metabolism. The cells in the center had depleted their glycogen storage; whereas the cells in a position for greater gas exchange were able to use the medium to better advantage (Figure 32).

The pattern of development in vitro may best be evaluated by a comparison with corresponding development in vivo. This pattern of development in organ culture was studied more extensively in Experiment I but in more detail, although over a narrower" range, in Experiment II. As indicated above many of the data from the first experiment were fragmentary, so that good comparisons could not consistently be made. Table 3 has been prepared from the data derived from Experiment II; however, comparable results from Experiment I when available, tend to confirm those data presented in Table 3.

These data (Table 3) are presented as two groups of five and are composite views obtained from the examination of the control material $(O R)$ relative to the three series $(A, B$, and $C)$ of experiments. The first entry of each group was from explants cultured on the designated day of gestation and incubated for four hours (series $A$ and $B$ ). The second and fourth entries of each group were explanted the same day as the first entry, but allowed to develop in vitro for one and three days respectively (series $A$ and $B$ ). The third and fifth 
Table 3. Characteristics of In Vitro. Development of Fetal Rat Liver Explants - Expt. II. ${ }^{3}$

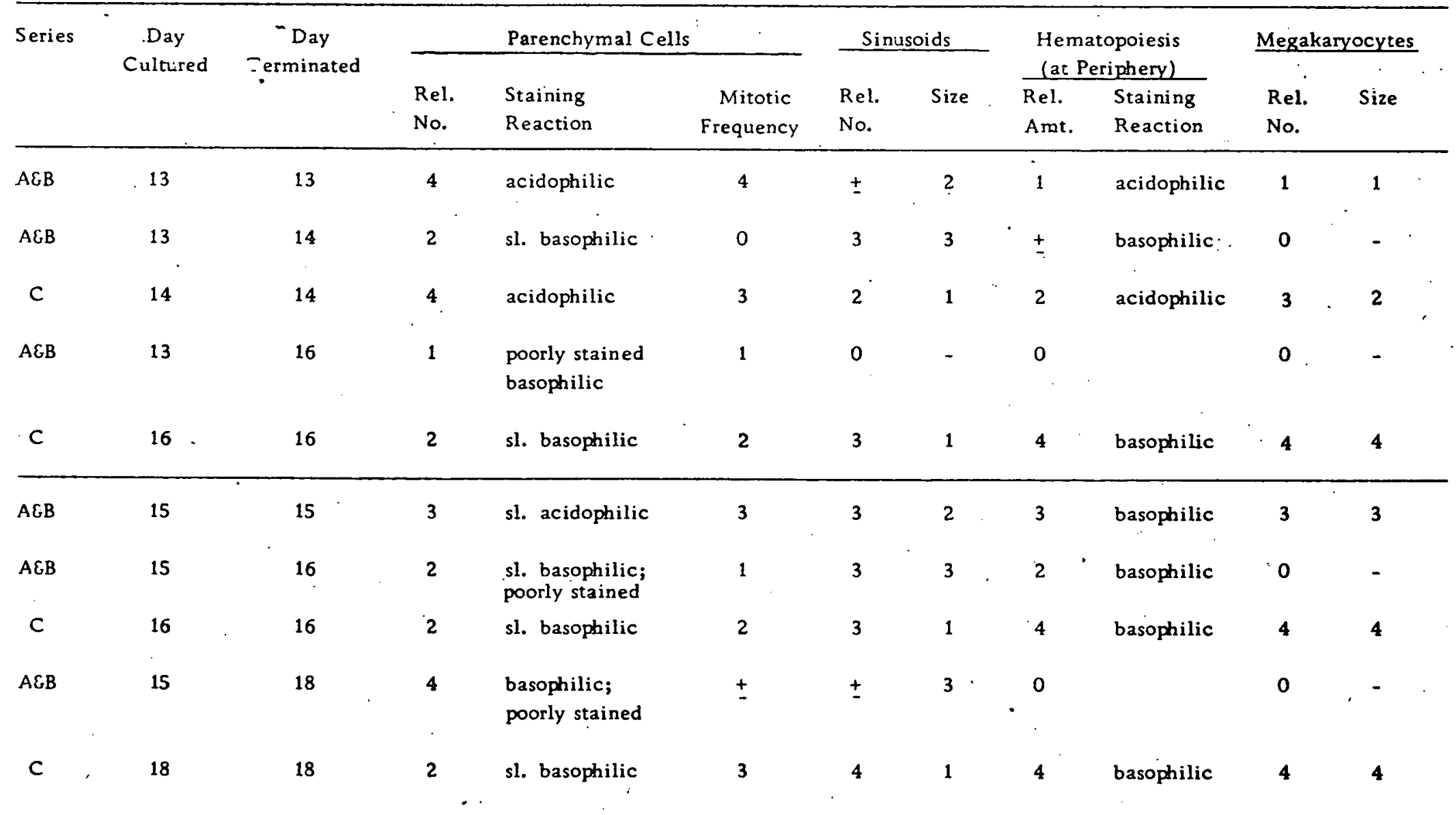


Table 3. Continued.

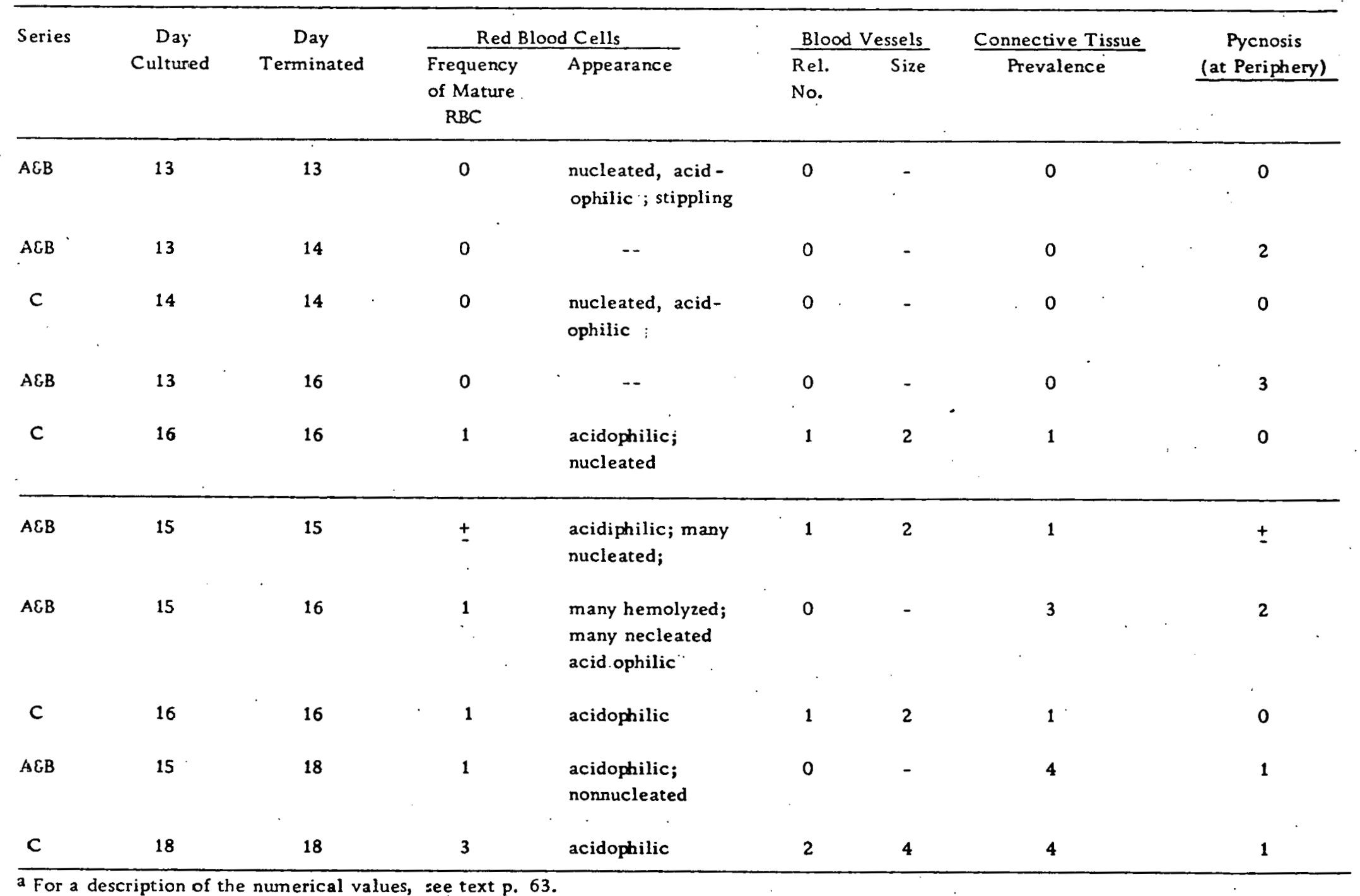

a For a description of the numerical values, see text p. 63 . 
entries are the in vivo controls (series C) which were cultured for four hours on the same day that the cultures of the second and fourth entries were terminated.

There is a tendency for the parenchymal cells in livers which were in culture to stain more poorly than the in vivo controls and to form "webs" of fibrinogenic parenchymal cells. There was usually a decrease in the number of parenchymal cells, hematopoietic cells, mitotic cells, megakaryocytes and bloodvessels with inc reased times" of incubation. There was an increase in fibrinogenesis and necrosis with time in culture. In the limited number of autoradiog raphs examined, proline incorporation was associated with the fibrinogenic parenchymal cells in the 13- and 15-day fetal livers after three days in culture.

The effects of radiation at 13 to 19 days of gestation were studied in Experiment I. In general the most pronounced alterations were observed in organs exposed at 13 and 15 days of gestation; accordingly these times were selected for further study in Experiment II. The results of Experiment I have been used to supplement the overall pattern which was seen in Experiment II. Table 4 compares the effects of $x$-irradiation administered in vivo and in vitro during 13 th day of gestation on hepatic development. The first nine entries, arranged in three groups of three, tabulate the effects of $x$ irradiation on the in vitro development. In the firet group of three 
entries, the first entry represents cultures irradiated in vitro (series $A$ ), the second entry pertains to organs from rats irradiated in vivo and than explanted (series B), while the cultures of the third entry were sham irradiated (series $A$ and $B$ ). In all instances the explants were cultured for four hours. The second and third groups of three entries are arranged in the same sequence as the first group except that the cultures were incubated for one and three days, respectively.

The last four entries in two groups of two, present the effects of $x$ - ray on in vivo development. In the first group of two entries, the fetal livers were exposed to 435 or $O R$ and left in utero for one day before explantation and the four-hour incubation. In the last group of two entries, the control and irradiated fetal livers, remained in utero for three days before they were cultured for four hours. Table 5 is arranged in the same way as Table 4, except data are derived from fetal livers exposed to $x$-ray on the 15 th day of gestation.

It was noted that both in vivo and in vitro radiation increased the frequency of both pycnotic and fibroblastic-like cells as well as the size of the sinusoids. In vivo but not in vitro exposure increased the relative amount of vacuoles in the cytoplasm. Concurrently radiation tended to decrease the mitotic frequency, the relative number of megakaryocytes and the amount of hematopoiesis (Figures 12: 
15 and 26-29). These changes became more pronounced as the time of in vitro incubation was prolonged.

At four hours, the cultures irradiated in vitro showed less deterioration than their counterparts irradiated in vivo (Figures 3, 4, 5 , and $16,17,18)$. After one day in culture many of the explants irradiated in vivo tended to appear more viable than the controls or the cultures irradiated in vitro (Figures $6,7,8$ and 19,20,21). Degeneration was progressive and by the third day sections from all three groups of cultures of liver explanted at 13 days of gestation. revealed necrosis (Figure 9, 10, 11). In contrast, however, sections of liver which were cultured for three days after explantation at 15 days of gestation seemed to demonstrate recovery. They appeared to have a greater proportion of viable cells than their counterparts incubated in vitro for one day whether they had been exposed to $x$-ray treatment or not (Figures 22, 23, and 24).

Examination of the limited number of autoradiog raphs of liver explants irradiated on the fifteenth day of gestation indicated that ${ }^{3} \mathrm{H}$-proline incorporation was concentrated in the zones of necrosis along the periphery (Figure 25).

Among the most prominent effects noted in fetal livers after in vivo exposure to $435 \mathrm{R}$ on the seventeenth and nineteenth day of gestation (Experiment I) were the disintegration of the lining of the blood vessels and vascular engorgement. A decrease in hematopoiesis 
Table 4. Characteristics of Development of 13-Day Fetal Rat Liver After In Vivo or In Vitro Exposure to 435 R of X-Ray - Expt. II.

\begin{tabular}{|c|c|c|c|c|c|c|c|c|c|c|c|c|}
\hline \multirow[b]{2}{*}{$\underset{c}{a}$} & \multirow[b]{2}{*}{ } & \multirow[b]{2}{*}{ 訤苞 } & \multirow{2}{*}{\multicolumn{2}{|c|}{ 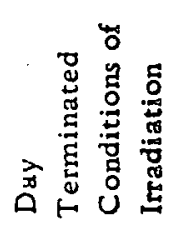 }} & \multicolumn{3}{|c|}{ Parenchymal Cells } & \multicolumn{2}{|c|}{$\begin{array}{l}\text { Hematopoiesis } \\
\text { (at Periphery) }\end{array}$} & \multirow{2}{*}{$\begin{array}{l}\text { Megakaryocytes } \\
\text {. Rel. } \\
\text {. No. }\end{array}$} & \multirow{2}{*}{$\begin{array}{l}\begin{array}{c}\text { Cytoplasmic } \\
\text { Vacuoles }\end{array} \\
\begin{array}{l}\text { Rel. } \\
\text { Amt. }\end{array}\end{array}$} & \multirow{2}{*}{$\begin{array}{l}\text { Pycnosis } \\
\text { (at Periphery) }\end{array}$} \\
\hline & & & & & $\begin{array}{l}\text { Rel. } \\
\text { No. }\end{array}$ & $\begin{array}{l}\text { Staining } \\
\text { Reaction }\end{array}$ & $\begin{array}{c}\text { Mitotic } \\
\text { Frequency }\end{array}$ & $\begin{array}{l}\text { (at P } \\
\text { Rel. } \\
\text { Amt. }\end{array}$ & $\begin{array}{l}\text { Staining } \\
\text { Reaction }\end{array}$ & & & \\
\hline A. & 13 & 13 & 13 & vitro & 3 & basophilic & 0 & \pm & acidophilic & 1 & 1 & \pm \\
\hline E & 13 & 13 & 13 & vivo & 3 & $\begin{array}{l}\text { sl. basophilic; } \\
\text { poorly stained }\end{array}$ & 2 & \pm & acidophilic: & 2 & 2 & 1 \\
\hline A\&B & 13 & 13 & 13 & 0 & 4 & . & 4 & 1 & acidophilic & 1 & \pm & 0 \\
\hline $\mathbf{A}$ & 13 & 13 & 14 & vitro & 0 & strongly basophilic & 0 & 0 & & 0 & 0 & 4 \\
\hline B & 13 & 13 & 14 & vivo & 2 & sl. acidophilic & 1 & \pm & acidophilic: & 2 & 3 & 2 \\
\hline$A$ & 13 & 13 & 16 & vitro & 0 & bascphilic & - & 0 & & 0 & 0 & 4 \\
\hline B & 13 & 13 & 16 & vivo & 0 & acićophilic & - & $\mathbf{0}$ & & 0 & 0 & 4 \\
\hline 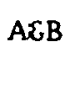 & 13 & 13 & 16 & 0 & 1 & $\begin{array}{l}\text { poorly stained } \\
\text { basophilic }\end{array}$ & 1 & 0 & . & 0 & 0 & 3 \\
\hline C & 13 & 14 & 14 & vivo & 2 & sl. basophilic & 0 & 1 & basophilic. & 2 & 4 & 2 \\
\hline$c$ & 14 & 14 & 14 & 0 & 4 & acidophilic & 3 & 2 & acidophilic & 3 & 1 & 0 \\
\hline$c$ & 13 & 16 & 16 & vivo & 3 & sl. acidophilic & \pm & 3 & basophilic & \pm & 4 & 2 \\
\hline c & 16 & 16 & 16 & 0 & 2 & sl. basophilic & 2 & 4 & basophilic & 4 & 2 & 0 \\
\hline
\end{tabular}

a For a description of the numerical values, see text p. 63 . 
Figure 3. (Top) Photomicrograph of fetal liver which was sham irradiated and cultured for four hours at 13 days of gestation. Numerous mitotic figures are present $(225 \mathrm{x})$.

Figure 4. (Lower left) Photomicrograph of fetal liver explanted at 13 days of gestation, immediately exposed to $435 \mathrm{R}$ of $x$-ray and incubated for four hours. Increased pycnosis and a decreased mitotic frequency $(225 \mathrm{x})$.

Figure 5. (Lower right) Photomicrograph of liver explanted from fetus immediately after exposure to $435 \mathrm{R}$ at 13 days of gestation and cultured for four hours. Note the pycnotic hematopoietic elements, typical megakaryocytes and decreased mitotic frequency $(225 \mathrm{x})$. 

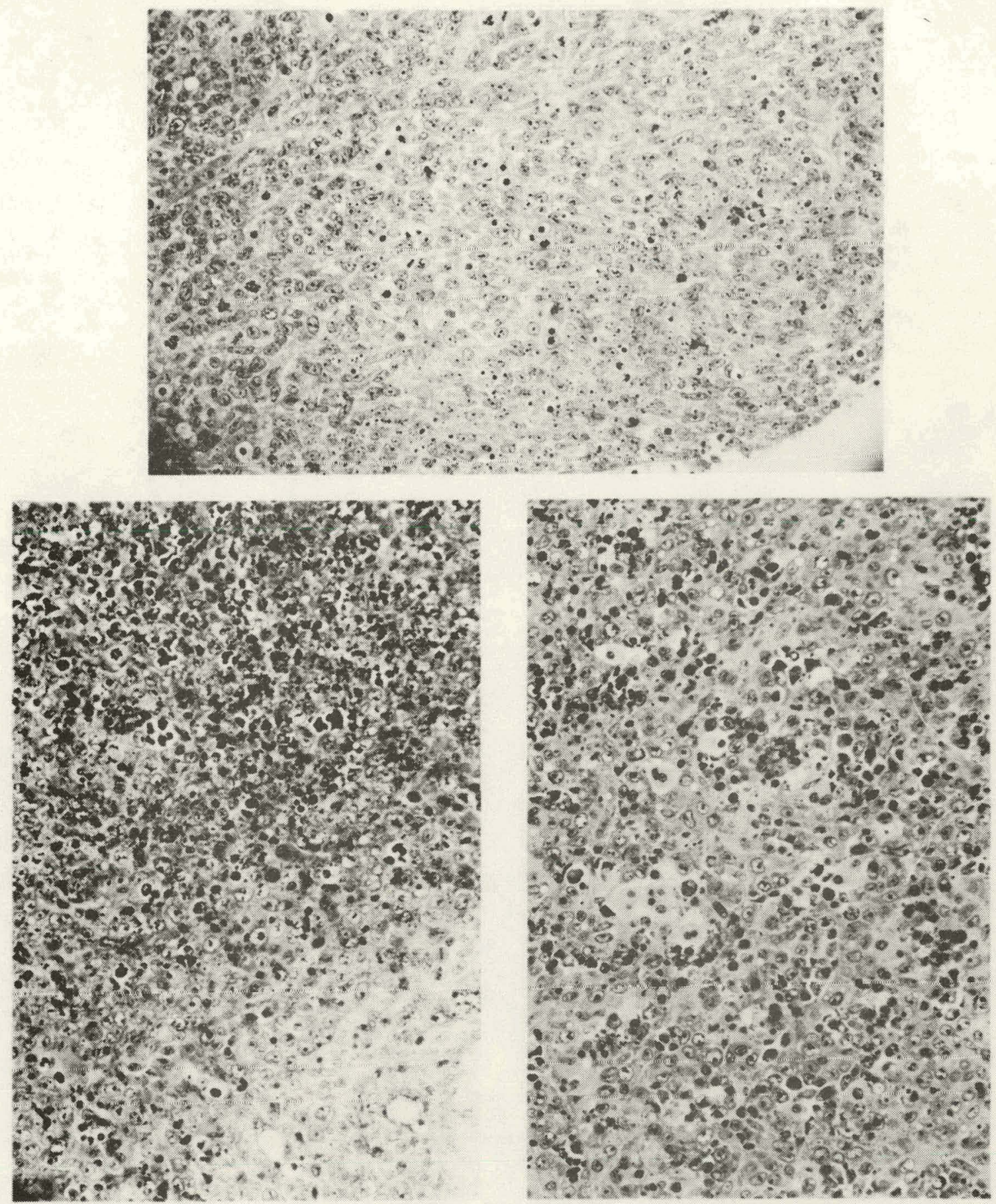
Figure 6. (Top) Photomicrograph of fetal liver which was sham i rradiated and explanted at 13 days of gestation and cultured for one day. Note fibrinogenic epithelium (lower left) and marked necrosis $(225 \mathrm{x})$.

Figure 7. (Lower left) Photomicrograph of fetal liver which was explanted at 13 days of gestation and immediately exposed to $435 \mathrm{R}$ of $\mathrm{x}$-ray, and then cultured for one day. Green staining cellular debris is present $(225 \mathrm{x})$.

Figure 8. (Lower right) Photomicrograph of liver explanted from fetus immediately after being exposed to $435 \mathrm{R}$ of $\mathrm{x}$-ray at 13 days of gestation and cultured for one day. Note "cords" of fibrinogenic epithelium (along periphery) between zones of necrosis $(225 \mathrm{x})$. 

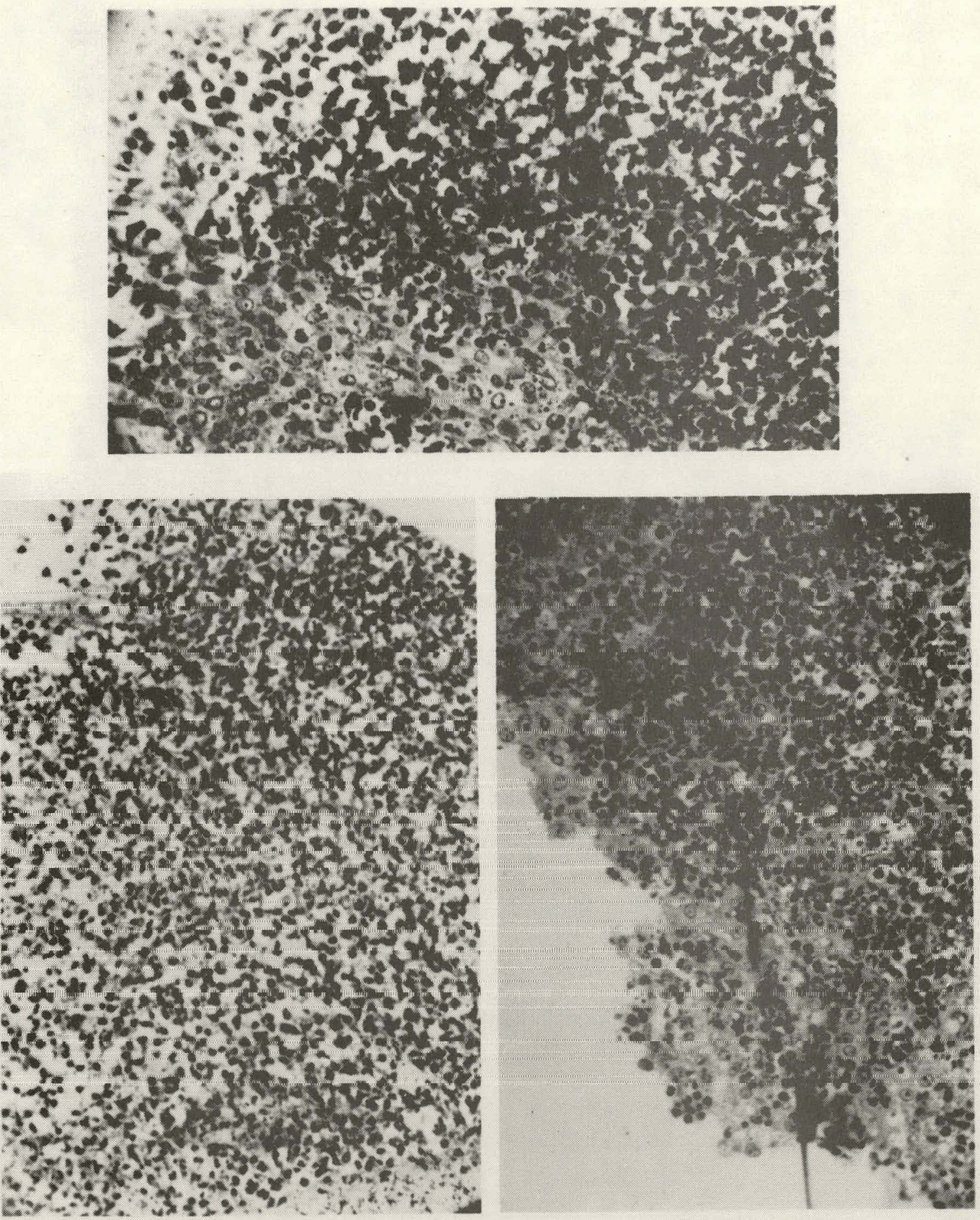
Figure 9. (Top) Photomicrograph of fetal liver which was sham irradiated at 13 days of gestation and cultured for three days. Note the fibroblastic-like cells (left), fibrinogenesis and necrosis $(225 \mathrm{x})$.

Figure 10. (Lower left) Photomicrograph of fetal liver which was explanted and immediately exposed to $435 \mathrm{R}$ of $\mathrm{x}$-ray at 13 days of gestation, and cultured for three days. There is karyolysis of macrophages and green-staining cellular debris present $(225 \mathrm{x})$.

Figure 11. (Lower right) Photomicrograph of liver explanted from fetus immediately after being exposed to $435 \mathrm{R}$ of $\mathrm{x}$-ray at 13 days of gestation and cultured for three days. Section shows necrosis, autolys is and green-staining ccllular debris $(225 \mathrm{x})$. 

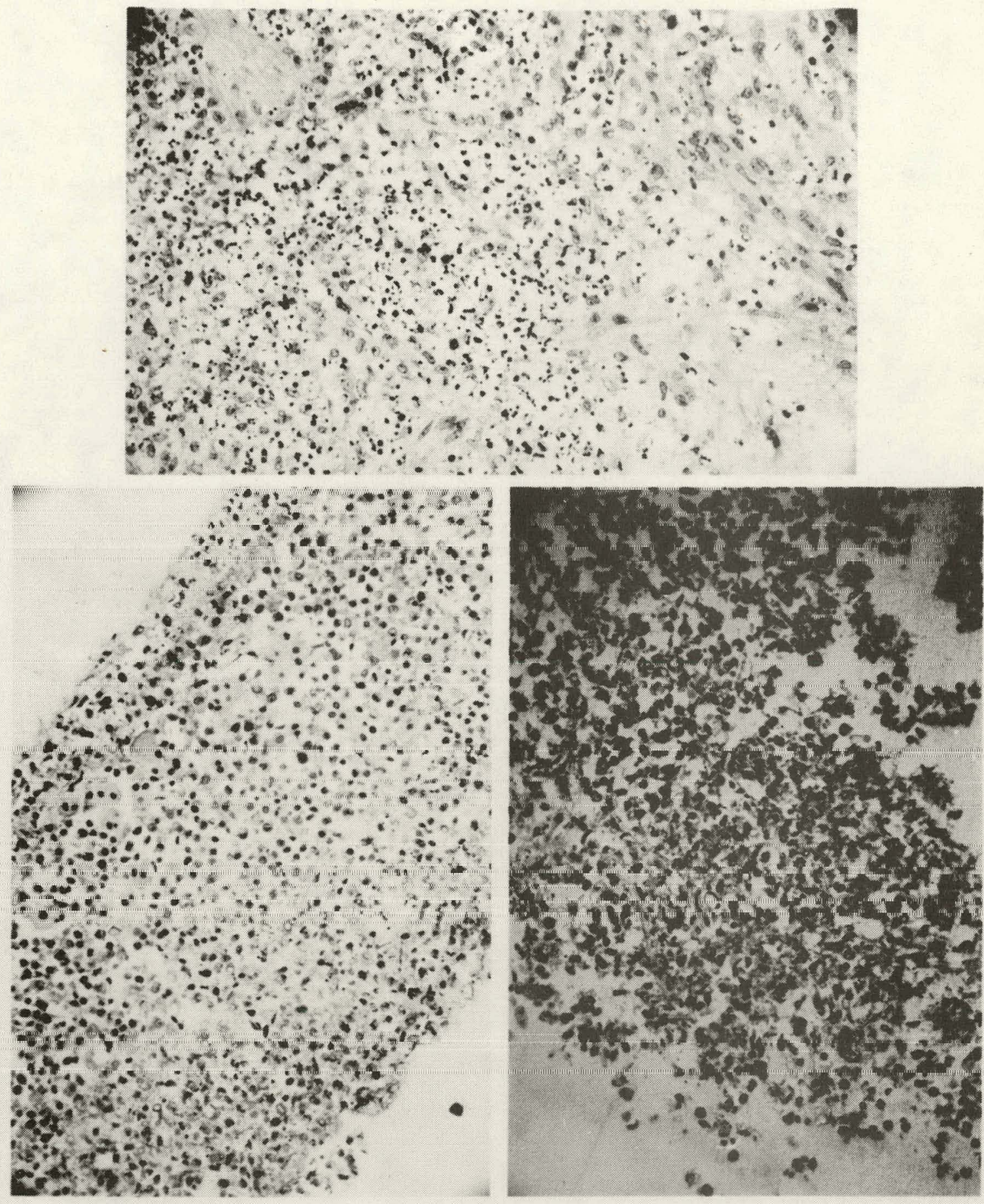
Figure 12. (Upper left) Photomicrograph of fetal liver which was sham irradiated in vivo at 13 days of gestation, explanted at 14 days of gestation and incubated for four hours. Note the many megakaryocytes and clear epithelium $(225 \mathrm{x})$.

Figure 13. (Upper right) Photomicrograph of fetal liver which was exposed to $435 \mathrm{R}$ in vivo at 13 days of gestation and incubated for four hours. Note the fibrinogenesis and presence of the macrophage $(m)$ in zone of necrosis $(225 \mathrm{x})$.

Figure 14. (Lower left) Photomicrograph of fetal rat liver which was sham irradiated at -1.3 tays of gestation, explanted at 16 days of gestation and incubated for four hours. Note the sinusoids (s) containing the hematopoietic elements $(225 \mathrm{x})$.

Figule 15. (Luwer right) Photomicrograph of fetal liver which was exposed to $435 \mathrm{R}$ in vivo at 13 days of gestation, explanted at 16 days of gestation and incubated for four hours. Note the disruption of sinusoids and increased cytoplasmic vacuoles $(225 \mathrm{x})$. 

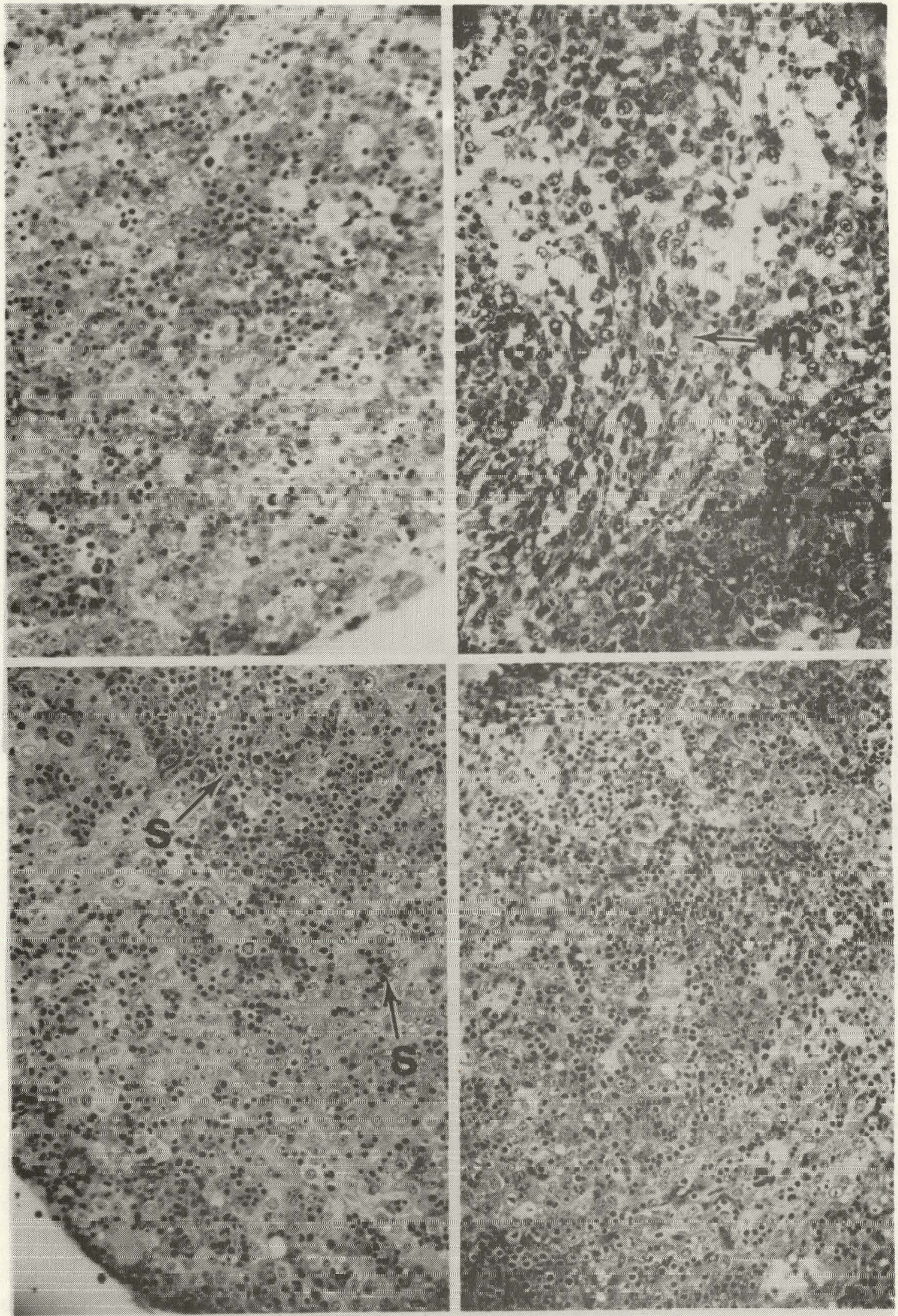
-able 5. Characteristics of Development of 15-Day Fetal Rat Liver after In Vivo or In Vitro Exposure to $435 \mathrm{R}$ of X-Ray - Expt. II. a

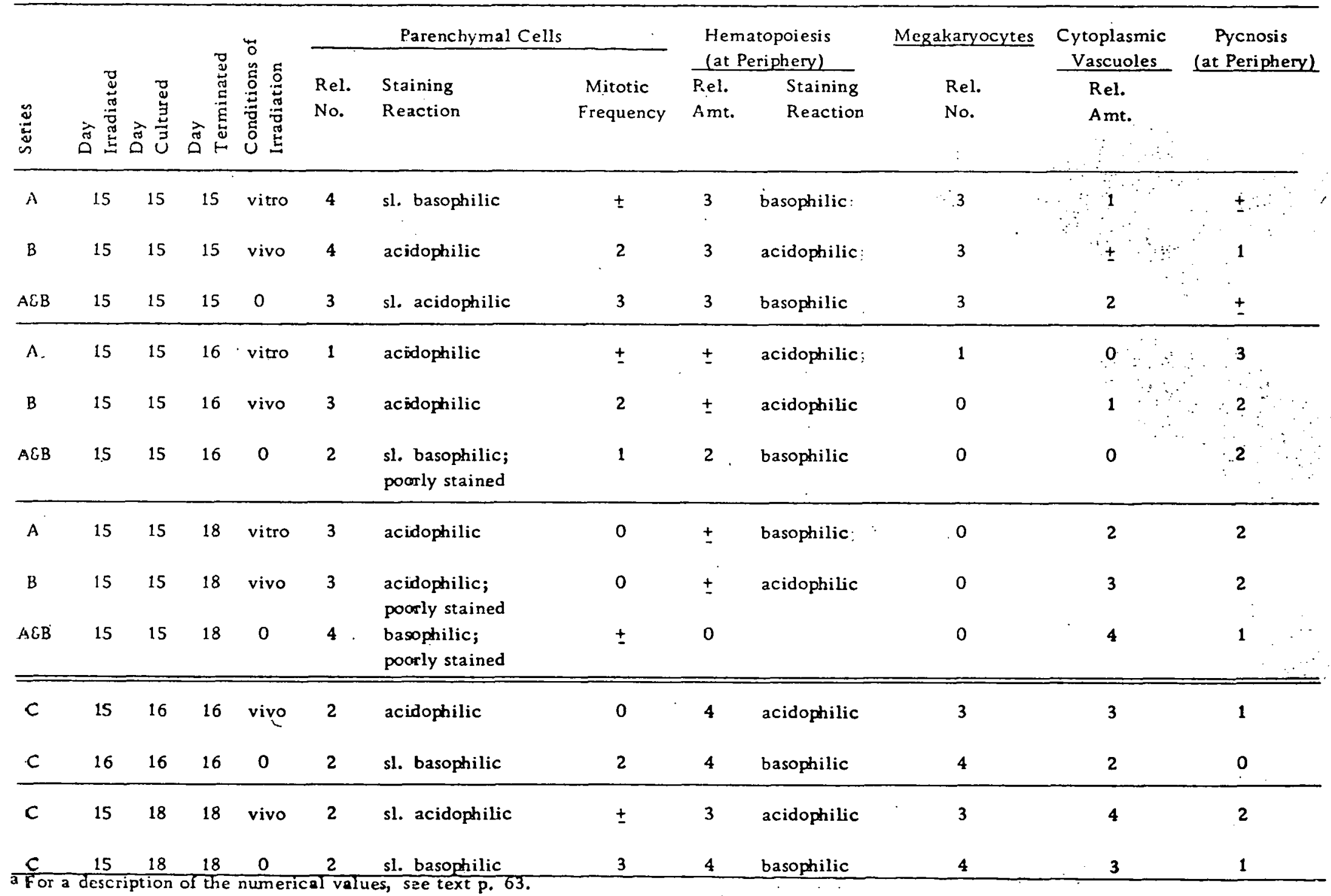


Figure 16. (Top) Photomicrograph of fetal liver which was sham irradiated at 15 days of gestation and cultured for four hours. There is an extrusion of $\mathrm{RBC}^{\prime} \mathrm{s}(225 \mathrm{x})$.

Figure 17. (Lower left) Photomicrograph of fetal liver which was explanted and immediately irradiated with $435 \mathrm{R}$ of $\mathrm{x}$-ray at 15 days of gestation and cultured for four hours. There is an enlargement of intercellular spaces $(225 \mathrm{x})$.

Figure 18. (Lower right) Photomicrograph of liver explanted from fetus immediately after being exposed to $435 \mathrm{R}$ of $\mathrm{x}$-ray at 15 days of gestation and cultured for four hours. Pycnosis is increased and central zone of necrosis can be seen at the upper right $(225 \mathrm{x})$. 

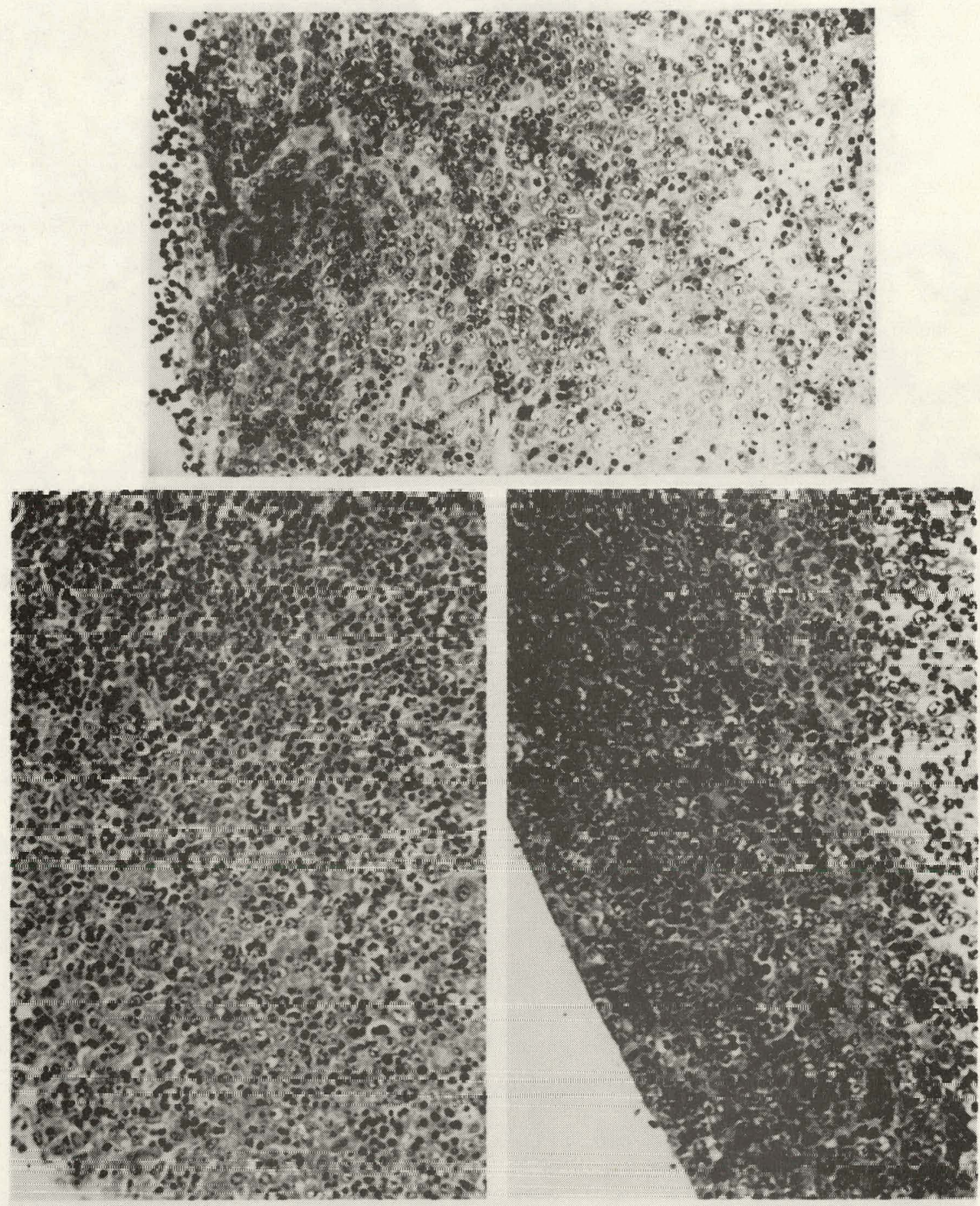
Figure 19. (Top) Photomicrograph of fetal liver which was sham irradiated and explanted at 15 days of gestation and cultured for one day. There are large zones of necrosis between the web of fibrinogenic epithelial cells $(225 \mathrm{x})$.

Figure 20. (Lower left) Photomicrograph of fetal liver which was explanted at 15 days of gestation and immediately exposed to $435 \mathrm{R}$ of $\mathrm{x}$-ray and cultured for one day. Web of parenchymal cells and marked necrosis is seen in the section $(225 \mathrm{x})$.

Figure 21. (Lower right) Photomicrograph of liver explanted from fetus immediately after being exposed to $435 \mathrm{R}$ at 15 days of gestation and cultured for one day. There is an extrusion of $R B C^{\prime} s$, a degeneration of sinusoids and a prevalence of clear epithelium $(225 x)$. 

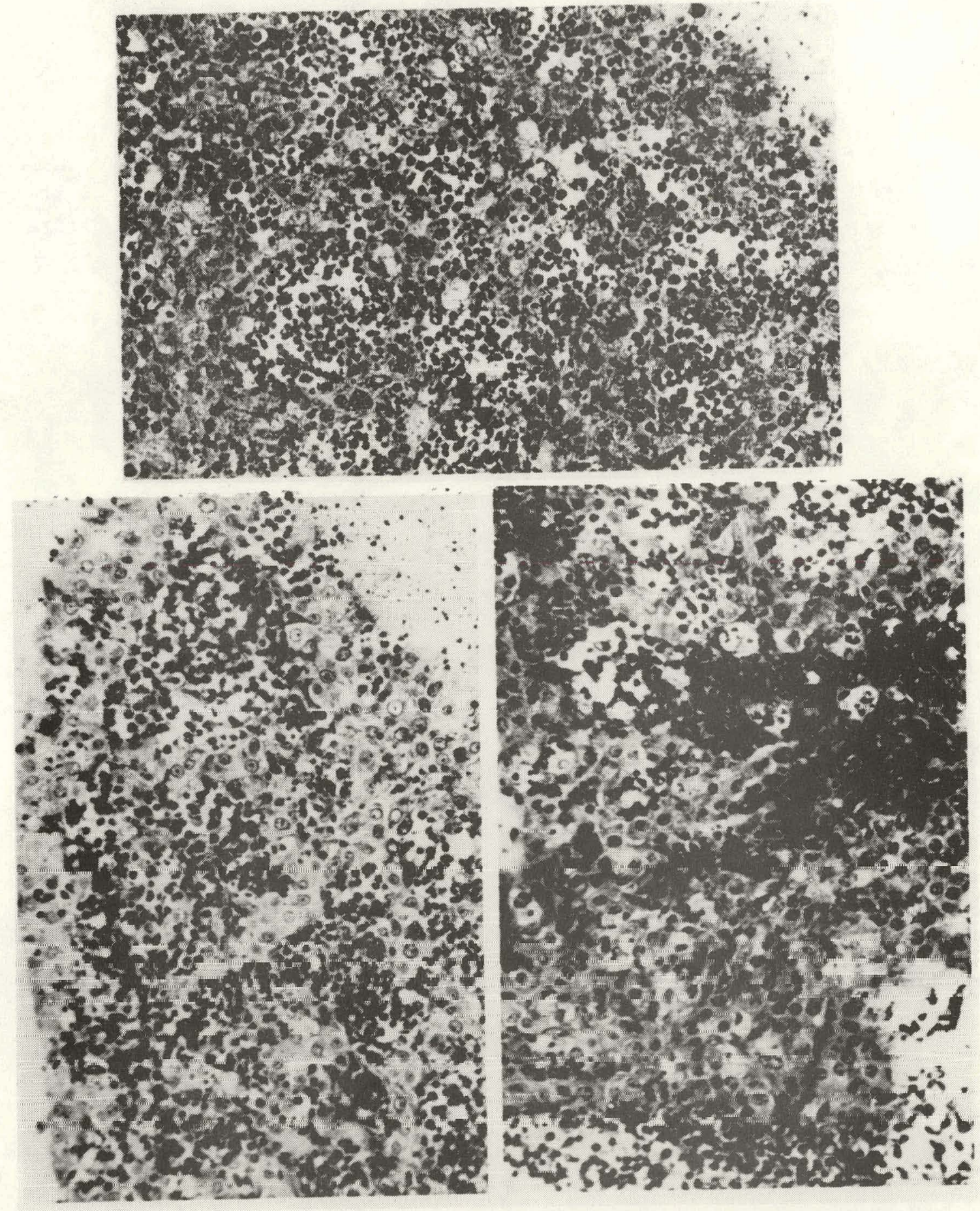
Figure 22. (Upper left) Photomicrograph of fetal liver which was sham irradiated and explanted at 15 days of gestation and cultured for three days. Note the localization of hematopoietic elements and predominance of clear epithelium $(225 x)$.

Figure 23. (Upper right) Photomicrograph of fetal liver which was explanted at 15 days of gestation and immediately exposed to $435 \mathrm{R}$ of $\mathrm{x}$-ray and cultured for three days. A web of fibrinogenic epithelium can be seen between necrotic zones $(225 \mathrm{x})$.

Figure 24. (Lower left) Photomicrograph of liver explanted from fetus immediately after being exposed to $435 \mathrm{R}$ of $\mathrm{x}$-ray at 15 days of gestation, and cultured for three days. There is a web of granular epithelium between zones of necrosis $(225 \mathrm{x})$.

Figure 25. (Lower right) Autoradiograph of ${ }^{3} \mathrm{H}$-proline incorporated into liver explanted from fetus immediately after being exposed to $435 \mathrm{R}$ of $\mathrm{x}$-ray at 15 days of gestation and cultured for three days. Note localization of $3_{\mathrm{H}}$ as indicated by the darkening along the lower peripheral zones of necrosis $(90 \mathrm{x})$. 


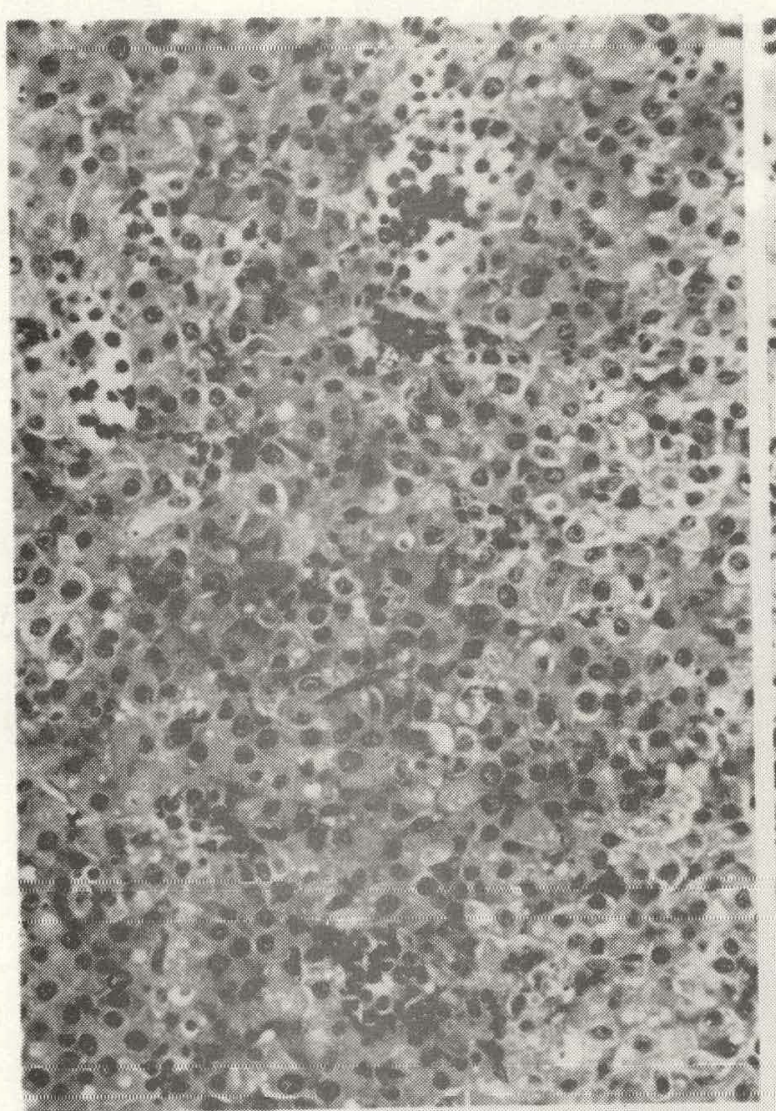

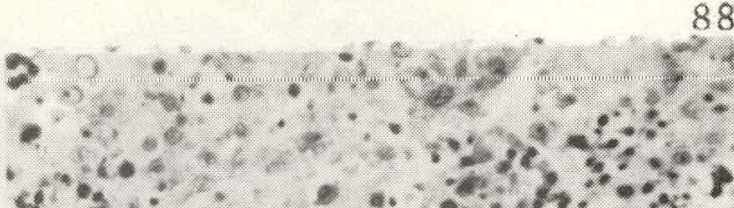

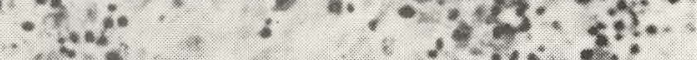

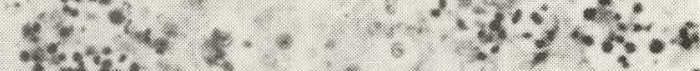

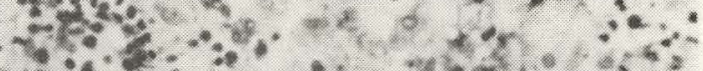

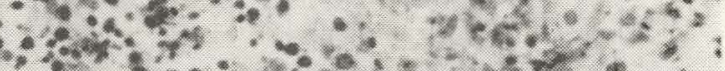

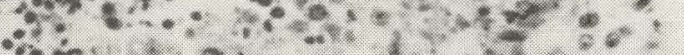
ชét.

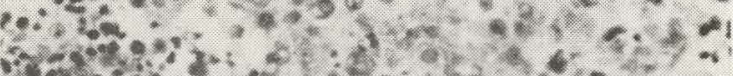

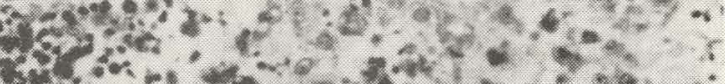

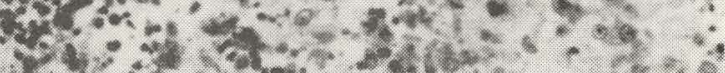

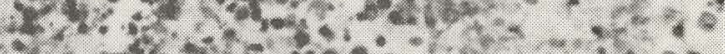

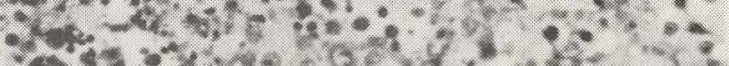

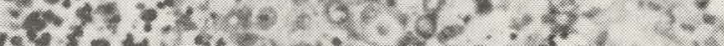

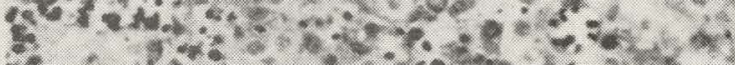

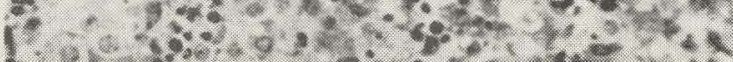

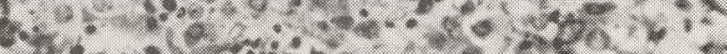

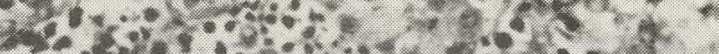

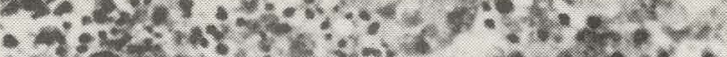

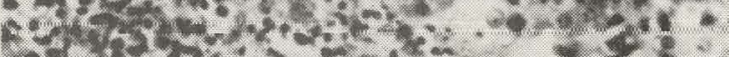

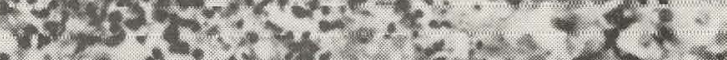

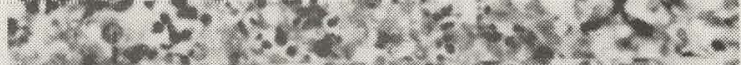

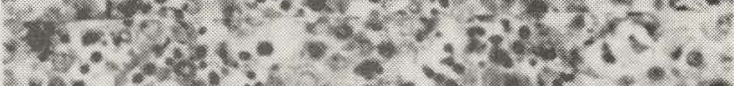

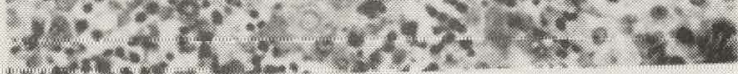
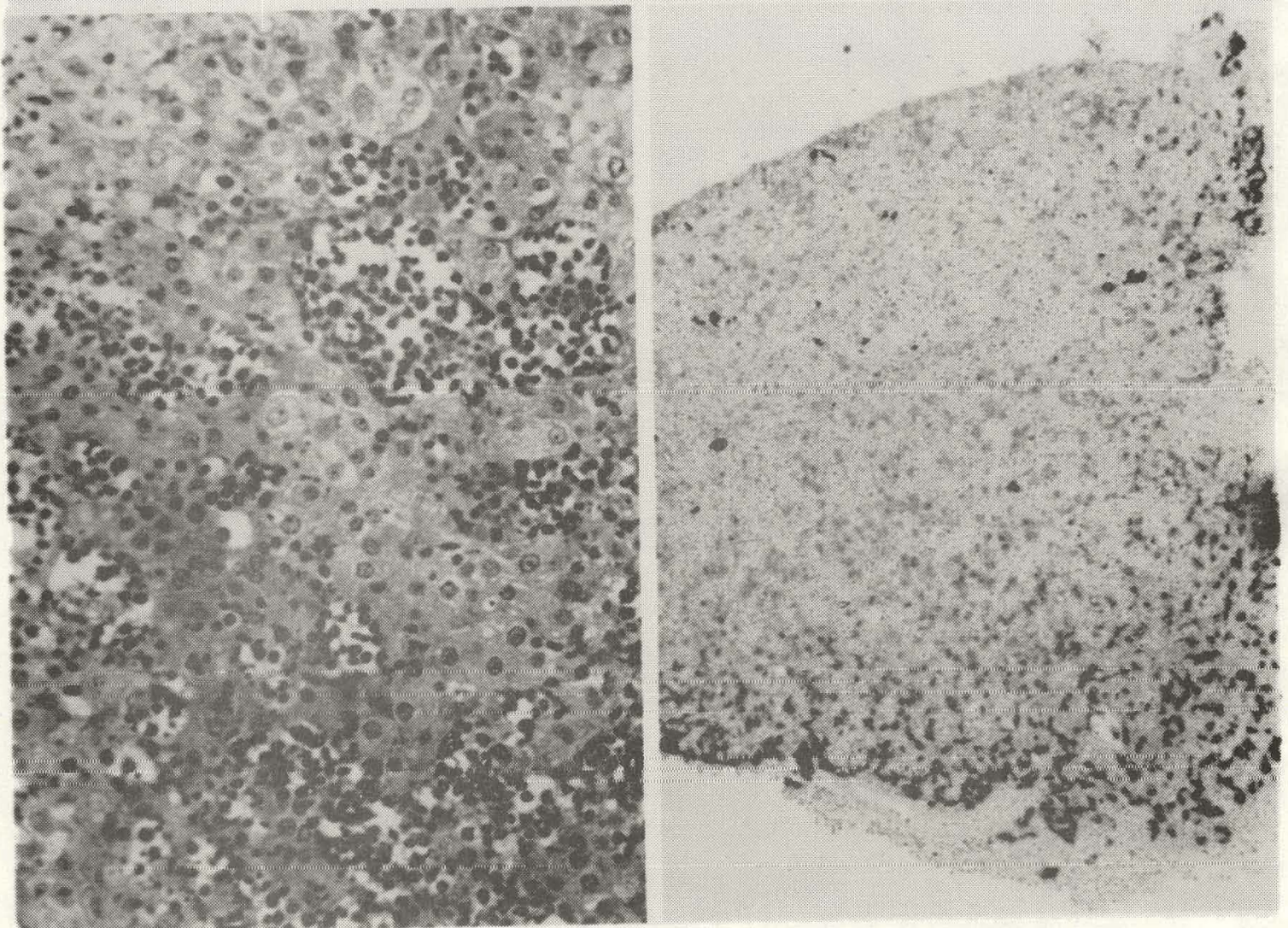
Figure 26. (Upper left) Photomicrograph of fetal liver which was sham irradiated in vivo at 15 days of gestation, explanted at 16 days of gestation and cultured for four hours. There are many megakaryocytes and well-defined sinusoids present $(225 \mathrm{x})$.

Figure 27. (Upper right) Photomicrograph of fetal liver which was irradiated in vivo with $435 \mathrm{R}$ of $\mathrm{x}$-ray at 15 days of gestation, explanted at 16 days of gestation and cultured for four hours. Note the atypical megakaryocytes, the intense staining reaction and increased pycnosis $(225 \mathrm{x})$.

Figure 28. (Lower left) Photomicrograph of fetal liver which was sham irradiated in vivo at 15 days of gestation, explanted at 18 days of gestation and cultured for four hours. Note the many megakaryocytes $(m)$ and the predominance of hematopoiesis $(225 \mathrm{x})$.

Figure 29. (Lower right) Photomicrograph of fetal liver which was irradiated in vivo with $435 \mathrm{R}$ of $\mathrm{x}$-ray at 15 days of gestation explanted at 18 days and cultured for four hours. There is an increase in the number and size of the cytoplasmic vacuoles and clear epithelium is seen at lower right $(225 \mathrm{x})$. 

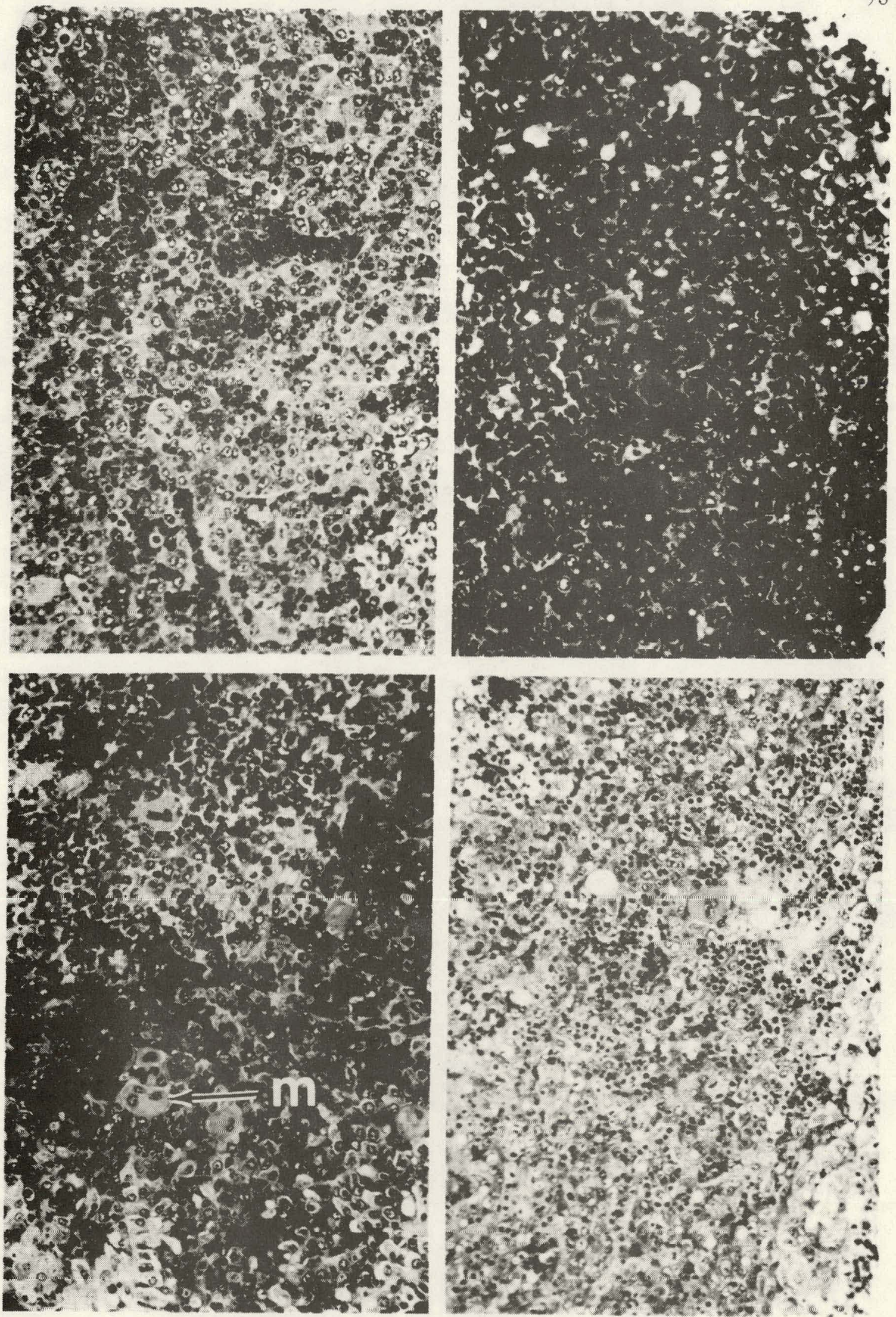
Figure 30. (Upper right) Photomicrograph of liver explanted from fetus immediately after being sham irradiated at 17 days of gestation and cultured for four hours. (Paraffin; 225x)

Figure 31. (Upper left) Photomicrograph of liver explanted from fetus immediately after being exposed to $435 \mathrm{R}$ at 17 days of gestation and cultured for four hours. Note the depletion of hematopoietic elements and marked increase in cytoplasmic vacuoles. (Paraffin; 225x)

Figure 32. (Lower left) Photomicrograph of fetal liver which was sham irradiated at 19 days of gestation and cultured for four hours at 22 days. Note the non-staining granules in the cytoplasm (glycogen) which are more concentrated at the periphery (Paraffin; 225x).

Figure 33. (Lower right) Photomicrograph of fetal liver which was exposed to $435 \mathrm{R}$ of $\mathrm{x}$-ray at 19 days of gestation and cultured for four hours at 22 days. Note the lack of cytoplasmic granules, the extrusion of $\mathrm{RBC}^{\prime}$ s, vascular engorgement and clear epithelium. (Paraffin; 225x) 

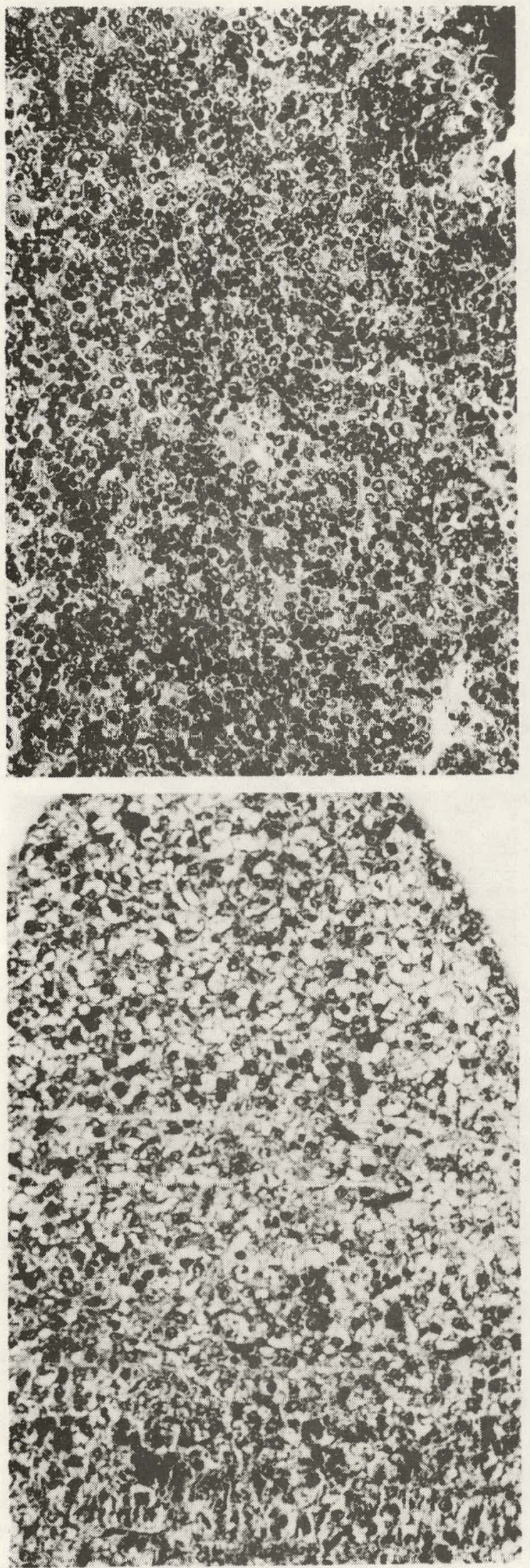

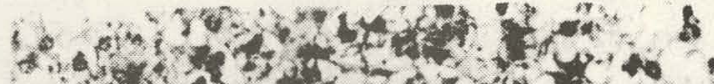

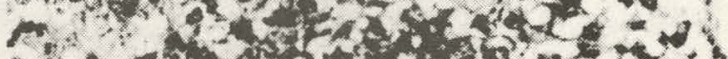

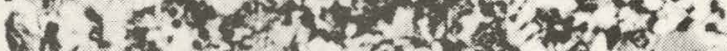

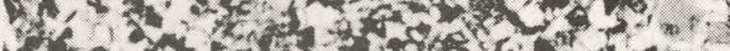

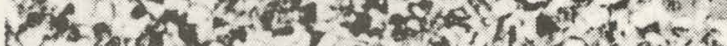

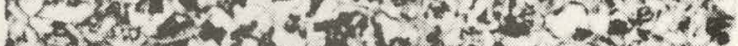
$5 x^{2}-x^{2}-3 y^{2}-4,20$

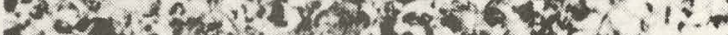

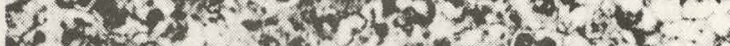

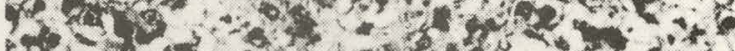

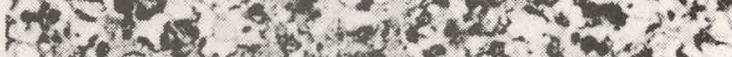

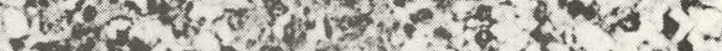

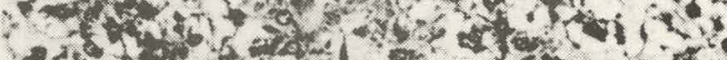

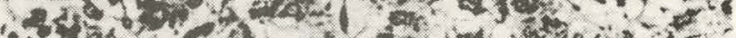

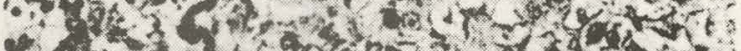

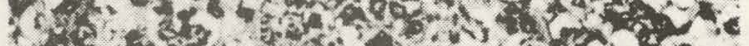

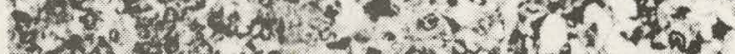

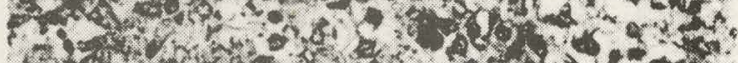

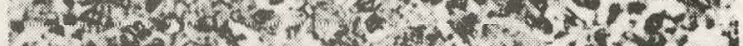

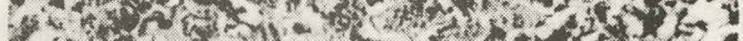

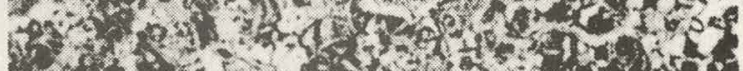

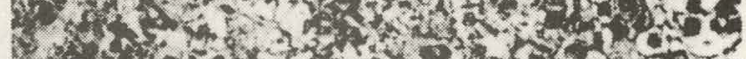
Port 3034 .

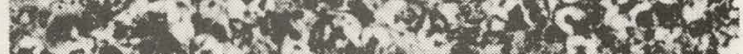

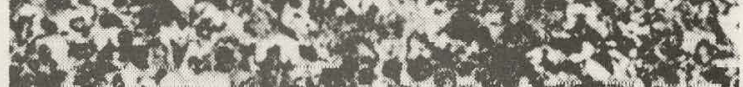

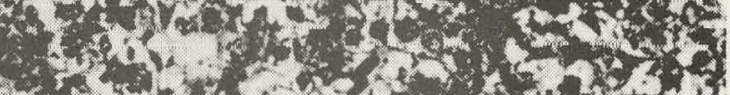

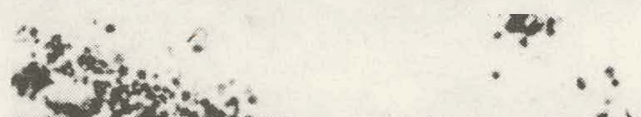
1.

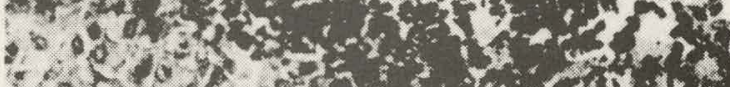

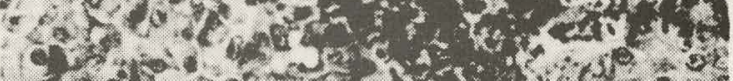
3.

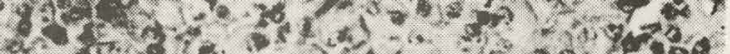

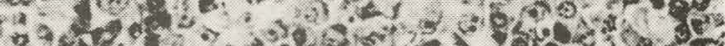

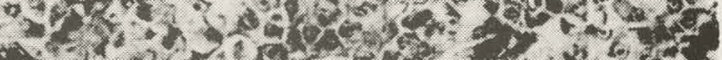

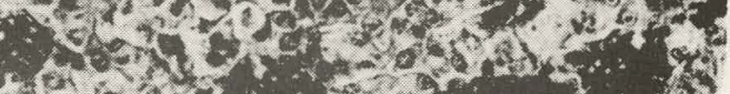

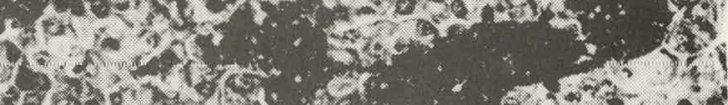

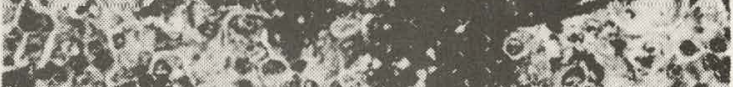

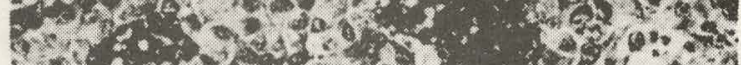

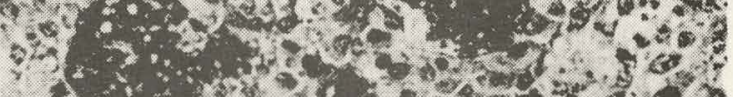

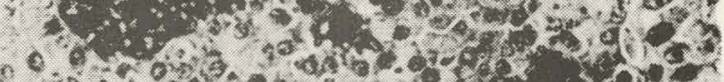

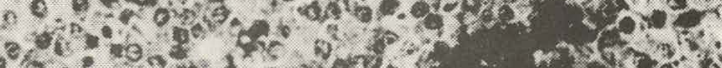

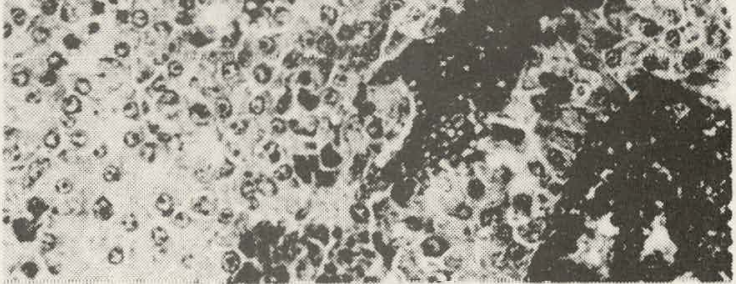


was also observed although this was less prominent than in livers exposed at earlier times of gestation. In liver exposed to $x$-ray and cultured at 17 days of gestation there was a marked increase in the size and number of cytoplasmic vacuoles compared to the control (Figures 30 and 31). A depletion of glycogen, vascular dilation and extrusion of RBC's was observed in liver at 22 days (birth) of development after exposure to $435 \mathrm{R}$ on the nineteenth day of gestation (Figures 32 and 33).

\section{Discussion}

In Vitro Development of Fetal Rat Liver

As is apparent from the results there is a variability between liver cultures within a single treatment group. To some extent, this may be attributed to the normal variation which occurs between litters. In addition, the precise stage of organogenesis can vary between embryos within a singlc littcr (Wilson alid Kärr, 1951). It has been suggested that the radiation dose in vivo is dependent upon the location of the embryo in the uterus (Rugh, 1969), however, under the conditions of exposure these differences in the present studies are probably insignificant.

The most consistent finding in the cultures of liver explants was the degeneration of the hepatic cells and the presence of zones of 
necrosis. There may be several factors which contribute to the deterioration observed in the liver culture:

1) The overlay of the medium can be critical to the survival of hepatic cells in culture because it may interfere with gas exchange. While care was taken to minimize the fluid overlay, there were still a few cultures which were partially submerged after long incubation.

2) The organ size has been shown to be critical in determining the final outcome of organ cultures (Wessels, 1967); but even in explants less than $2 \mathrm{~mm}$, the re was a central zone of necrosis. This zone probably is the result of a nutritional and/or gas exchange gradient. The central zone of necrosis does not extend to the extreme upper surface of explants less than $2 \mathrm{~mm}$; again indicating the importance of gas exchange in hepatic cell metabolism.

3) Inadequate gas exchange can cause deterioration of the parenchymal cells. Sandstrom (1965) found that the parenchymal cells of live $r$ explànts degenerated within five hours under anaerobic culture conditions. Campbell and Hales (1971) found that adult liver cultures survived best in $95 \% \mathrm{O}_{2} / 5 \% \mathrm{CO}_{2}$. In the present studies which used $95 \%$ air $/ 5 \% \mathrm{CO}_{2}$, the granular epithelium showed degeneration within four hours. 
Although the pattern of enzymic activity of fetal liver shifts from anaerobic to oxidative during late gestation, the metabolism of the earlier fetus is primarily a naerobic (glycolytic) (Burch et al. , 1963). It is paradoxical that the incubation conditions used in these experiments do not appear to meet the oxygen requirements of the explanted liver. It may be that the stress imposed during the removal of fetal liver from the uterine environment and/or the subsequent in vitro incubation results in an alteration of its metabolic requirements.

It was noted that a single culture could develop into a "mosaic" of cell types especially after prolonged incubation (see Figure 1). For instance, a band of "fibroblastic-like" cells might span across the interior of the explant without an apparent relationship to the organ morphology. This is similar to the findings reported by Sandstrom (1965). It is suggested that these distinct areas containing various non-hematopoietic cells probably represent a variation in the "microenvironment" to which the cells are exposed and does not have any functional significance in organogenesis.

The few outgrowths observed were small and were found exclusively in control cultures. Outg rowths containing tubular epithelium, as reported by Alexander and Grisham (1970), were not observed. Other cell types such as the clear epithelium, fibroblastic-like cells and macrophages as described by others (Alexander 
and Grisham, 1970; Sandstrom, 1965; Watanbe, 1966; Bang and Warwick, 1965) were observed in the present studies. The "fibrinogenic epithelium" appeared to resemble Sandstrom's (1965) Type IV cell which probably represents the degenerate parenchymal cell in anaerobic culture conditions. The above cell types appea to lack the fastidious oxygen requirement of the granular hepatocyte. Consequently, the culture method used in these studies permitted selective growth of these "glycolytic cells."

The Millipore-filter method does not retard the rate of diffusion of metabolites between the tissue explant and the fluid medium, as does the agar or plasma clot method. Moreover, this method permits an extrusion of hematopoietic elements from the hepatic sinusoids. Chen (1954) also made this similar observation on liver explanted on lens paper, but offered no explanation. In contrast, hematopoietic elements are retained when the plasma-clot method of culture is used (Bang and Warwick, 1965). These observations suggest that this extrusion is a physical phenomenon related to the use of liquid medium. Although the "results" of liver organ culture were not definitive, there were three trends consequential to in vitro development that could be discerned: 1) increased necrosis, for the reasons discussed above; 2) increased fibrinogenesis; 3) decreased hematopoiesis. 
In vitro growth conditions are often selective for the proliferation of the glycolytic fibroblasts, and the subsequent in vitro fibrinogenesis has long been known (Fell, 1951). The presence of macrophages within the cellular debris of the liver explants may be involved in this process if the report by Chvapil and Hurych (1968) that a "fibrosis stimulating" substance is released during macrophage breakdown, is correct.

Campbell and Hales (1971) have found that the concentrations of electrolytes in organ culture of adult liver are dependent on oxygen concentrations. It would seem probable that in the present studies, the concentrations of the electrolytes have also been altered, although probably not to the same degree for all the cells within the culture. Since electrolyte concentration may control fibrinogenesis (Fitton Jackson, 1964), this could result in an elevated synthesis of connective tissue. In autoradiog raphic studies, labeled proline was concentrated in the small necrotic zones along the periphery but not in the more anaerobic central zone. The oxygen requirement for collagen biosynthesis (Chyapil and Hurych, 1968) may explain the pattern of tritiated proline incorporation.

\section{Effect of Radiation on the Develupment of Fetal Rat Liver}

The most prominent effect of radiation was growth retardation regardless of whether the subsequent development was in vivo or in 
vitro. This is in agreement with the observations made by Wilson and Karr (1951), who found the decreased hepatic size did not become marked in vivo until three days post-irradiation. In contrast, the cultured livers exhibited marked atrophy within 24 hours after exposure to the $\mathrm{x}$-ray either in vivo or in vitro. When 13 -day fetuses were irradiated in utero and explanted three days later, some recovery of the hematopoietic elements was observed, although it was not equivalent to the control. Fetal livers which were two days older at exposure (15 days) and explanted three days later did not display such recovery.

Hazzard and Budd (1969) found that 15-day fetuses which were exposed to lower doses of $x$-ray (up to $240 \mathrm{R}$ ) had a normal red blood cell count at birth although they were leukopenic. Thus recovery may be in progress subsequent to the $x$-ray exposure at 15 days of gestation but not yet apparent on the 18 th day of development. Alterna- : tively, the more undifferentiated cells of the 13-day liver that survive after radiation exposure are perhaps able to compensate and restore the hematopoiesis of the liver better than the more differentiated cells at 15 days of gestation.

The 17- and 19-day livers appear to survive the insult of radiation better than those at the 13 th or 15 th day of development. The mitotic frequency of the parenchyma is lower in the older fetal livers; hence chromosomal damage may not he sn readily obvious. 
As discussed above, biochemical development of fetal livers is altered with the explantation of the organ. The activity of some enzymes (such as lactic and glycerophosphate dehydrogenases is lowered during post-irradiation in utero development of fetal rat liver (Smith and Shore, 1966). This shift in metabolic activity may serve to explain the aberrant histology of the irradiated explants. An increase in lipid may be inferred from the increase in the relative frequency and size of the cytoplasmic vacuoles seen in irradiated fetal livers developing in utero. The degranulation in newborn livers that had been irradiated three days earlier would suggest that there is a decrease in glycogen content. Although not previously studied in fetal liver, these observations a re in accord with the results of radiation studies of adult liver. The radioresistant adult liver cell exhibits fatty infiltration and a dec reased glycogen content following exposure to large doses of radiation (Casarett, 1968).

There are some difficulties in comparing the effects of in vivo and in vitro radiation for it is not possible to completely simulate the in vivo condition outside the uterus. As Trowell (1966) has pointed out, the intracellula $r$ oxygen concentration cannot be determined in the two situations, but the in vitro should be more anoxic than in vivo. As described in the results, at four hours post-irradiation, the 13day hepatic cultures irradiated in vitro showed better survival than the cultures irradiated in vivo. This finding is partially explained by 
the fact that the cultures irradiated in utero had nea rly an hour longer (the time required between irradiation in vivo and explantation) following irradiation, because all explants were terminated after four hours in culture. This explanation is. supported by the fact that after one day in culture, the 13 -day liver exposed to $x$-ray in utero showed less degeneration than the other cultures irradiated in vivo. The 15 -day liver cultures exhibited a similar pattern, and by the third day no recovery could be detected from the progressive degeneration of all cultures.

In some cases, the cultures which had been irradiated appeared to be more viable than the controls. This may be due to the variations as discussed above. It may be, however that radiation has, in fact, enhanced the in vitro survival of the organ cultures. It is known that cells which have a lower intracellular oxygen content will sustain less damage when exposed to ionizing radiation. These more anaerobic cells may be favored in this method of culture. Thus radiation may act to select cells more inclined to survive the culture conditions, and consequently minimize the cellular competition which may occur in the control. 


\section{STUDIES ON FETAI LUNG}

\section{$\underline{\text { Results }}$}

The studies on fetal lung were more satisfactory in the technical sense than those on liver, for there was a greater reproducibility in the results. It was possible to observe macroscopically the progressive growth and differentiation as well as the effects of irradiation in lung cultures. The progressive growth of typical cultures of lung at 13 days of gestation, as seen at four hours (Figure 34), one day (Figure 35 ) and three days (Figure 36 ) in culture, was readily apparent. An increase in size and branching of the bronchial tree, as demarcated by blood vessels, was also obvious in the cultures of lungs explanted at 15 days of gestation when the incubation time increased from four hours (Figure 37) to one day (Figure 38) and three days (Figure 39). Figure 40, shows a lung irradiated in vivo at 13 days of gestation and then cultured immediately for four hours on the same day. Figure 41 shows the marked degeneration which had occurred in this explant 24 hours later. Lung explants exposed to $435 \mathrm{R}$ of $\mathrm{x}$-ray in utero at 15 days of gestation and cultured immediately for four hours (Figure 42) or one day (Figure 43) showed atrophy and marked deterioration of the vascular system. Comparison of Figures 44 and 45 show the effects of irradiation on the lung at 13 days of gestation when it was allowed to remain in utero for one day. The vascular 
Figure 34. (Top) Photograph of lung from sham irradiated fetus (13 days of gestation) after four hours in culture. Note the presence of lung buds (lower center) (50x).

Figure 35. (Lower left) Photograph of the same fetal lung explant shown in Figure 34 one day later. Note the continued growth and differentiation as evidenced by the blood vessels $(50 x)$.

Figure 36. (Lower right) Photograph of the same fetal lung explant shown in Figure 34 after three days in culture. Note the increased size and loss of blood vessels (50x). 

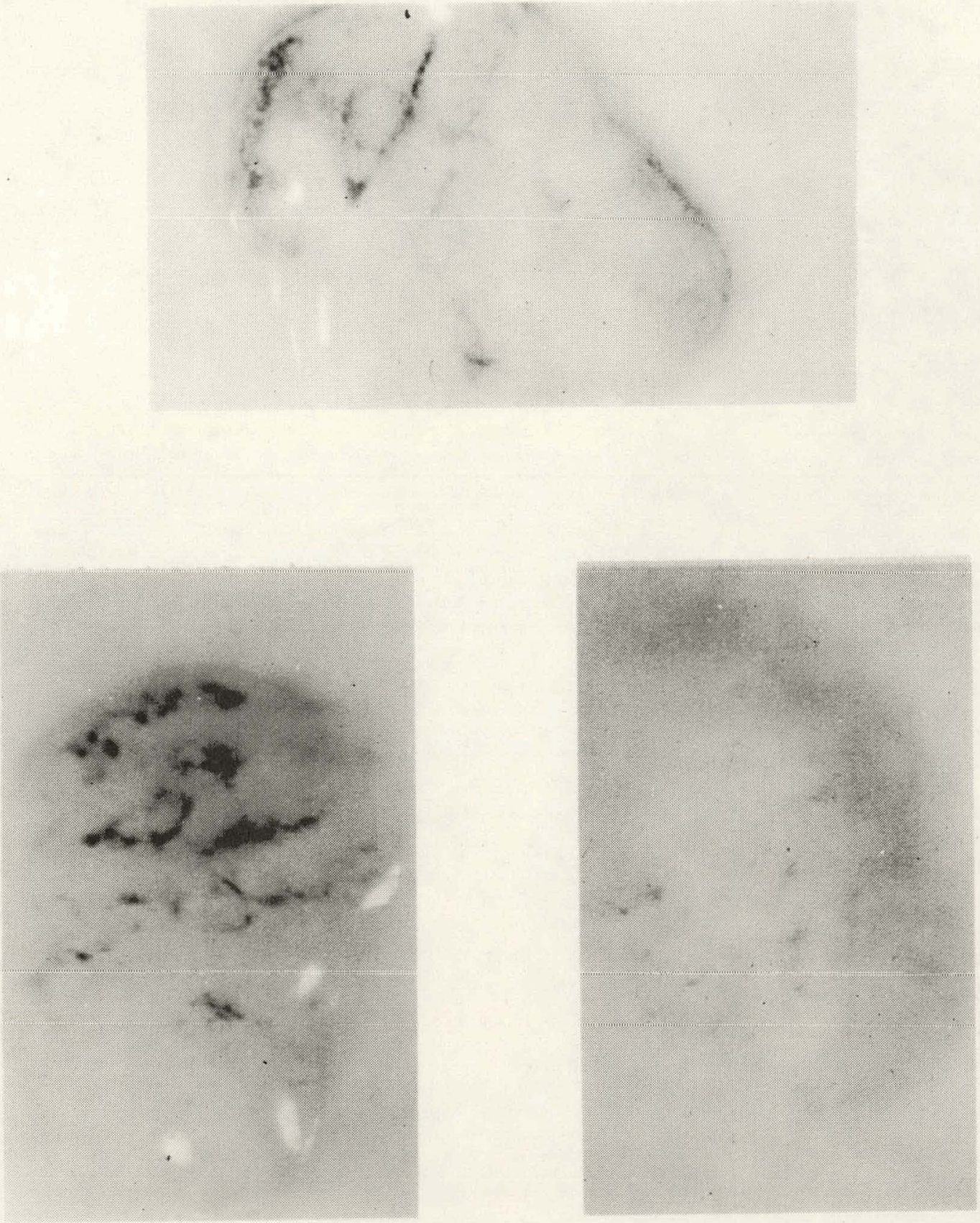
Figure 37. (Top) Photograph of fetal lung from sham irradiated fetus (15 days of gestation) after four hours in culture. The branching of the bronchial tree is outlined by the vascular system $(50 \mathrm{x})$.

Figure 38. (Lower left) Photograph of the same explant shown in Figure 37 one day later. Note the increased size and continued branching of the bronchial tree $(50 \mathrm{x})$.

Figure 39. (Lower right) Photograph of the same explant shown in Figure 37 after three days in culture. Note the los of blood vessels and increased size $(50 x)$. 

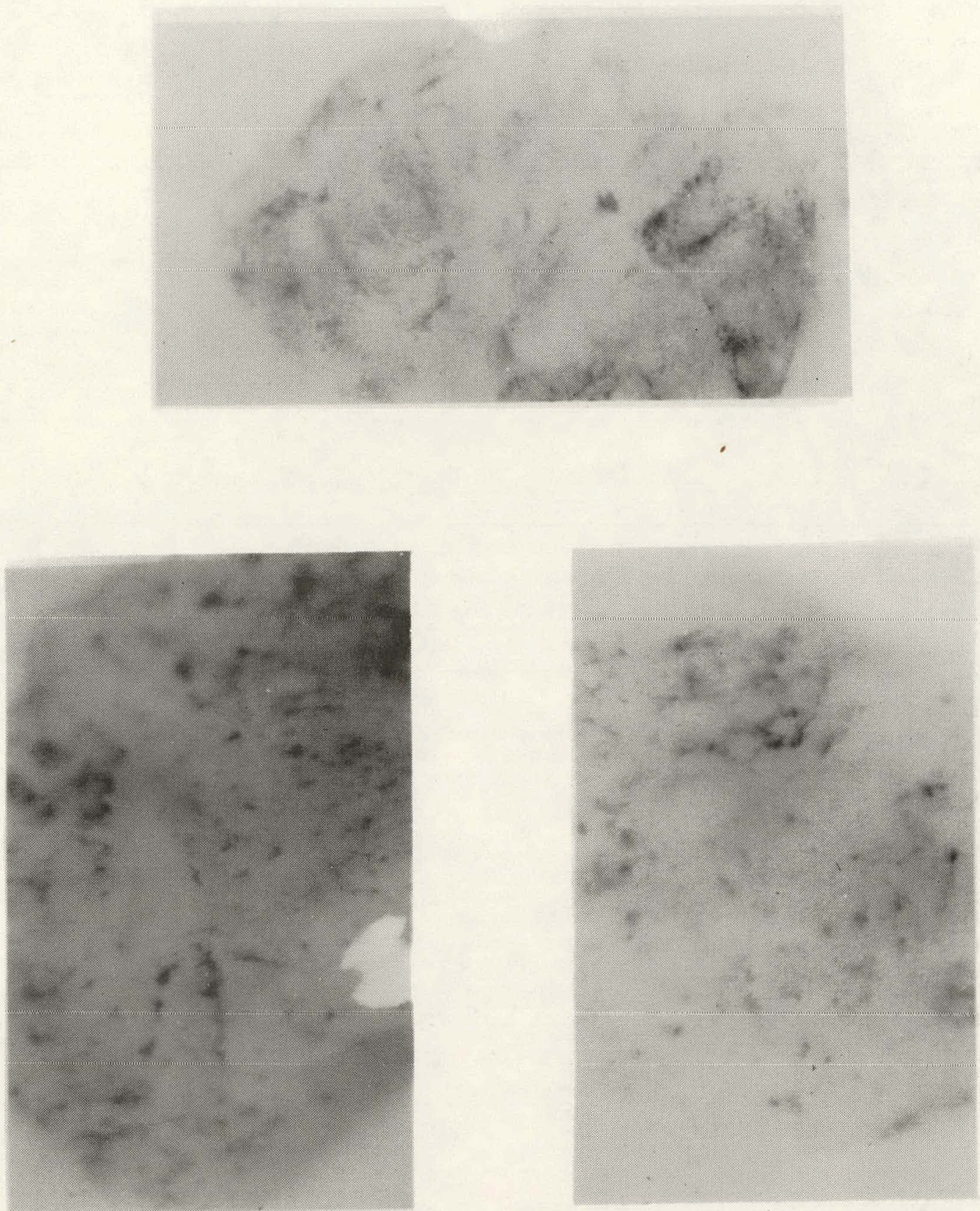
Figure 40. (Upper left) Photograph of lung explanted from fetus immediately after exposure to $435 \mathrm{R}$ at 13 days of gestation and cultured for four hours. Note the smaller size and loss of structure when compared to Figure 34 (50x).

Figure 41. (Upper right) Photograph of the same lung explant shown in Figure 40 after one day in culture. There is a loss of blood vessels and a lack of growth $(50 \mathrm{x})$.

Figure 42. (Lower left) Photograph of lung explanted from fetus immediately after exposure to $435 \mathrm{R}$ at 15 days of gestation and cultured for four hours. Note the absence of bronchial tree branching. (See Figure 37: 50x).

Figure 43. (Lower right) Photograph of the same lung explant shown in Figure 42 after one day in culture. Note the loss of blood vessels and lack of growth (50x). 
107
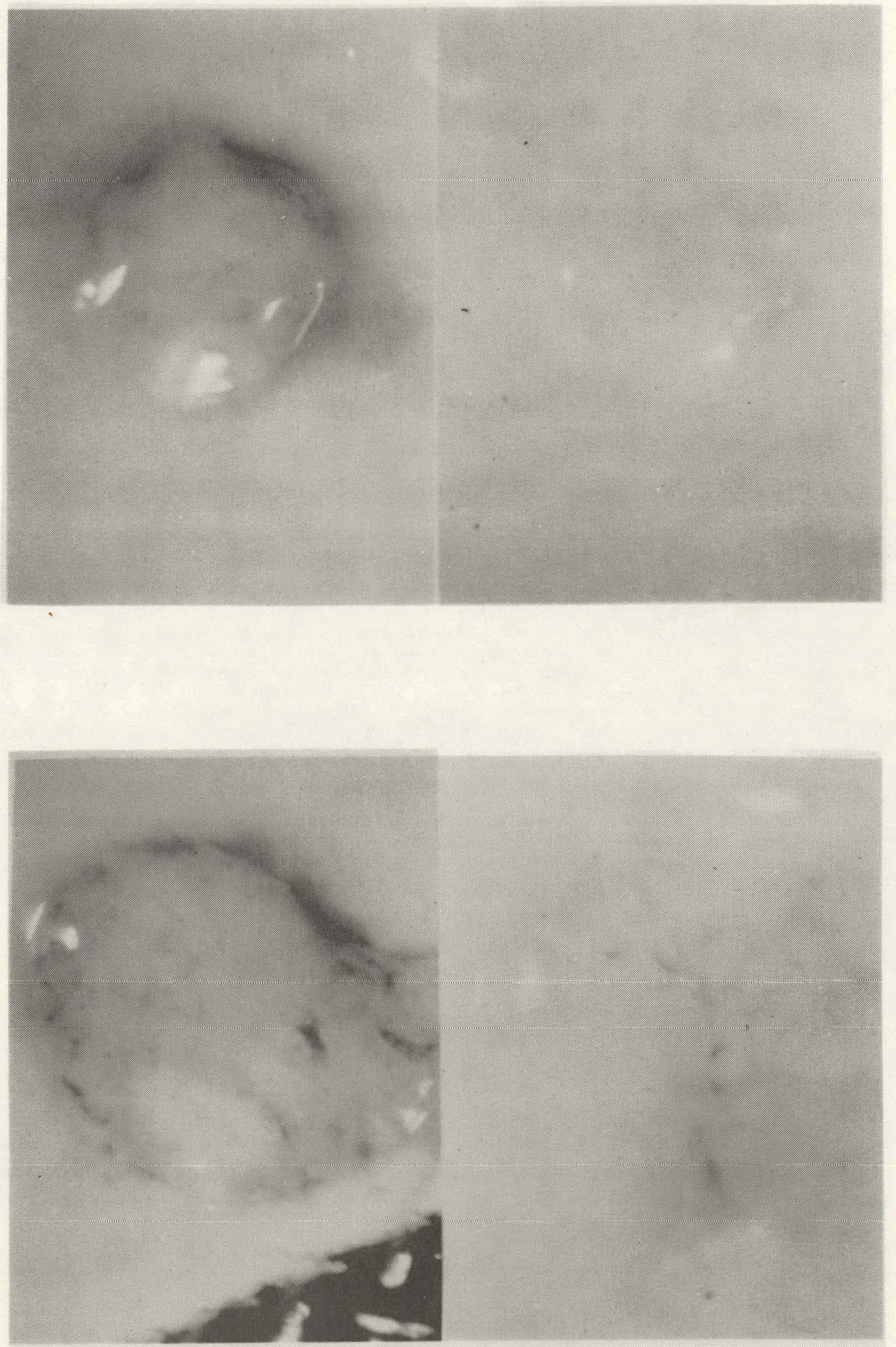
Figure 44. (Top) Photograph of fetal lung which was sham irradiated at 13 days of gestation and explanted at 14 days of gestation. This photograph was taken immediately after explantation $(50 \mathrm{x})$.

Figure 45. (Bottom) Photograph of fetal lung which was irradiated with $435 \mathrm{R}$ at 13 days of gestation and explanted at 14 days of gestation. This photograph was taken immediately after explantation. Note the vascular congestion and extrusion of blood cells $(50 \mathrm{x})$. 

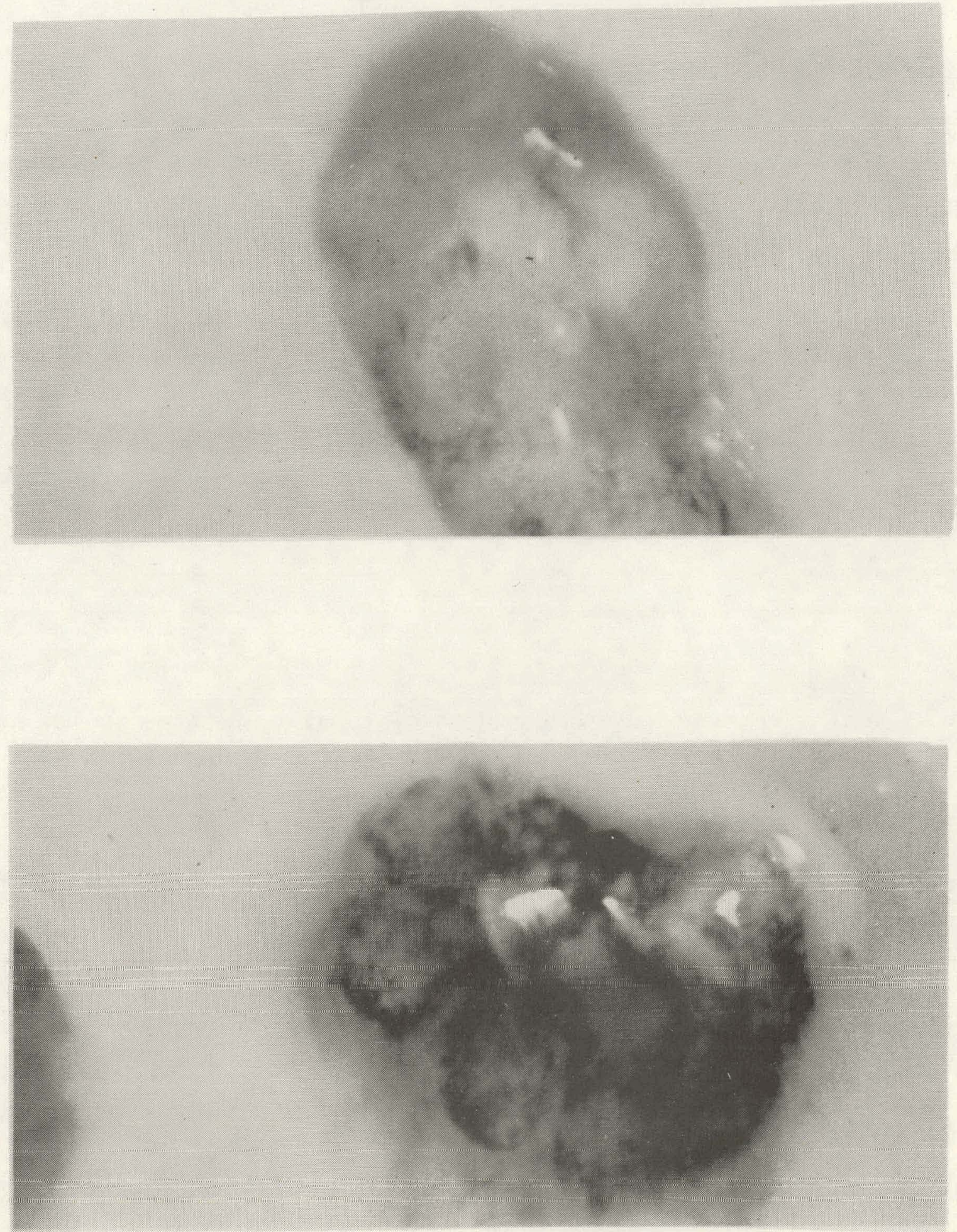
congestion and extrusion of blood cells a re obvious in the irradiated, 14-day fetal lung.

\section{$\underline{\text { Histological Studies }}$}

The following criteria were used to define cell types and structure in the study of the histology of the lung explants. Lobules of pseudostratified to columnar epithelium, usually without an opening, and of ten encircled by a basement membrane were defined as terminal bronchioles (Figure 80). In more mature lungs the epithelium in the lobules was cuboidal and these were considered to be a more proximal part of the bronchial tree, the alveolax ducts. Mesenchymal cells have less organization, larger nuclei and less intense staining properties than the differentiated epithelial cells lining the bronchial cavity (Figure 58). The fibroblasts were considered here to have a more "stellate" appearance compared to the mesenchymal cells. The fibroblasts appeared to be streaming around the bronchial tree and were associated with the connective tissue (Figure 81 ). The cytoplasmic vacuoles occurring in the epithelium were probably triglycerides though special histological techniques would be required to prove this. Since collagen, elastin and reticulum a re all present in the lung and stain green with Van de Grift's staining procedure, the presence of fibrous material was evaluated collectively as connective tissue. Blood vessels were larger structures outlined by connective tissue whereas the 
capillaries were smaller and filled with red blood cells.

The short comings of the first experiment were discussed previously. It should be noted that the central zone of necrosis did not occur as frequently with the fetal lung as with liver culture. The number of lung cultures lost in paraffin was greater; consequently the results are incomplete. The second experiment with improved techniques and a smaller, more concentrated range increased the reliability of the observations. The arrangement of the tables in this section follows the same sequence as the tables in the liver studies, i. e. ; in vivo development; in vitro development; the effect of $x$ irradiation on the in vitro development and the effect of $x$-irradiation on the in utero development.

The in vivo development of the fetal rat lung, as observed in the first and second experiments, is shown in Tables 6 and 7 , respectively. All explants were incubated for four hours to provide sufficient time for "flattening." In the smaller lungs at 13 and 14 days gestation, the entire organ was cultured. However, with increased size and differentiation only the tip of the lung was removed; consequently. the sections reveal the development of the most distal part of the organ.

The relative number of lumina and terminal bronchioles increased as the bronchial tree branched with development (Figure 16-53). On day 20 the alveolar ducte were numerous and thesc were 
Table 6. Characteristics of Fetal Rat Lung Developing In Vivo as Observed at Four Hours after Explantation - Expt. I. a

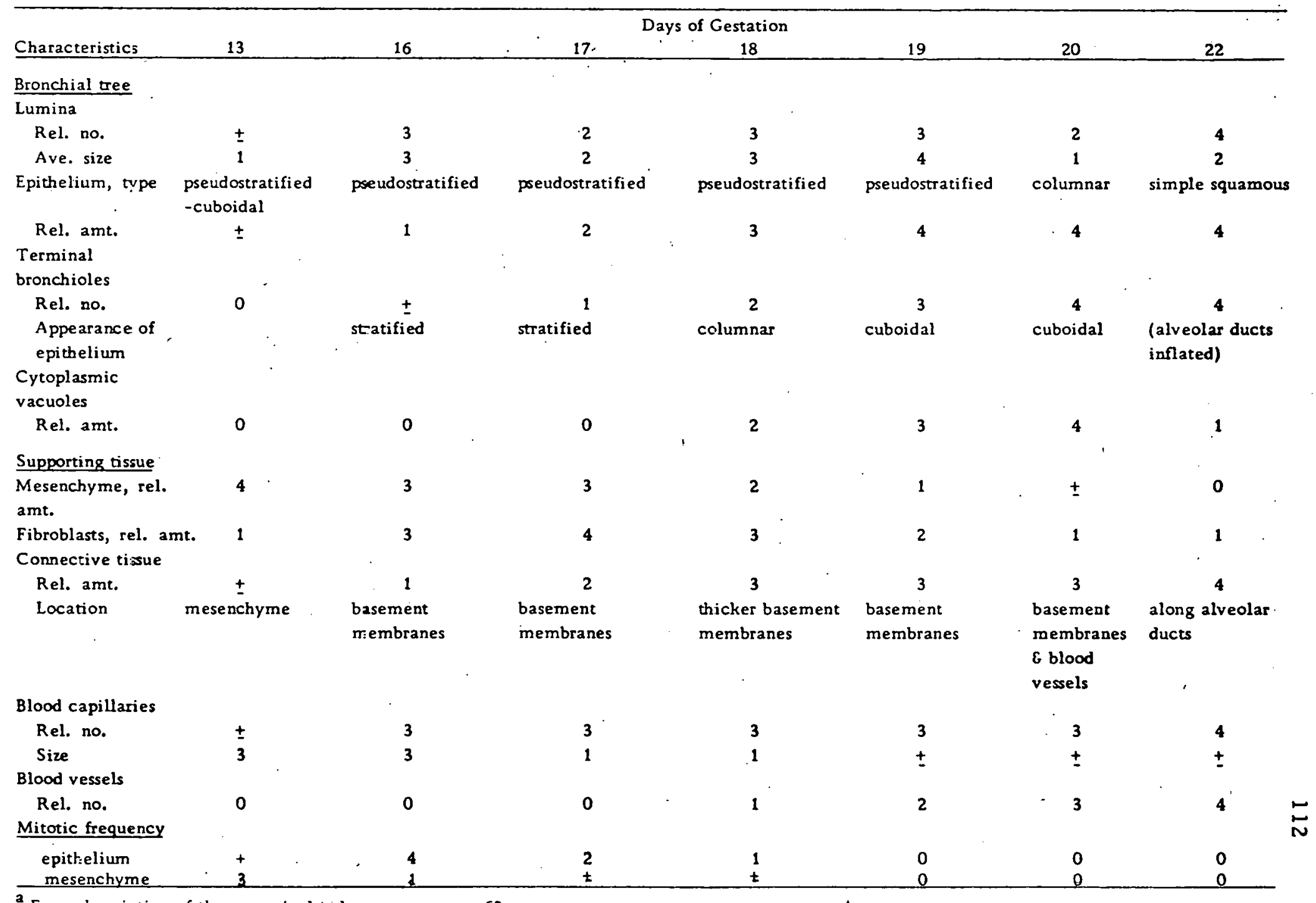

${ }^{3}$ For a description of the numerical values, see text p. 63. 
Table 7. Characteristics of Fetal Rat Lung Developing In Vive as Observed at Four Hours a fter Explentation - Expt. II.

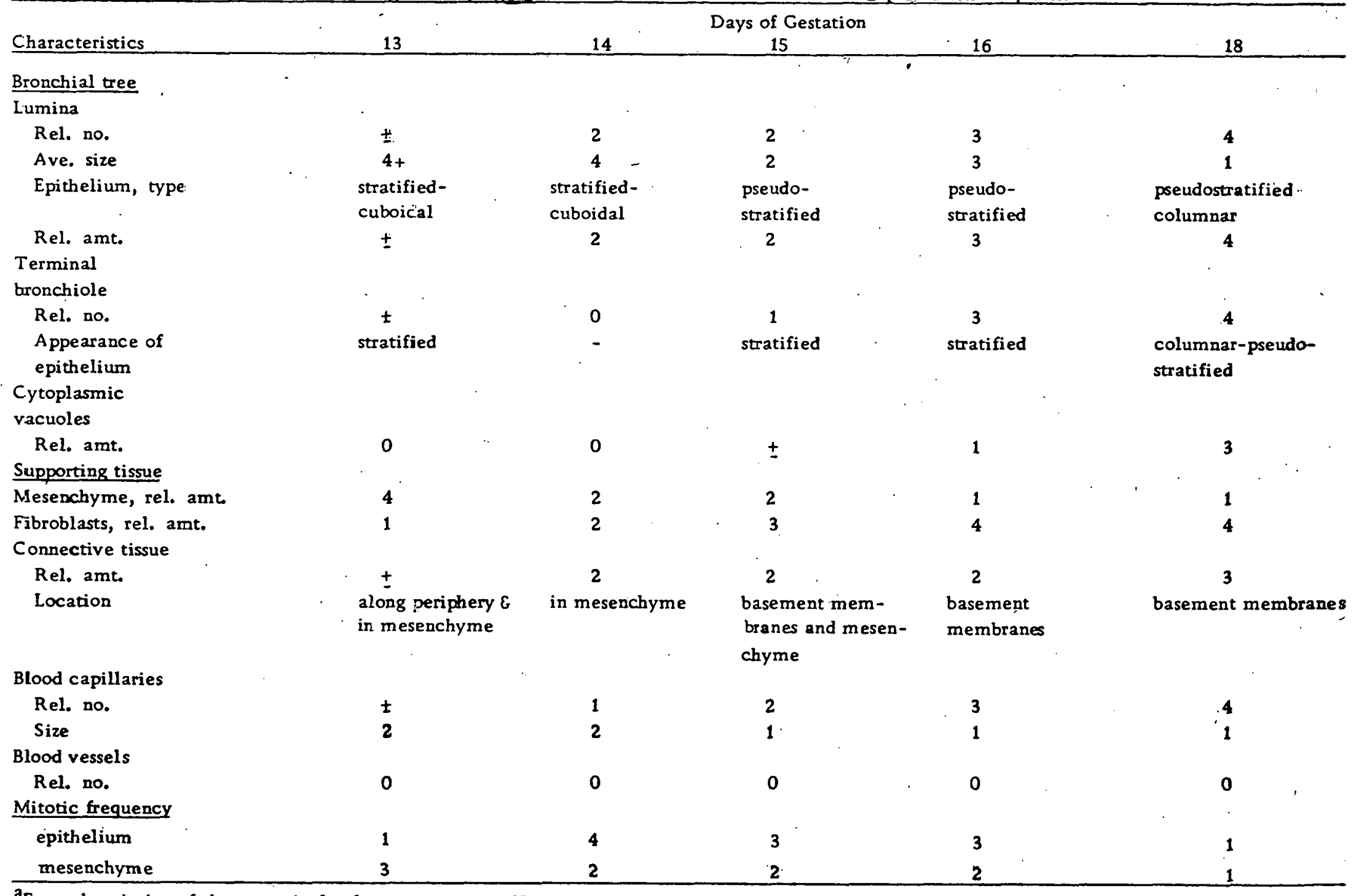


Figure 46. (Upper left) Photomicrograph of lung at 13 days of gestation after four hours in culture. Lung bud protrudes into single lumen; predominantly mesenchymal. (Translucent folds are Millipore filter $(90 \mathrm{x})$.

Figure 47. (Upper right) Photomicrograph of lung at 14 days of gestation after four hours in culture. Branching of bronchial tree and increased number of lumina a re evident $(90 x)$.

Figure 48. (Lower left) Photomicrograph of lung at 15 days of gestation after four hours in culture. Fibroblasts (f) a re "streaming" a round the developing bronchial tree $(90 \mathrm{x})$.

Figure 49. (Lower right) Photomicrograph of lung at 16 days of gestation after four hours in culture. There is progressive increase in the branching of bronchial tree and number of lumina $(90 x)$. 

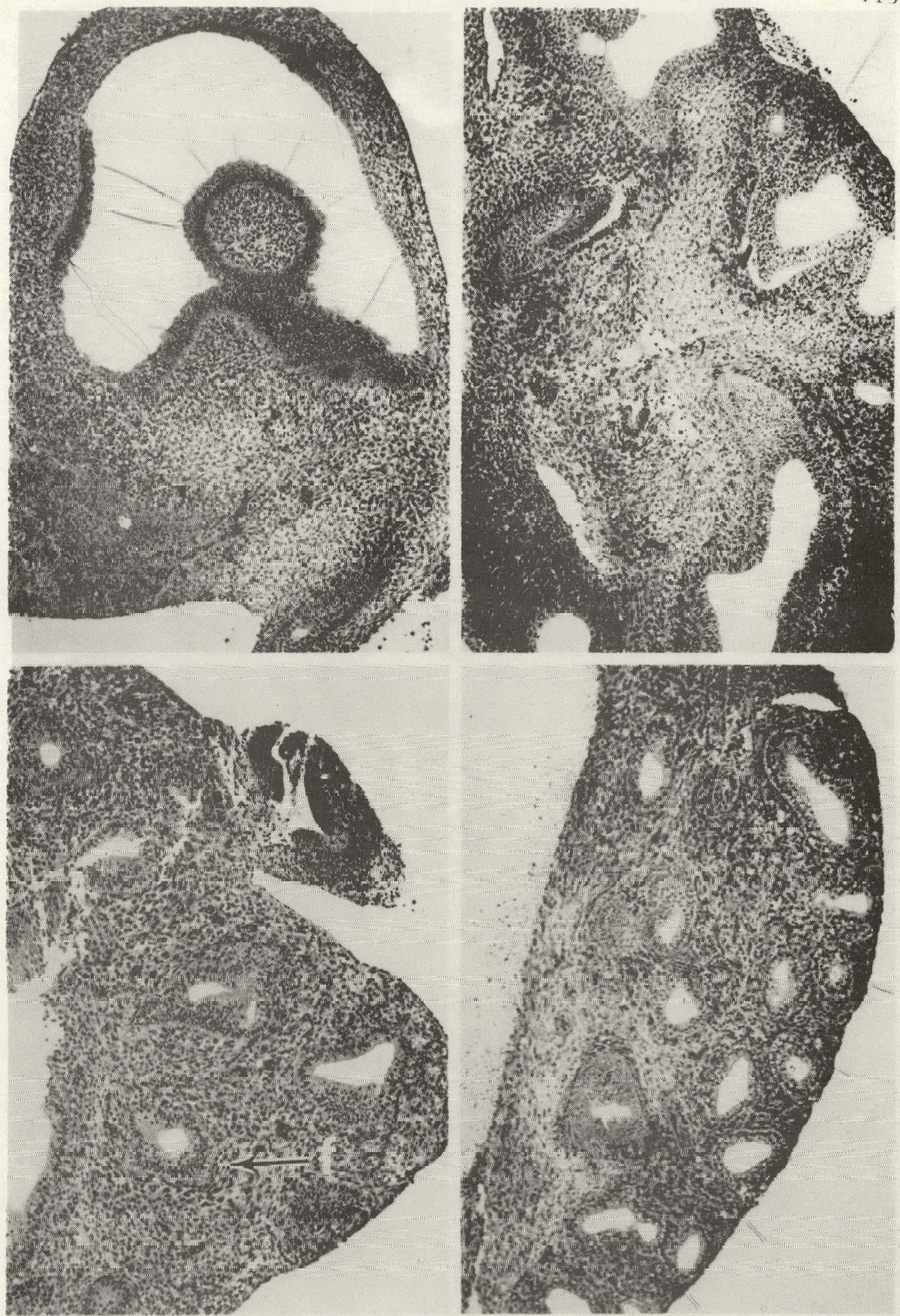
Figure 50. (Upper left) Photomicrograph of lung at 18 days of gestation after four hours in culture. Note presence of many terminal bronchioles and cytoplasmic vacuoles in epithelium (90x).

Figure 51. (Upper right) Photomicrograph of lung at 19 days of gestation after four hours in culture. A cross section of an air passage (center) and the trachea (lower right) $c a n$ be seen. in addition to the many terminal bronchioles (Paraffin; 90x).

Figure 52. (Lower right) Photomic rograph of lung at 20 days of gestation after four hours in culture. There is a marked increase in cytoplasmic vacuoles in epithelia lining the terminal bronchioles and alveolar ducts (Paraffin; 90x).

Figure 53. (Lower left) Photomicrograph of fetal lung at 22 days of development after four hours in culture. The alveolar ducts which are lined with simple squamous epithelium are partially inflated. The large lumen (b) is a bronchus $(90 x)$. 

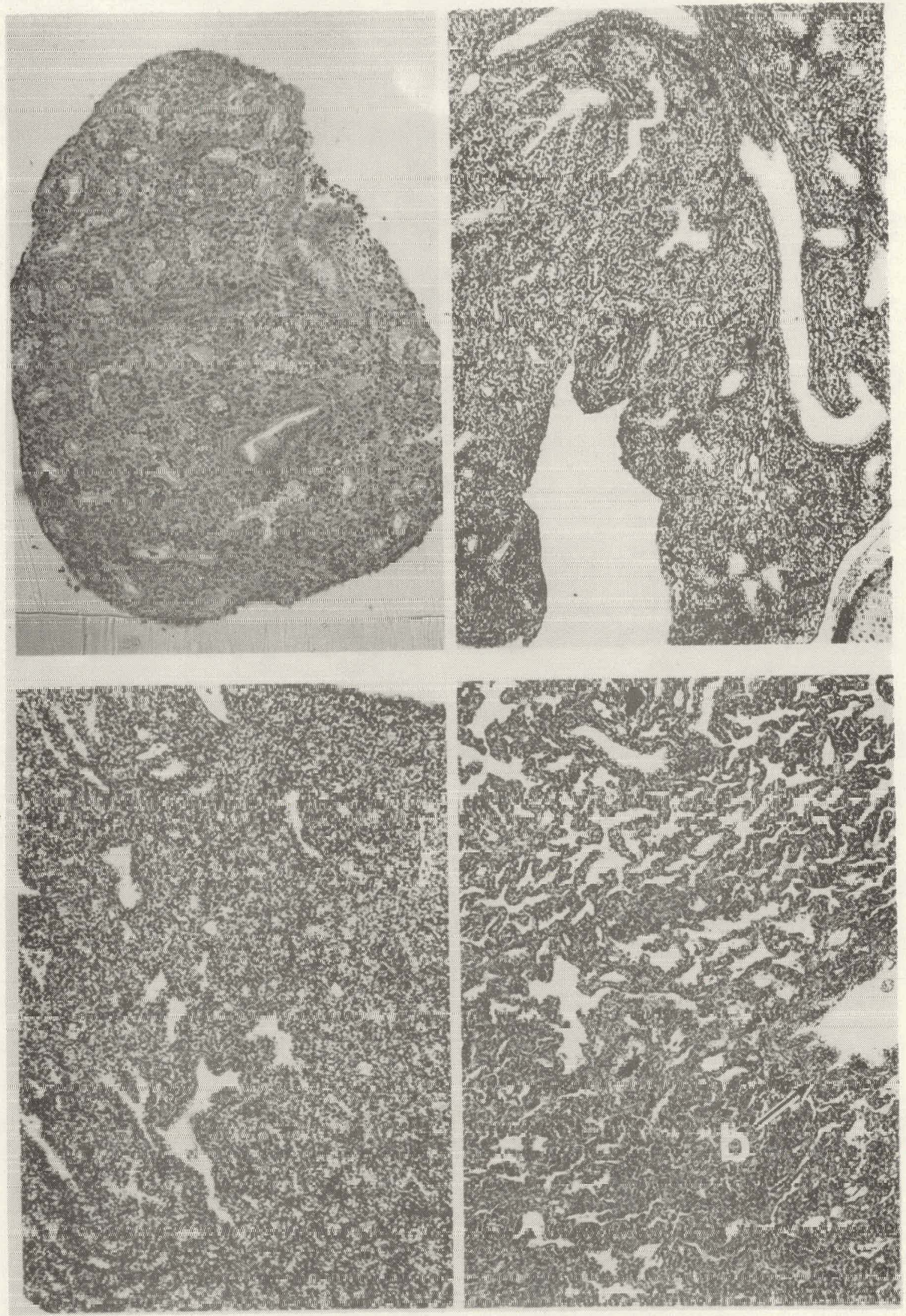
inflated after birth on the twenty-second day (Figure 52, 53). The cytoplasmic vacuoles of the epithelium increased through the twentieth day of gestation. There was a continued increase in the relative amount of connective tissue, and blood vessels were first seen on the eighteenth or nineteenth day of gestation. The blood capillaries became more numerous, and smaller, with lung morphogenesis. The frequency of mitosis peaked around the fourteenth to sixteenth day in gestation and. the reafter declined. Except for the 13-day lung, the mitotic frequency was always greater in the epithelium than in. mesenchyme. With maturation the relative amount of mesenchyme decreased as it differentiated into epithelium. The morphology of the epithelium lining the lumina changed from pseudostratified in the bronchi to simple squamous in the alveolar ducts.

Table 8 compares the in vivo and in vitro development of nonirradiated lungs from Experiment I. The entries are arranged in groups of three. In each group the first two entries pertain to cultures explanted on the same day; the first was terminated after four hours in culture while the second was incubated for one or three days as indicated (series B). The control organs (the third entry) were allowed to develop in utero and were cultured for four hours on the same day as the cultures of the second entry were terminated (series $C$ ). These control cultures represent the simultaneous in vivo 
development which serve as standards to compare fetal lung growing in vitro.

In vivo and in vitro development of 13- and 15-day of fetal lung explants, as observed in Experiment II, are compared in Table 9. These data in Table 9 are arranged in two groups of five and a re composite views obtained from examination of the control material $(O R)$ relative to the three series (A, B and $C$ ) of experiments. The first entry of each group was from explants cultured on the designated day of gestation and incubated for four hours (series $A$ and $B$ ). The second and fourth entries of each group were explanted the same day as the first entry but allowed to develop in vitro for one and three days respectively (series $A$ and $B$ ). The third and fifth entries are in vivo controls (series C) which were cultured for four hours on the same day that cultures of the second and fourth entries were terminated.

When cultured at 13- or 15-days of gestation, the continued in vitro differentiation of the fetal lung resulted in progressively increasing numbers of terminal bronchioles and "budding" of the bronchial tree (Figures 58, 6la, b, 64a, b, c, 69, 72a, b, 75a, b). By contrast the 17-and 19-day fetal lungs did not tolerate in vitro incubation as readily. Notwithstanding the excellent growth and differentiation observed in 13 - and 15 -day fetal lungs, in vitro development of these lungs showed a number of departures from the control 
Table 8. Characteristics of In Vitro Development of Fetal Rat Lung Explants - Expt. I. ${ }^{\text {a }}$

\begin{tabular}{|c|c|c|c|c|c|c|c|c|c|c|}
\hline \multirow{2}{*}{ Series } & \multirow[b]{2}{*}{$\begin{array}{l}\text { Day of } \\
\text { Culture }\end{array}$} & \multirow[b]{2}{*}{$\begin{array}{c}\text { Day of } \\
\text { Termination }\end{array}$} & \multicolumn{3}{|c|}{ Epithelium of Lumina } & \multicolumn{3}{|c|}{$\begin{array}{r}\text { Bronchial Tree - } \\
\text { Lumina } \\
\end{array}$} & \multicolumn{2}{|c|}{ Terminal Bronchioles } \\
\hline & & & Arat. & Type & $\begin{array}{l}\text { Staining } \\
\text { Reaction }\end{array}$ & $\begin{array}{l}\text { Rel. } \\
\text { No. }\end{array}$ & $\begin{array}{l}\text { Ave. } \\
\text { Size }\end{array}$ & Debris & $\begin{array}{l}\text { Rel. } \\
\text { No. }\end{array}$ & $\begin{array}{l}\text { Appearance } \\
\text { of Epithelium }\end{array}$ \\
\hline B & 13 & 13 & 0 & pseudostratified & sl. acidophilic & \pm & 2 & 0 & 0 & --- \\
\hline B & 13 & 16 & 1 & "fuzzy" clumped & sl. acidophilic & 1 & 4 & 4 & 0 & --- \\
\hline $\mathrm{C}$ & 16 & 16 & 1 & pseudostratified & sl. basophilic & 3 & 3 & \pm & 0 & -- \\
\hline B & 17 & 17 & 2 & pseudostratified & sl. acidophilic & 2 & 2 & 0 & 1 & stratified \\
\hline B & 17 & 18 & , 2 & cuboidal & sl. acidophilic & 3 & 3 & 1 & 1 & stratified \\
\hline C & 18 & 18 & 3 & pseudostratified & sl. acidophilic & 3 & 3 & \pm & 2 & columnar \\
\hline B & 19 & 19 & 4 & pseudostratified & sl. acidophilic & 3 & 4 & 0 & 3 & columnar \\
\hline B & 19 & 20 & 2 & cuboidal & basophilic & 3 & 3 & 1 & 3 & stratified \\
\hline $\mathrm{C}$ & 20 & 20 & 4 & pseudostratified & sl. acidophilic & 2 & 1 & \pm & 4 & cuboidal \\
\hline B & 19 & 19 & 4 & pseudostratified & sl. acidophilic & 3 & 4 & 0 & 3 & columnar \\
\hline B & $\cdot 19$ & 22 & 2 & cuboidal & basophilic & 1 & 1 & 4 & 2 & stratified \\
\hline C & 22 & 22 & \pm & simple squamous & sl. basophilic & 4 & 2 & 0 & 4 & $\begin{array}{l}\text { inflated } \\
\text { alveolar ducts }\end{array}$ \\
\hline
\end{tabular}


Table 8. Continued.

\begin{tabular}{|c|c|c|c|c|c|c|c|c|c|c|c|c|}
\hline \multirow{3}{*}{ 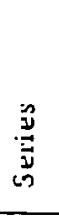 } & \multirow{3}{*}{ 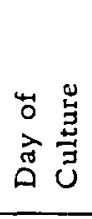 } & \multirow{3}{*}{ 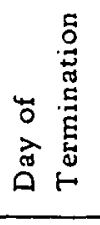 } & \multirow{3}{*}{$\begin{array}{l}\text { Mesenchyme } \\
\text { Rel. } \\
\text { Amt. } \\
\end{array}$} & \multirow{3}{*}{$\begin{array}{c}\text { Fibroblast } \\
\text { Rel. } \\
\text { Amt. }\end{array}$} & \multicolumn{3}{|l|}{ Supporting Tissue } & \multirow{2}{*}{ Blood Vessels } & \multicolumn{2}{|c|}{ Pycnosis } & \multicolumn{2}{|c|}{ Mitotic Frequency } \\
\hline & & & & & Connective Tissue & $\begin{array}{r}\text { Blo } \\
\text { Capil } \\
\end{array}$ & & & Epithelium & Mesenchyme & Epithelium & Mesenchym \\
\hline & & & & & $\begin{array}{l}\text { Rel. } \\
\text { Amt. }\end{array}$ & $\begin{array}{l}\text { Rel. } \\
\text { No. }\end{array}$ & Size & $\begin{array}{l}\text { Rel. } \\
\text { No. } \\
\end{array}$ & & & & \\
\hline $\mathrm{E}$ & 13 & 13 & 4 & 1 & \pm & \pm & 3 & 0 & 0 & \pm & \pm & 3 \\
\hline B & 13 & 16 & 2 & 4 & 3 & 1 & 3 & 0 & 0 & 2 & 2 & \pm \\
\hline$c$ &, 16 & 16 & 3 & 3 & 1 & 3 & 3 & 0 & \pm & 0 & 4 & 1 \\
\hline E. & 17 & 17 & 3 & 4 & 2 & 3 & 1 & \pm & $\cdot$ & 0 & 2 & \pm \\
\hline $\mathrm{B}$ & 17 & 18 & 3 & 4 & 2 & 1 & 2 & \pm & 0 & 1 & 3 & 1 \\
\hline c & 18 & 18 & 2 & 3 & 3 & 3 & 1 & 1 & 0 & 1 & 1 & 0 \\
\hline B & 19 & 19 & 1 & 2 & 3 & 3 & \pm & 2 & 4 & \pm & 0 & 0 \\
\hline B & 19 & 20 & 0 & 0 & 4 & 1 & \pm & 3 & 0 & 0 & 0 & 0 \\
\hline c & 20 & 20 & 1 & 1 & 3. & 3 & \pm & 3 & 0 & 0 & 0 & 0 \\
\hline B & 1.9 & 19 & 1 & 2 & 3 & 3 & \pm & 2 & 0 & \pm & 0 & 0 \\
\hline B & 19 & 22 & 0 & 0 & $4+$ & 2 & 2 & \pm & 2 & 4 & 0 & 0 \\
\hline$c$ & 22 & 22 & 0 & 1 & 4 & 4 & \pm & 4 & 0. & 0 & 0 & 0 \\
\hline
\end{tabular}

${ }^{a}$ For a description of the numerical values, see text p. 63. 
Table 9. Characteristics of In Vitro Development of Fetal Rat Lung Explants - Expt. II. a

\begin{tabular}{|c|c|c|c|c|c|c|c|c|c|c|}
\hline \multirow[b]{2}{*}{ Series } & \multirow[b]{2}{*}{$\begin{array}{l}\text { Day of } \\
\text { Culture }\end{array}$} & \multirow[b]{2}{*}{$\begin{array}{c}\text { Day of } \\
\text { Termination }\end{array}$} & \multicolumn{3}{|c|}{ Epithelium of Lumina } & hial T & Lumina & & \multicolumn{2}{|c|}{ Terminal Bronchioles } \\
\hline & & & Amt. & Type & $\begin{array}{l}\text { Staining } \\
\text { Reaction }\end{array}$ & $\begin{array}{l}\text { Rel. } \\
\text { No. }\end{array}$ & $\begin{array}{l}\text { Ave. } \\
\text { Size }\end{array}$ & Debris & $\begin{array}{l}\text { Rel. } \\
\text { No. }\end{array}$ & $\begin{array}{l}\text { Appearance } \\
\text { of Epithelium }\end{array}$ \\
\hline$A G B$ & 13 & 13 & \pm & $\begin{array}{l}\text { stratified- } \\
\text { cuboidal }\end{array}$ & sl. acidophilic & \pm & $4+$ & 0 & \pm & stratified \\
\hline$A \& B$ & 13 & 14 & 1 & $\begin{array}{l}\text { stratified- } \\
\text { cuboidal }\end{array}$ & neutral & 1 & 4 & 0 & 1 & stratified \\
\hline C & 14 & . 14 & 2 & $\begin{array}{l}\text { stratified- } \\
\text { cuboidal }\end{array}$ & sl. acidophilic & 2 & 4 & 0 & 0 & -- \\
\hline AEB & 13 & 16 & 2 & $\begin{array}{l}\text { cuboidal- } \\
\text { stratified }\end{array}$ & $\begin{array}{l}\text { sl. acidophilic; } \\
\text { poorly stained }\end{array}$ & 1 & 4 & \pm & 2 & stratified \\
\hline C & 16 & 16 & 3 & pseudostratified:' & sl. basophilic & 3 & 3 & 0 & 3 & stratified \\
\hline$A \sqsubseteq B$ & 15 & 15 & 2 & pseudcostratified & sl. basophilic & 2 & 2 & \pm & 1 & stratified \\
\hline AEB & 15 & 16 & 2 & pseudostratified & $\begin{array}{l}\text { sl. basophilic; } \\
\text { poorly stained }\end{array}$ & 3 & 2 & 1 & 1 & stratified \\
\hline C & 16 & 16 & 3 & pseudostretified & sl. basophilic & 3 & 3 & 0 & 3 & stratified \\
\hline AGB & 15 & 18 & 2 & $\begin{array}{l}\text { pseudostratified- } \\
\text { stratified }\end{array}$ & $\begin{array}{l}\text { basophilic; } \\
\text { poorly stained }\end{array}$ & 3 & 2 & 2 & 2 & cuboidal \\
\hline C & 18 & 18 & 4 & $\begin{array}{l}\text { pseudostratified-. } \\
\text { columnar }\end{array}$ & $\begin{array}{l}\text { sl. basophilic } \\
\text { poorly stained }\end{array}$ & 4 & 1 & 0 & 4 & $\begin{array}{l}\text { columnar- } \\
\text { pseudostre }\end{array}$ \\
\hline
\end{tabular}


Table 9. Continued.

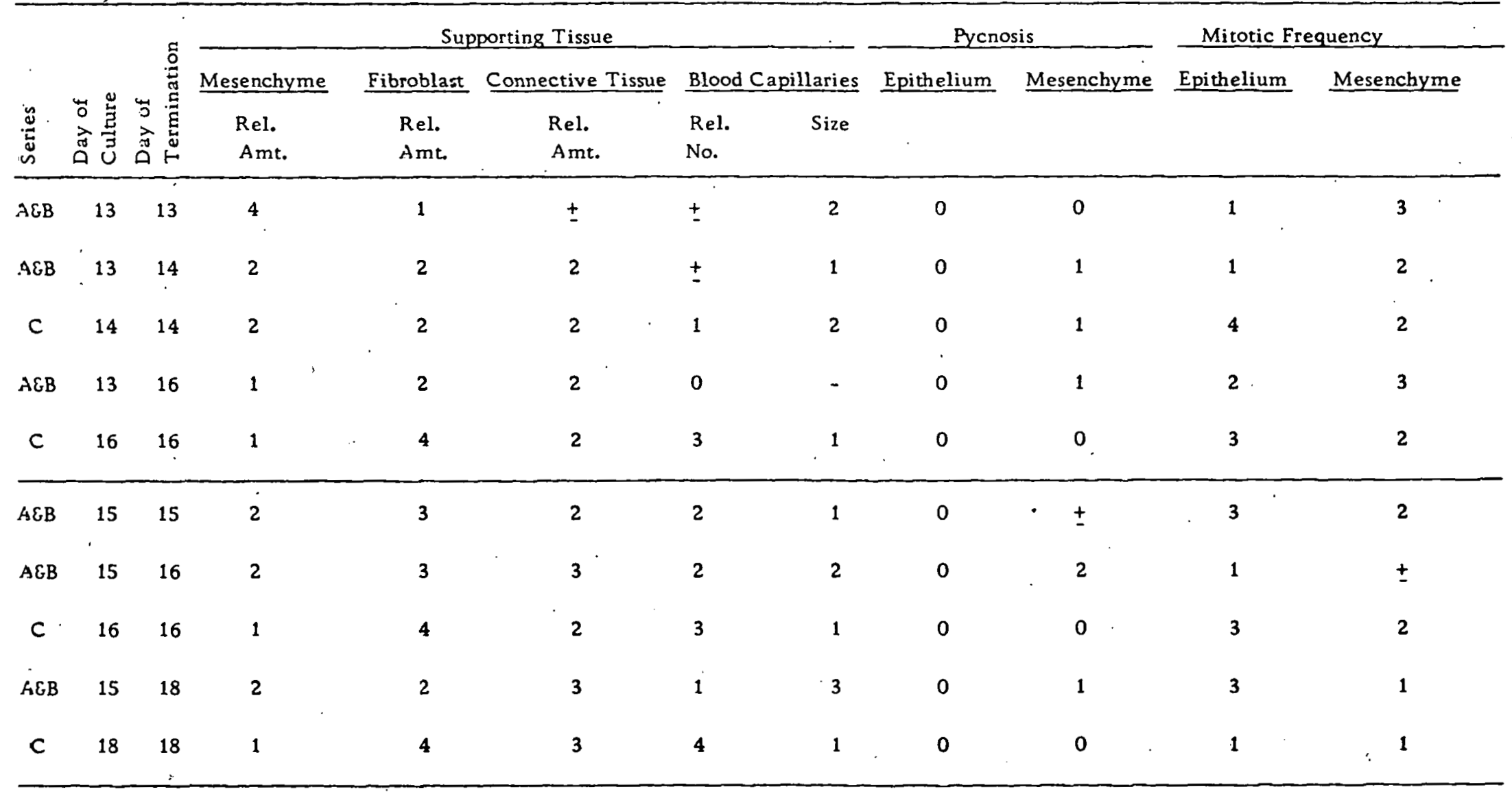

${ }^{a}$ For a description of the numerical values, see text p. 63. 
explants. There was attenuation of the epithelium surrounding the lumina which were filled with debris. Degeneration of the vascular system occurred and there was vascular engorgement. Pycnosis, which was concentrated in the mesenchyme, increased with incubation time. With few exceptions there was a relative increase in the amount of connective tissue which was often fibrous and basophilic in the case of 17 - and 19-day fetal lungs. In all cases, the in vitro development lagged behind in vivo development, but in 13- and 15-day fetal lungs there was a type of resurgence in the growth of the lung cultures after the first day, which was best exemplified by the increased mitotic frequency in the epithelium during the third day in culture (Compare Figures 72 and 75 ).

The development of fetal lung explants from Experiment I following in vivo $x$-i rradiation with $435 \mathrm{R}$ is characterized in Table 10 (Figures 54-57). Of the nine comparisons made in Table 10, only pairs number five and six were incubated for more than four hours. In these two pairs of entries, the controls which were incubated one and three days respectively, showed deterioration. With the exception of increased connective tissue, the difference between the ir radiated lung and its control became less marked with increasing time in culture.

In explants which were incubated for four hours a few general differences between the irradiated organ and its control were noted. 
Although most of the criteria were not consistently affected, ir radiation appeared to increase the amount of connective tissue and decrease the frequency of mitosis in the cultures of the younger lungs. Vascular engorgement tended to be more marked in organs exposed to $x$-ray. Although some pycnosis was observed in those cultures incubated for one or three days, there was little pycnosis seen in any lung explant cultured for four hours regardless of previous treatment. Lungs cultured for four hours at 17 days of gestation after in utero exposure to $x$-ray, appeared to have increased numbers of cytoplasmic vacuoles and a marked distention of the proximal bronchial tree (Figures 54 and 55). When compared to the control, sections of lung irradiated at 19 days of gestation and cultured three days later for four hours, revealed a dis ruption of the proximal part of the bronchial tree, and a marked condensation of the distal part of the organ (Figures 56 and 57 ).

Table 11 characterizes the effect of $435 \cdot R$ of $x$-ray on the development of 13-day fetal lung from Experiment II and Table 12 presents the changes in 15-day fetal lung. In each table the first nine entries, arranged in three groups of three, tabulate the effects of $\mathbf{x}-$ irradiation on the in vitro development. In the first group of three entries, the first entry represents cultures irradiated in vitro (series $A$ ), the second entry pertains to organs from rats irradiated in vivo and then explanted (series B), while the cultures of the third 
Table 10. Characteristics of Development of Fetal Rat Lung after In Vivo Exposure to $435 \mathrm{R}$ of X-Ray - Expt. I. ${ }^{2}$

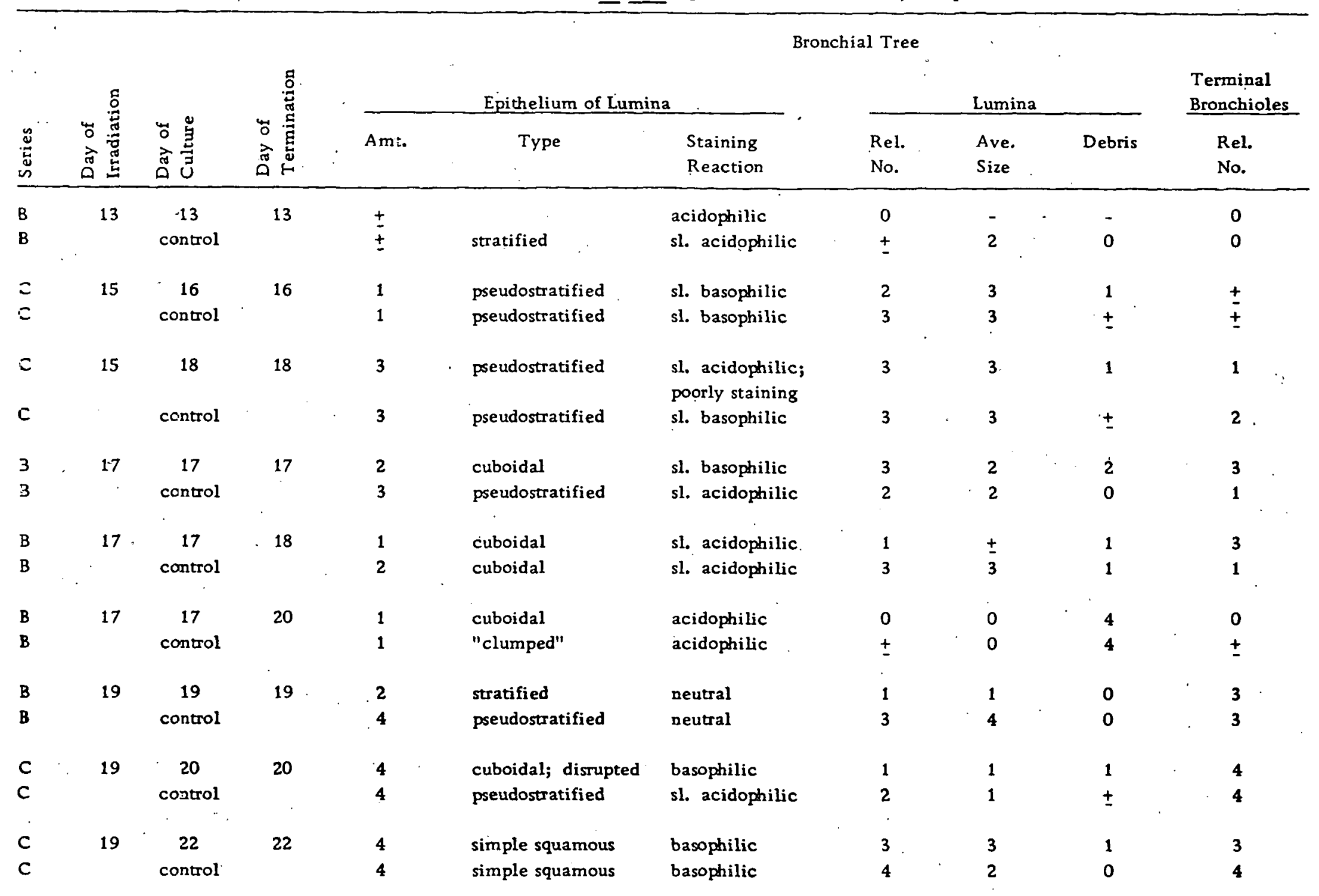


Table 10. Continued.

\begin{tabular}{|c|c|c|c|c|c|c|c|c|c|c|c|c|c|}
\hline \multirow[b]{2}{*}{$\stackrel{\mathscr{E}}{\mathscr{E}}$} & \multirow{2}{*}{\multicolumn{2}{|c|}{ 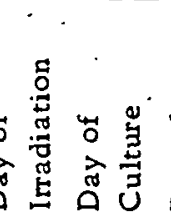 }} & \multirow[b]{2}{*}{ 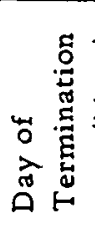 } & \multicolumn{6}{|c|}{ Supporting Tissue } & \multicolumn{2}{|c|}{ Pycnosis } & \multicolumn{2}{|c|}{ Mitotic Frequency } \\
\hline & & & & $\begin{array}{l}\text { Mesenchyme } \\
\text { Rel. } \\
\text { Amt. }\end{array}$ & $\begin{array}{c}\text { Fibroblast } \\
\text { Rel. } \\
\text { Amt }\end{array}$ & 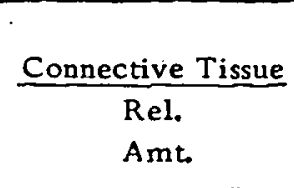 & $\begin{array}{l}\text { Blo } \\
\text { Capil } \\
\text { Rel. } \\
\text { Amt. }\end{array}$ & $\frac{\text { llaries }}{\text { Size }}$ & $\begin{array}{l}\text { Blood Vessels } \\
\text { Rel. } \\
\text { No. }\end{array}$ & Epithelium & Mesenchyme & Epithelium & Mesenchym \\
\hline 3 & 13 & 13 & 13 & 4 & 2 & 1 & \pm & 1 & 0 & 0 & 1 & 0 & 0 \\
\hline B & & control & & 4 & 1 & \pm & \pm & 3 & 0 & 0 & \pm & \pm & 3 \\
\hline$=$ & 15 & 16 & $1 \overline{0}$ & 3 & 3 & 3 & 2 & 4 & 0 & 0 & + & 3 & 0 \\
\hline$\Xi$ & & control & & 3 & 3 & 1 & 3 & 3 & 0 & 0 & \pm & 4 & 1 \\
\hline$\Xi$ & 15 & 18 & 18 & 2 & 4 & 3 & 1 & 1 & 1 & 0 & 0 & 1 & \pm \\
\hline$c$ & & control & & 2 & 3 & 3 & 3 & 2 & 1 & 0 & 1 & 1 & \pm \\
\hline 3 & 17 & 17 & 17 & 3 & 4 & 3 & 2 & 2 & \pm & 0 & 2 & 0 & 0 \\
\hline 3 & & control & & 3 & 4 & 2 & 3 & 1 & \pm & 0 & 1 & 2 & \pm \\
\hline 3 & 17 & 17 & 18 & 2 & 2 & 4 & + & 3 & 3 & \pm & 1 & 0 & 0 \\
\hline B & & control & & 3 & 4 & 2 & $\overline{1}$ & 2 & \pm & 0 & 1 & 3 & 1 \\
\hline B & 17 & 17 & 20 & 2 & 1 & 4 & 1 & $\begin{array}{c}4 \\
\text { (distup }\end{array}$ & ed) & 1 & 4 & 0 & 0 \\
\hline B & & control & & 3 & 2 & 3 & 1 & \pm & 0 & 1 & 4 & 0 & 0 \\
\hline B & 19 & 19 & 19 & 1 & 2 & 3 & 2 & $i$ & 1 & 0 & 0 & 0 & 0 \\
\hline B & & control & & 1 & 2 & 3 & 3 & \pm & 2 & 0 & 0 & 0 & 0 \\
\hline$c$ & 19 & 20 & 20 & 0 & 1 & 4 & 2 & \pm & 3 & 0 & \pm & 0 & 0 \\
\hline C & & control & & 0 & 1 & 3 & 3 & \pm & 3 & 0 & $\overrightarrow{0}$ & 0 & 0 \\
\hline$c$ & 19 & 22 & 22 & 0 & 1 & $4+$ & 3 & 1 & 3 & 0 & 0 & 0 & \pm \\
\hline c & & control & & 0 & 1 & 4 & 4 & \pm & 4 & 0 & 0 & 0 & 0 \\
\hline
\end{tabular}


Figure 54. (Upper left) Photomicrograph of a lung explanted from fetus immediately after being sham irradiated and cultured for four hours at 17 days of gestation. Fibroblasts migrating a round developing bronchial tree can be seen at the lower portion of the picture $(90 \mathrm{x})$.

Figure 55. (Upper right) Photomicrograph of a lung explanted from fetus immediately after exposure to $435 \mathrm{R}$ of $\mathrm{x}$-ray and culturedforfour hours at 17 days of gestation. There is a marked distention of proximal bronchial tree and increased size in the cytoplasmic vacuoles $(90 \mathrm{x})$.

Figure 56. (Lower left) Photomicrograph of lung sham irradiated at 19 days of gestation, explanted at 22 days of development (birth) and cultured for four hours. Inflation of the organ is uniform $(90 \mathrm{x})$.

Figure 57. (Lower right) Photomicrograph of lung irradiated with $4.35 \mathrm{R}$ at 19 days of gectation, cxplanted at 22 days of development and cultured for four hours. Note the distention of the proximal portion of the lung, but incomplete inflation of the distal part $(90 \mathrm{x})$. 

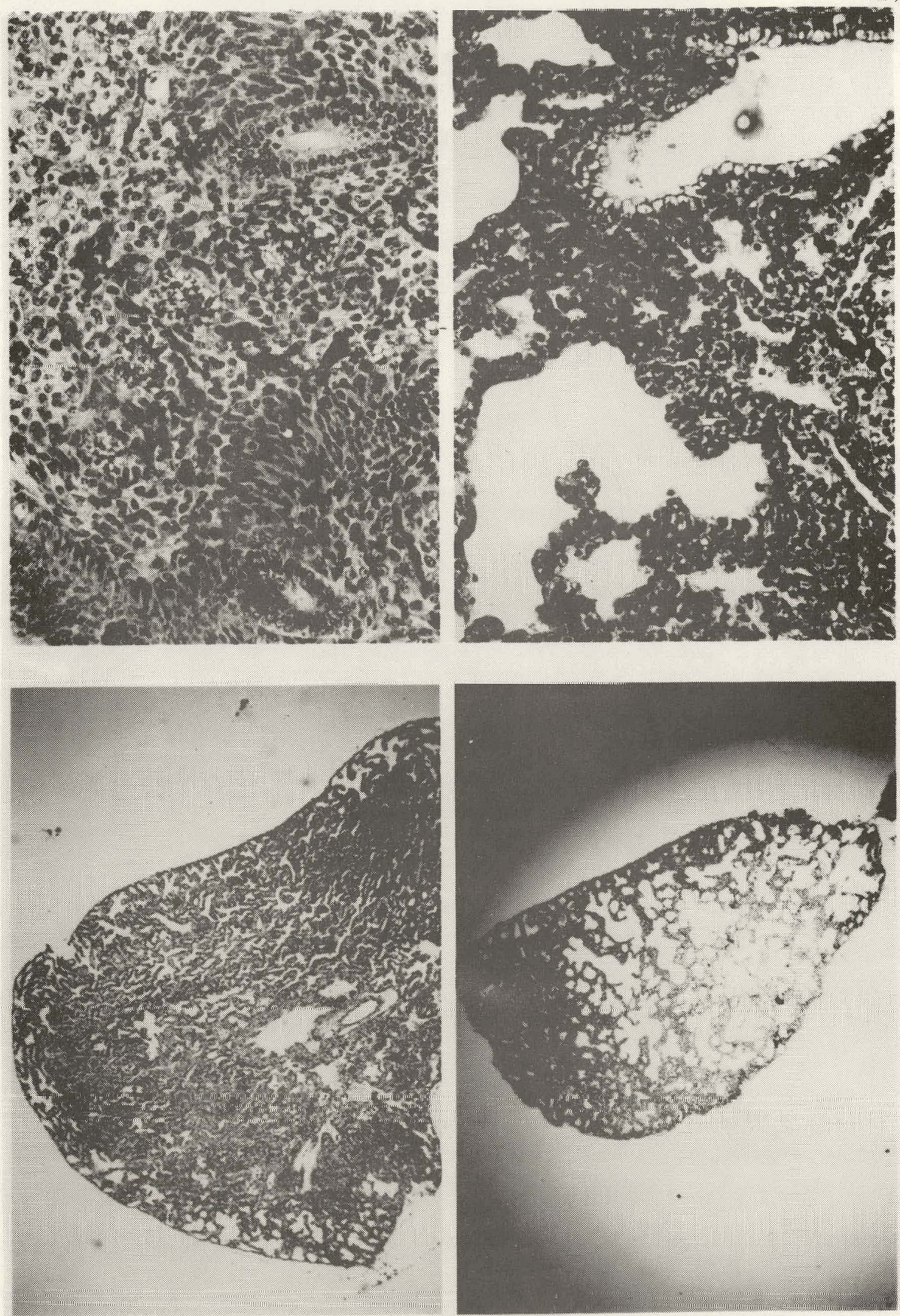
entry were sham irradiated (series $A$ and $B$ ). In all instances the explants were cultured for four hours. The second and third groups of three entries a re arranged in the same sequence as the first group except that the cultures were incubated for one and three days respectively.

The last four entries, as two groups of two, present the effects of radiation on in vivo development. In the first group of two entries, the fetal livers were exposed to 435 or $\mathrm{O} R$ and left in utero for one day before explantation and the four-hour incubation. In the last group of two entries, the control and irradiated fetal lungs remained in utero for three days before they were cultured again for four hours. Exposure to $435 \mathrm{R}$ of $\mathrm{x}$-ray at either 13 or 15 days of gestation appeared to inter rupt differentiation as there were fewer te rminal bronchioles. Radiation dis rupted the capillaries and altered the histology of the epithelium surrounding the lumina. Radiation increased the relative amount of connective tissue. When the insult of $x$-ray exposure was compounded with prolonged in vitro incubation, the results became more drastic. The 13-and 15-day lung cultures irradiated in vivo showed better survival at four hours and three days than the culture exposed in vitro; while the reverse was true at one day (See' Figures 58-63;69-77).

In the lung explants previously irradiated in utero, there was an increase in fibroblastic growth between one and three days in 
culture. Regardless of the conditions of the exposure to $x$-ray, the organ explants had disintegrated after three days in culture (Figures $75 \mathrm{a}, 76,77)$. This is in contrast to the recovery seen between one and three days post-irradiation in fetal lung developing in utero.

Thirteen-day fetal lungs cultured one day subsequent to exposure to $x$-ray, had enlarged, denuded lumina containing fibrous debris. These 14-day fetal lungs were acidophilic, showed vascular engorgement and were not as well differentiated as the controls (Figures $65,66 a, b)$. The 13-day fetal lungs explanted three days after irradiation showed a recovery as evidenced by fibroblastic "steaming" and a restoration of mitosis (Figures 67, 68a, b).

Lungs exposed to $x$-ray on day 15 of gestation and cultured one day later were acidophilic and contained distended terminal bronchioles (Figures $78,79 a, b)$. Lungs which were cultured three days after irradiation on day 15 also showed some recovery, this however, was not as marked as it was in the 13-day fetal lung (Figure $80,81 \mathrm{a}$, b). Differentiation lagged behind the control and vascular engorgement, degeneration of the epithelial lining, and debris in the lumina were indicative of the injurious effect of $x$-ray on the development of fetal lung. 
Table 11. Characteristios of Development of 13-Day Fetal Rat Lung after In Vivo or In Vitro Exposure to $435 \mathrm{R}$ of X-Ray - Expt. II. a

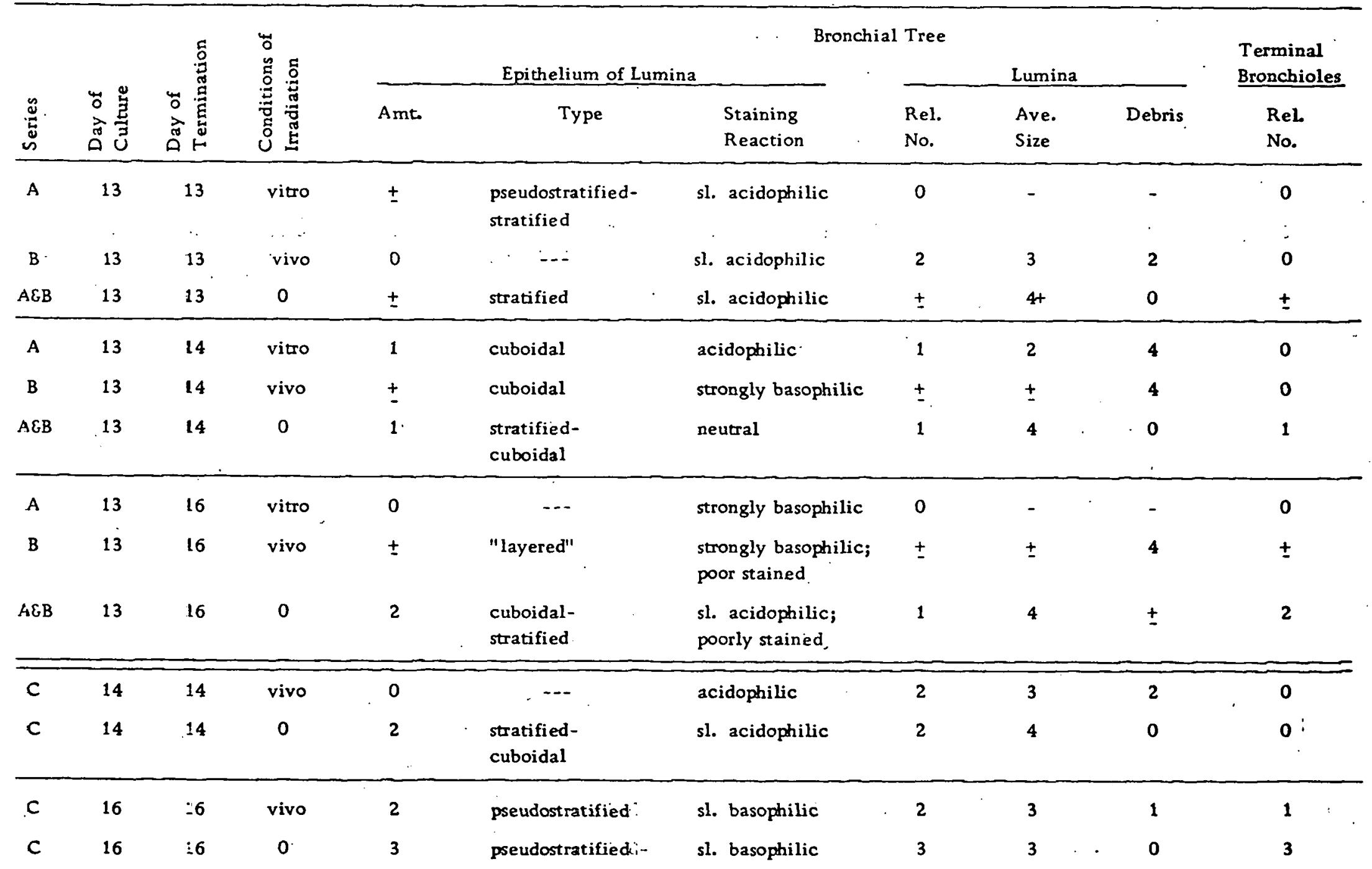


Table 11. Continued.

\begin{tabular}{|c|c|c|c|c|c|c|c|c|c|c|c|c|}
\hline \multirow[b]{3}{*}{ 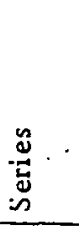 } & \multirow[b]{3}{*}{ 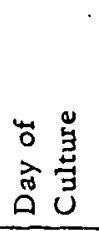 } & \multirow{3}{*}{ 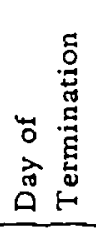 } & \multirow{3}{*}{ 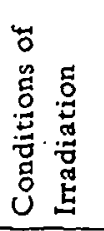 } & $\dot{2}$ & \multicolumn{2}{|c|}{ Supporting Tissue } & \multicolumn{2}{|c|}{ ¿ } & \multicolumn{2}{|c|}{ Pycnosis } & \multicolumn{2}{|c|}{ Mitotic Frequency } \\
\hline & & & & Mesenchyme & Fibroblast & Connective Tissue & Blood & 1laries & Epithelium & Mesenchyme & Epithelium & Mesenchyme \\
\hline & & & & $\begin{array}{l}\text { Rel. } \\
\text { Amt. }\end{array}$ & $\begin{array}{l}\text { Rel. } \\
\text { Amt. }\end{array}$ & $\begin{array}{l}\text { Rel. } \\
\text { Amt. }\end{array}$ & $\begin{array}{l}\text { Rel. } \\
\text { No. }\end{array}$ & Size & & & & \\
\hline A & 13 & 13 & vitro & 2 & 3 & 1 & 2 & 3 & 0 & 1 & 0 & 0 \\
\hline B & 13 & 13 & vivo & 2 & 2 & 2 & 0 & - & 0 & 3 & 0 & 0 \\
\hline$A E B$ & 13 & 13 & 0 & 4 & 1 & $\because \cdot$ & \pm & 2 & 0 & 0 & 1 & 3 \\
\hline A & 13 & 14 & vitro & 2 & 1 & 3 & 0 & - & 1 & 3 & 0 & 0 \\
\hline B & 13 & 14 & vivo & 3 & 2 & 4 & 0 & $\therefore$ & 1 & 3 & 0 & 0 \\
\hline A.GB & 13 & 14 & 0 & 2 & 2 & 2 & \pm & 1 & 0 & 1 & 1 & 2 \\
\hline$A$ & 13 & 16 & vitro & 4 & 2 & $4+$ & 0 & - & 0 & 4 & 0 & 0 \\
\hline B & 13 & 16 & vivo & 1 & 4 & 3 & 0 & - & 1 & 2 & 0 & \pm \\
\hline AEB & 13 & 16 & 0 & 1 & 2 & 2 & 0 & - & 0 & 1 & 2 & 3 \\
\hline$c$ & 14 & 14 & vivo & 3 & 3 & 4 & 2 & 3 & 0 & 2 & 0 & \pm \\
\hline C & 14 & 14 & 0 & 2 & 2 & 2 & 1 & 2 & 0 & 1 & 4 & 2 \\
\hline C & 16 & 16 & vivo & 2 & 3 & 2 & 2 & 1 & 0 & 0 & 3 & 2 \\
\hline$c$ & 16 & 16 & 0 & 1 & 4 & 2 & 3 & 1 & 0 & 0 & 3 & 2 \\
\hline
\end{tabular}

${ }^{a}$ For a description of the numerical values, see text p. 63. 
Figure 58. (Upper right) Photomicrog raph of fetal lung which was sham irradiated and cultured for four hours at 13 days of gestation. The basement membrane is not yet formed and mesenchyme $(m)$ is the predominant cell type $(225 \mathrm{x})$.

Figure 59a. (Upper left) Photomicrograph of lung explanted from fetus immediately after exposure to $435 \mathrm{R}$ at 13 days of gestation and cultured for four hours. There is degeneration and sloughing of epithelium lining the bronchial tree though the basement membrane is intact $(225 \mathrm{x})$.

Figure 59b. (Lower left) Same explant as Figure 59a. There is a disintegration of the lung structure and fibrous material occurs in the enlarged lumina. (Translucent folds a re the Millipore filter; $90 x)$.

Figure 60. (Lower right) Photomicrograph of fetal lung explanted at 13 days of gestation, immediately irradiated with 435 $R$ and incubated for four hours. There are small clumps of dark-staining $\mathrm{RBC}^{\prime} s$ and an inhibition of development $(90 x)$. 


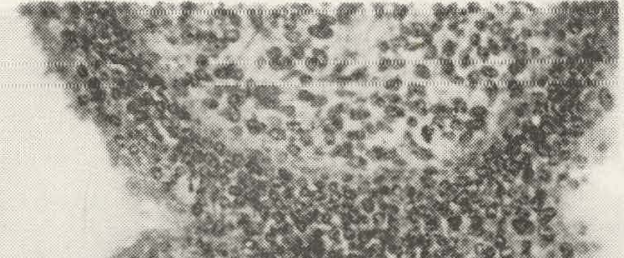

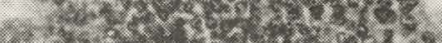

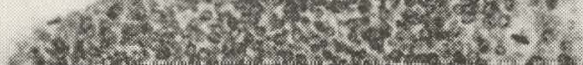

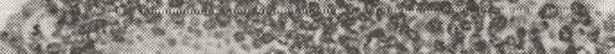

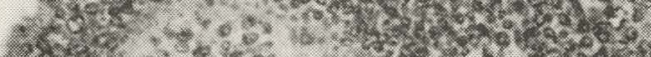

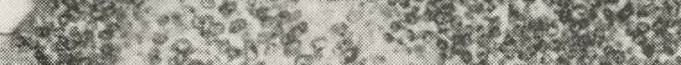

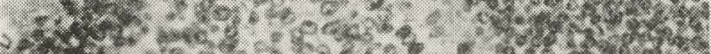

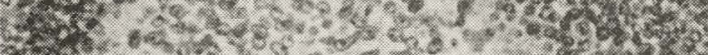

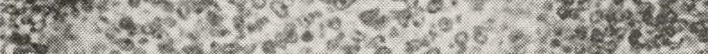

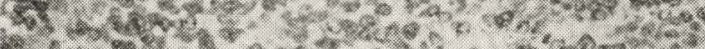
(1)

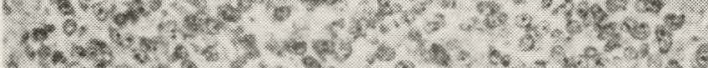

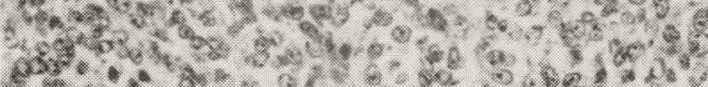

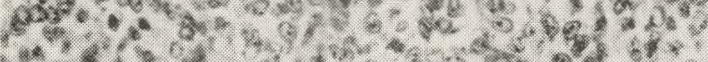

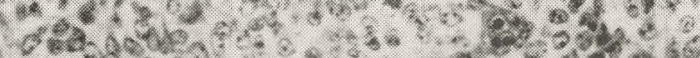

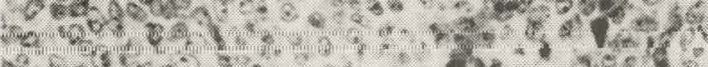

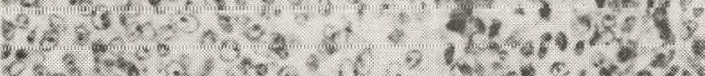

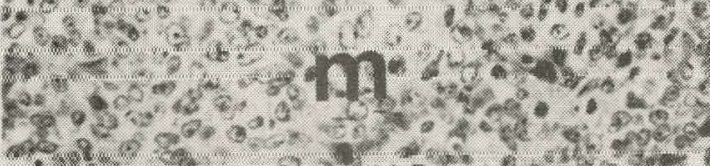

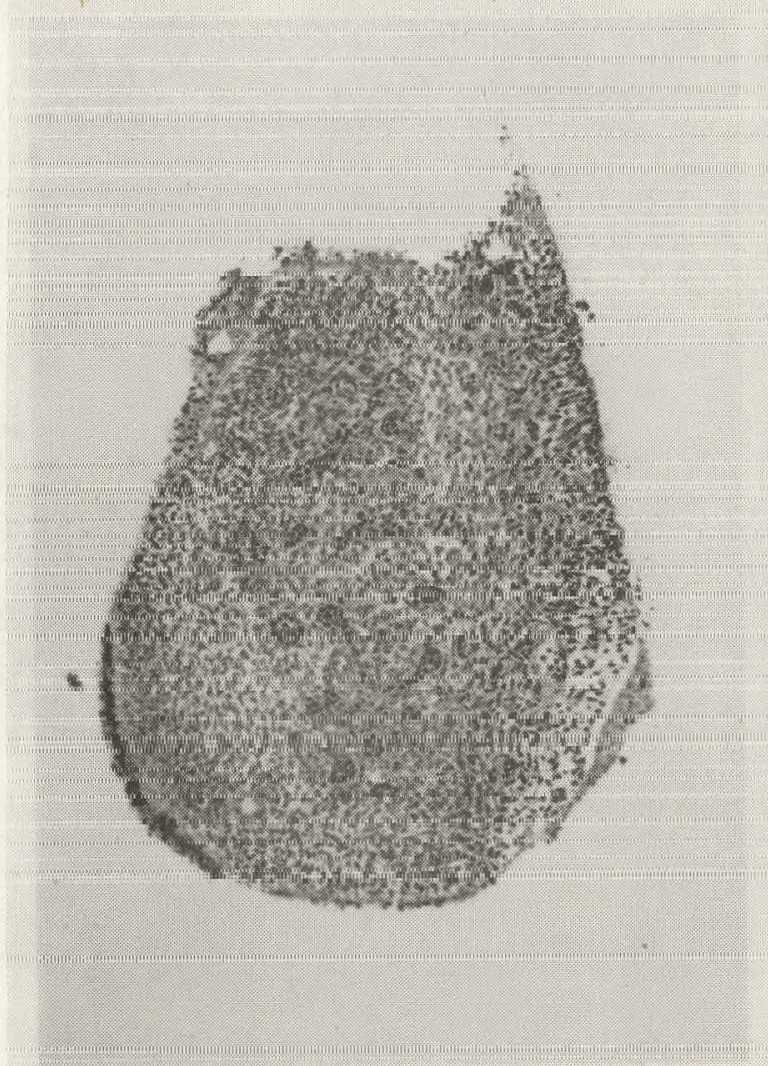

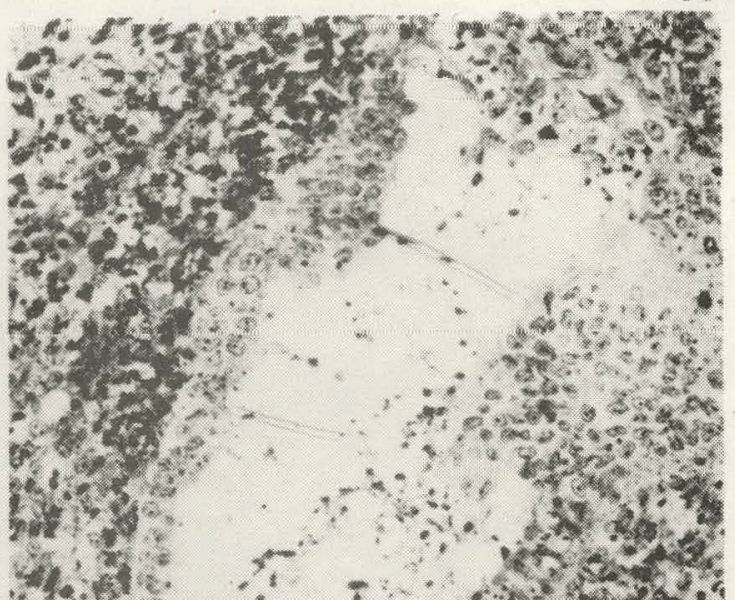

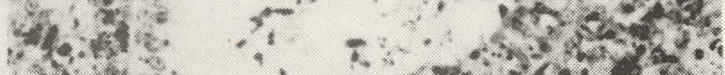
+

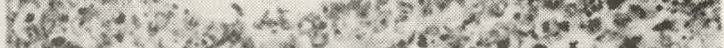

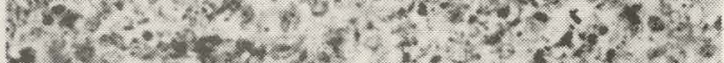

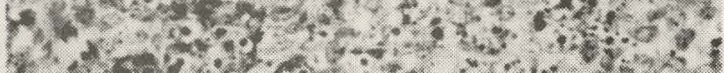

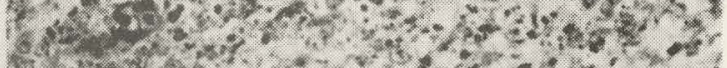

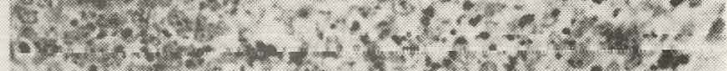

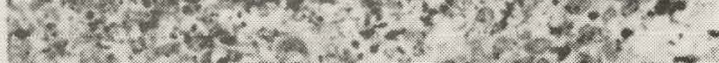

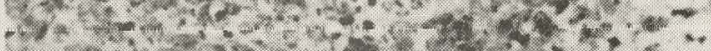

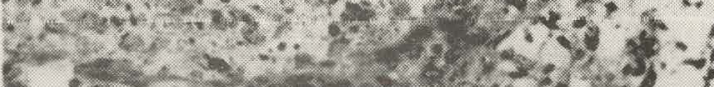

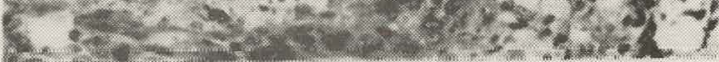

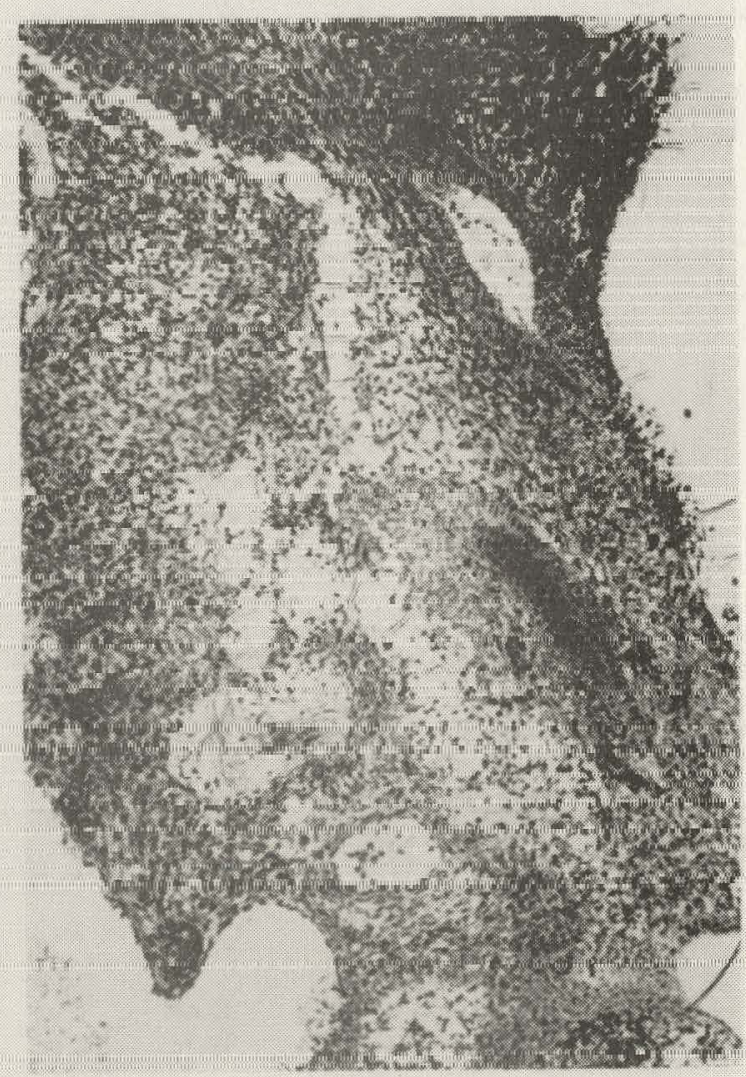


Figure 6la. (Upper left) Photomicrograph of fetal lung which was sham irradiated and explanted at 13 days of gestation and cultured for one day. The large lumen is more narrow than seen in the four-hour culture, see Figure $46(90 \mathrm{x})$.

Figure $61 \mathrm{~b}$. (Upper right) Higher magnification of outlined a rea of Figure 61 a. Mitosis is occurring in the epithelium although the basement membrane is not well defined. (Line across lumen is methac rylate a rtifact; $225 \mathrm{x}$ ).

Figure 62. (Lower left) Photomicrograph of fetal lung explanted at 13 days of gestation, immediately exposed to $435 \mathrm{R}$ of $x$-ray and incubated for one day. The one large lumen is filled with debris $(90 \mathrm{x})$.

Figure 63. (Lower right) Photomicrograph of lung explanted from fetus immediately after exposure to $435 \mathrm{R}$ at 13 days of gestation and cultured for one day. There is a small atrophied lumen surrounded by fibrous material $(90 \mathrm{x})$. 

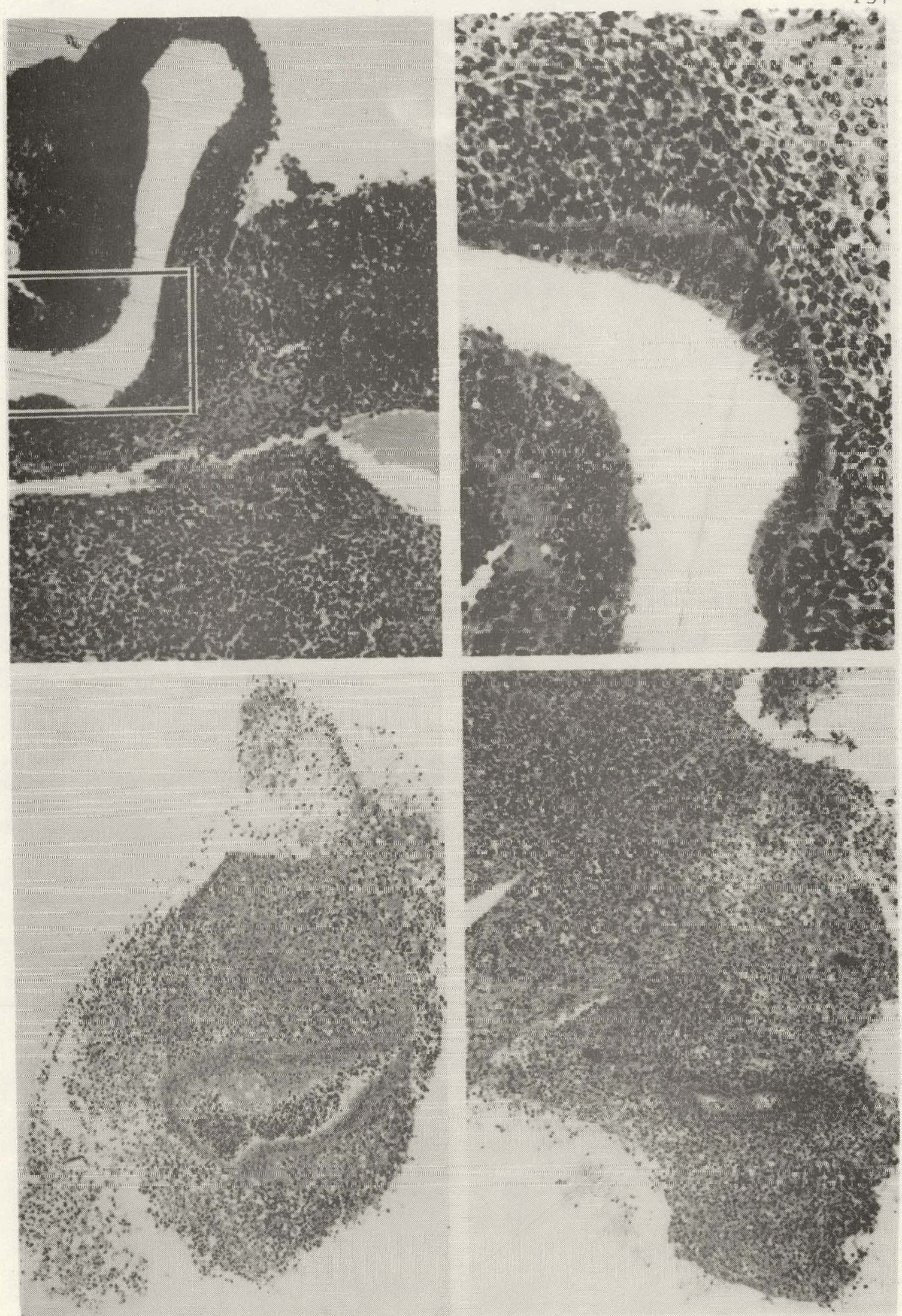
Figure 64a. (Top) Photomicrograph of fetal lung which was sham irradiated and cultured at 13 days of gestation and incubated for three days. Note the growth of the lung bud and decrease in size of large lumen. There is increased differentiation in upper portion of explant. Compare changes with Figure 46 (35x).

Figure 64b. (Lower left) Higher magnification of outlined area of Figure $64 \mathrm{a}$. There is "budding" of the bronchial tree from the central lumen. (Dark line through the section is an artifact due to methac rylate.) Note increased size compared to Figure $46(90 x)$.

Figure 64c. (Lower right) Higher magnification of 64b. "Budding" of the bronchial tree, mitosis in the epithelium and formation of possible "sacrules" can be seen $(225 \mathrm{x})$. 

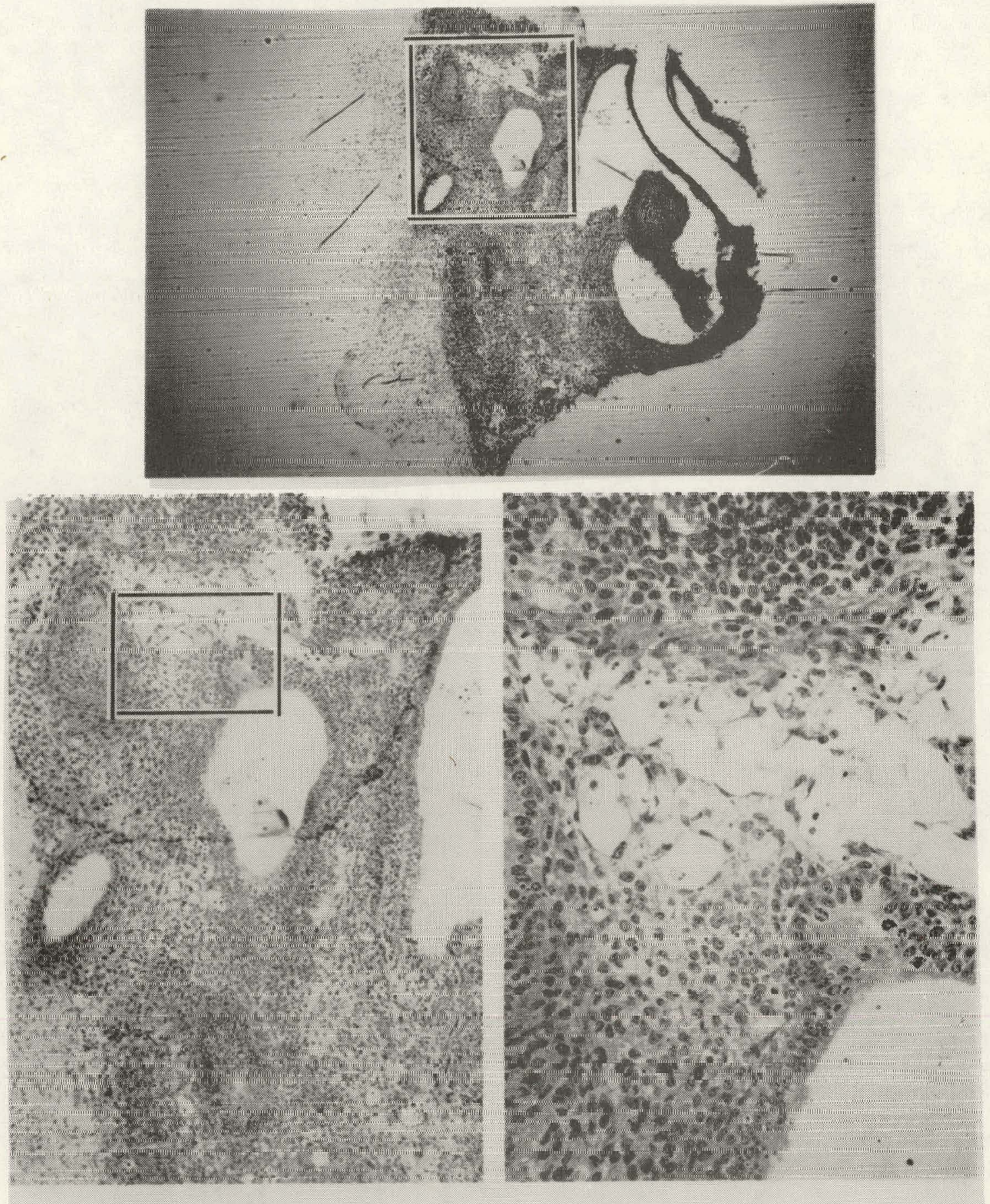
Figure 65. (Top) Photomicrograph of fetal lung which was sham irradiated at 13 days of gestation, explanted at 14 days of gestation and cultured for four hours. Fibroblasts are migrating near the epithelial lining which contains many mitotic figures $(225 \mathrm{x})$.

Figure 66a. (Lower left) Photomicrograph of fetal lung which was irradiated with $435 \mathrm{R}$ of $\mathrm{x}$-ray at 13 days of gestation, explanted at 14 days of gestation and cultured for four hours. The section is very acidophilic and the enlarged lumina, which are denuded, contain acidophilic fibers. See Figure $47(90 x)$.

Figure 66b. (Lower right) Higher magnification of a rea outlined in Figure 66a. Note the degeneration of blood vessels (center) and the fibrous nature of the cells (lower left) (225x). 

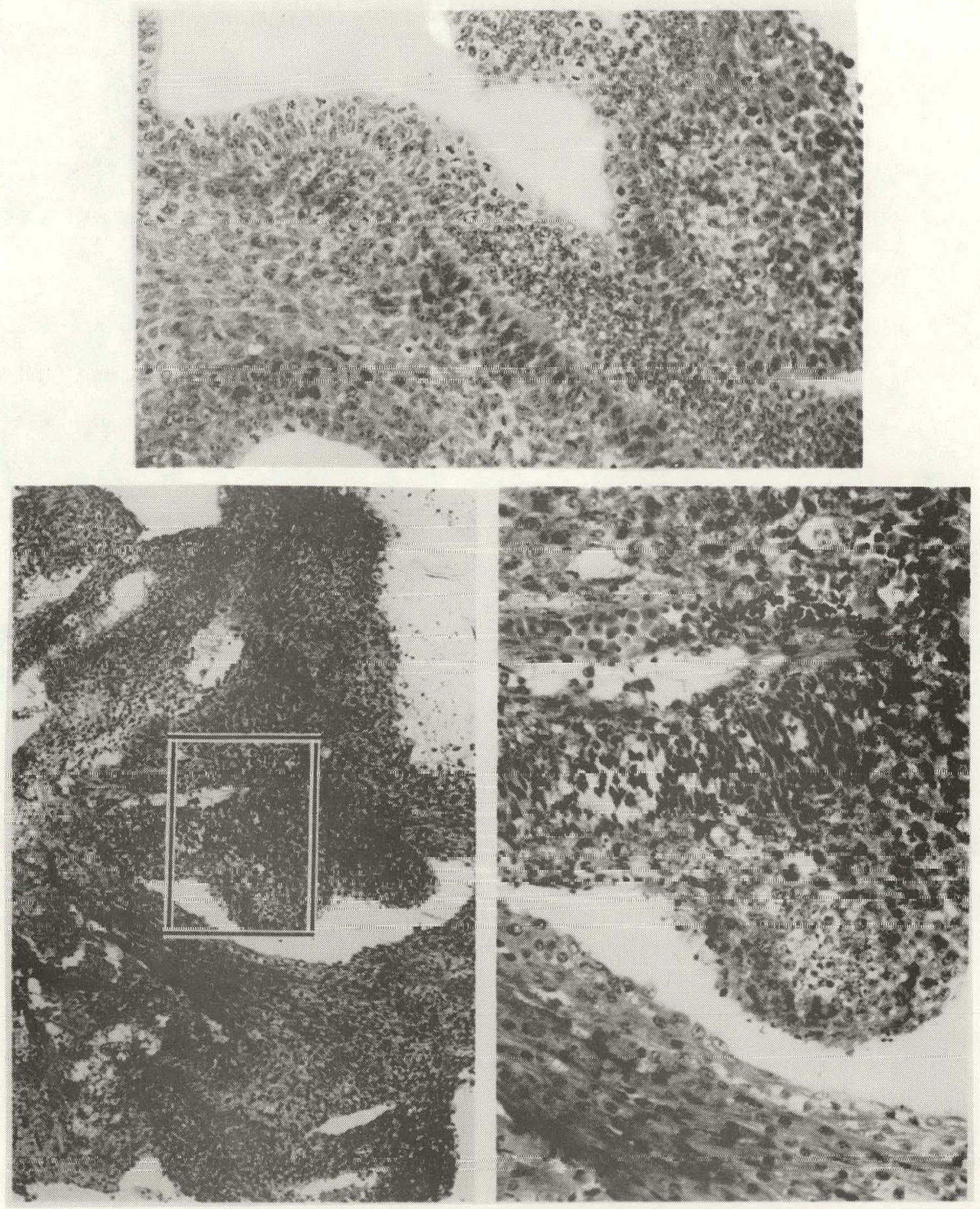
Figure 67. (Top) Photomic rograph of fetal lung which was sham irradiated at 13 days of gestation, explanted at 16 days of gestation and cultured for four hours. Fibroblasts a re "streaming" a round the large lumina (upper left); there is "budding" of the bronchial tree as indicated by the smaller lumina at the right $(225 \mathrm{x})$.

Figure 68a. (Lower left) Photomicrograph of fetal lung which was irradiated with $435 \mathrm{R}$ at 13 days of gestation, explanted at 16 days of gestation and cultured for four hours. There is a general recovery although development lags behind the control, see Figure 49 ( $90 \mathrm{x})$.

Figure 68b. (Lower right) Higher magnification of outlined area of Figure 68 a. There is an increased frequency in cytoplas mic vacuoles compared to the control (Figure 67). Note the slight amount of debris in the lumina and the large number mitotic figures in the epithelial lining and mesenchyme $(225 \mathrm{x})$. 

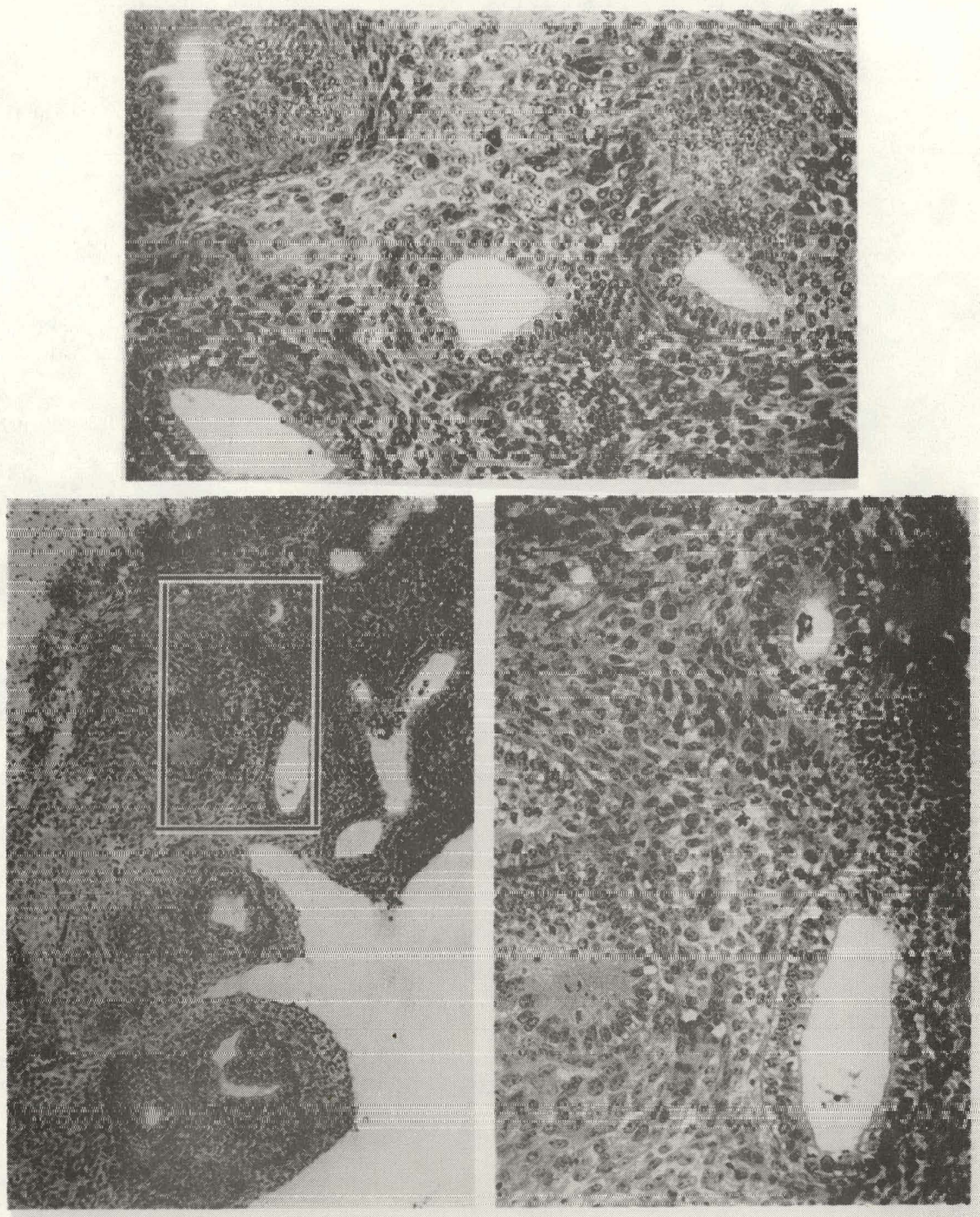
Table 12. Characteristics of Development of 15-Day Fetal Rat Lung after In Vivo or In Vitro Exposure to $435 \mathrm{R}$ of X-Ray - Expt. II.

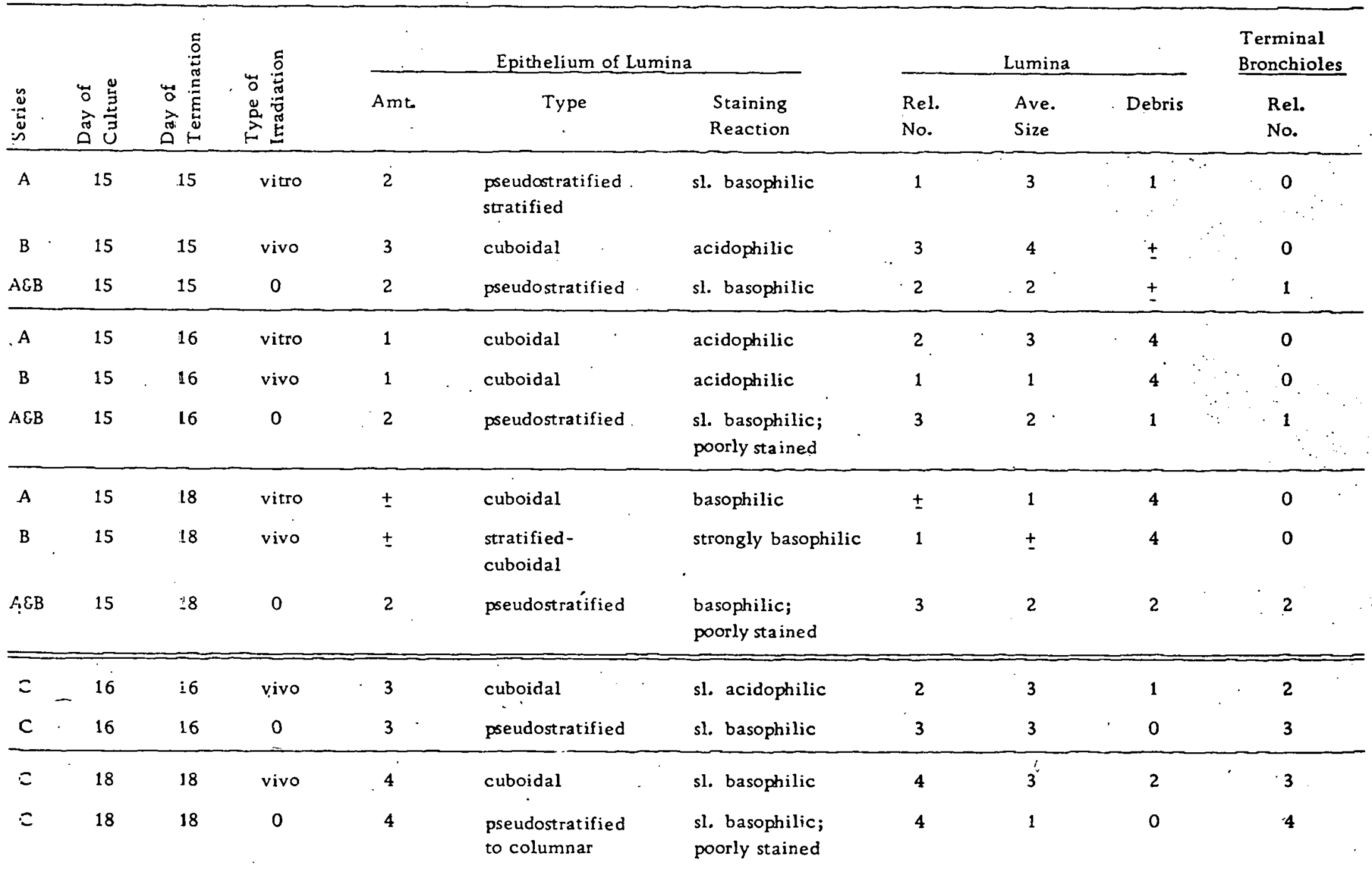


Table 12. Contizued.

\begin{tabular}{|c|c|c|c|c|c|c|c|c|c|c|c|c|}
\hline \multirow[b]{3}{*}{$\begin{array}{l}\tilde{N} \\
\tilde{u} \\
\tilde{w}\end{array}$} & \multirow[b]{3}{*}{ 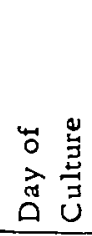 } & \multirow{3}{*}{ 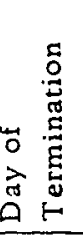 } & \multirow{3}{*}{ 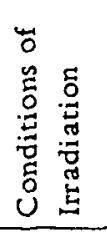 } & \multicolumn{5}{|c|}{ Supporting Tissue } & \multicolumn{2}{|c|}{ Pycnosis } & \multicolumn{2}{|c|}{ Mitotic Frequency } \\
\hline & & & & \multirow{2}{*}{$\begin{array}{l}\text { Mesenchyme } \\
\text { Rel. } \\
\text { Amt. }\end{array}$} & \multirow{2}{*}{$\begin{array}{c}\text { Fibroblast } \\
\begin{array}{c}\text { Rel. } \\
\text { Amt. }\end{array}\end{array}$} & \multirow{2}{*}{$\begin{array}{c}\text { Connective Tissue } \\
\text { Rel. } \\
\text { Amt. }\end{array}$} & \multicolumn{2}{|c|}{ Blood Capillaries } & \multirow{2}{*}{ Epithelium } & \multirow{2}{*}{ Mesenchyme } & \multirow{2}{*}{ Epithelium } & \multirow[t]{2}{*}{ Mesenchyme } \\
\hline & & & & & & & $\begin{array}{l}\text { Rel. } \\
\text { No. }\end{array}$ & Size & & & & \\
\hline$A$ & 15 & 15 & vitro & 1 & 3 & 2 & 2 & 2 & 0 & 1 & $\therefore 0$ & 0 \\
\hline $\mathrm{B}$ & 15 & 15 & vivo" & 1 & 3 & 3 & 4 & 4 & 0 & 0 & 0 & 0 \\
\hline AGB & 15 & 15 & 0 & 2 & 3 & 2 & 2 & 1 & 0 & \pm & 3 & 2 \\
\hline$A$ & 15 & 16 & vitro & 3 & 4 & $4+$ & 0 & - & 2 & 3 & 0 & 0 \\
\hline$B$ & 15 & 16 & vivo & 3 & 1 & 4 & 0 & - & 1 & 3 & 0 & 0 \\
\hline A\&B & 15 & 16 & 0 & 2 & 3 & 3 & 2 & 2 & 0 & 2 & 1 & $\pm \quad \because$ \\
\hline A & 15 & 18 & vitro & 3 & 1 & $4+$ & 0 & - & 2 & 4 & 0 & 0 \\
\hline B & 15 & 18 & vivo & 4 & 3 & 4 & 0 & - & 2 & 4 & 0 & 0 \\
\hline A\&B & 15 & 18 & 0 & 2 & 2 & 3 & 1 & 3 & 0 & 1 & 3 & 1 \\
\hline$c$ & 16 & 16 & vivo & 2 & 4 & 3 & 3 & 3 & 0 & 1 & 1 & 2 \\
\hline$c$ & 16 & 16 & 0 & 1 & 4 & 2 & 3 & 1 & 0 & 0 & 3 & 2 \\
\hline$c$ & 18 & 18 & vivo & 1 & 3 & 3 & 4 & 3 & 0 & 0 & 4 & 3 \\
\hline$c$ & 18 & 18 & 0 & 1 & 4 & 3 & 4 & 1 & 0 & 0 & 1 & 1 \\
\hline
\end{tabular}

${ }^{3}$ For a description of the numerical values, see text p. 63 . 
Figure 69. (Upper left) Photomicrograph of fetal lung which was sham irradiated and cultured for four hours at 15 days gestation. Note "budding" of the bronchial tree at lower left $(225 x)$.

Figure 70a. (Upper right) Photomicrograph of lung explanted from fetus immediately after exposure to $435 \mathrm{R}$ at 15 days of gestation and cultured for four hours. Higher magnification of area outlined in Figure $70 \mathrm{~b}$. There is debris in the dilated lumen and marked vascular engorgement is seen in mesenchyme $(225 \mathrm{x})$.

Figure 71. (Lower left) Photomicrograph of fetal lung explanted at 15 days of gestation, immediately exposed to $435 \mathrm{R}$ of $x$ - ray and incubated for four hours. There is increased pycnosis and debris in the lumina (90x).

Figure 70b. (Lower right) Same section as Figure 70a at a lower magnification. The lumina a re enlarged and more. numerous than those in the control. See Figure 48 (90x). 

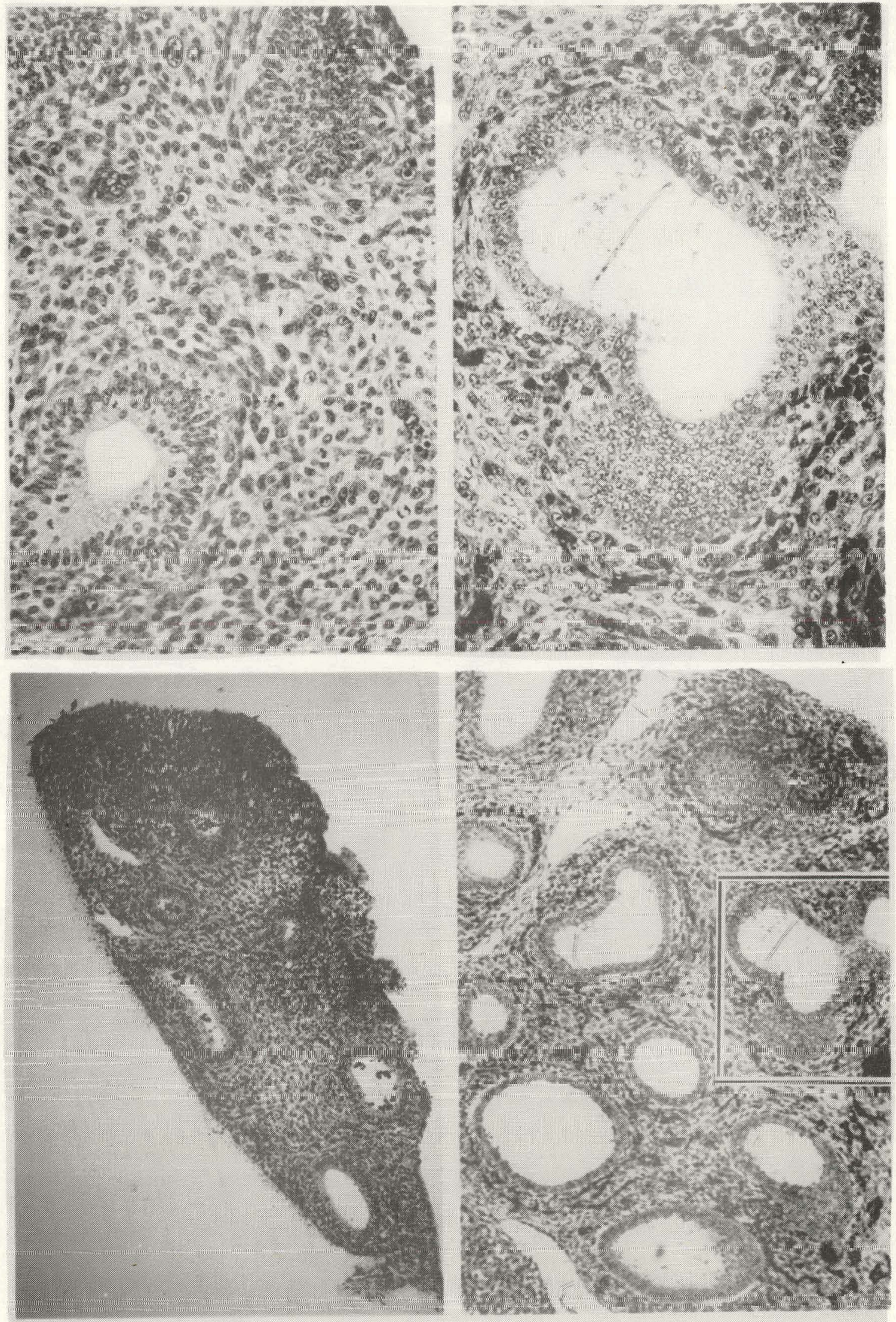
Figure 72a. (Upper left) Photomicrograph of lung which was sham irradiated and explanted at 15 days of gestation and cultured for one day. The lumina are enlarged and there is progressive branching of the bronchial tree. To compare with four hour culture, see Figure $48(90 \mathrm{x})$.

Figure 72b. (Upper right) Higher magnification of a rea outlined in Figure $72 \mathrm{a}$. There is "budding" of the bronchial tree; note that the epithelium has become indistinct. There is some degeneration of the mesenchyme $(225 \mathrm{x})$.

Figure 73. (Lower left) Photomicrograph of fetal lung explanted at 15 days of gestation, immediately exposed to $435 \mathrm{R}$ of $x$-ray and cultured for one day. There are enlarged lumina filled with debris which is probably from the epithelial lining $(90 \mathrm{x})$.

Figure 74. (Lower right) Photomicrog raph of lung explanted from fetus immediately after exposure to $435 \mathrm{R}$ and cultured for one day. The lumina that a re surrounded by pycnotic tissue, are filled with debris which is probably from the epithelial lining $(90 \mathrm{x})$. 

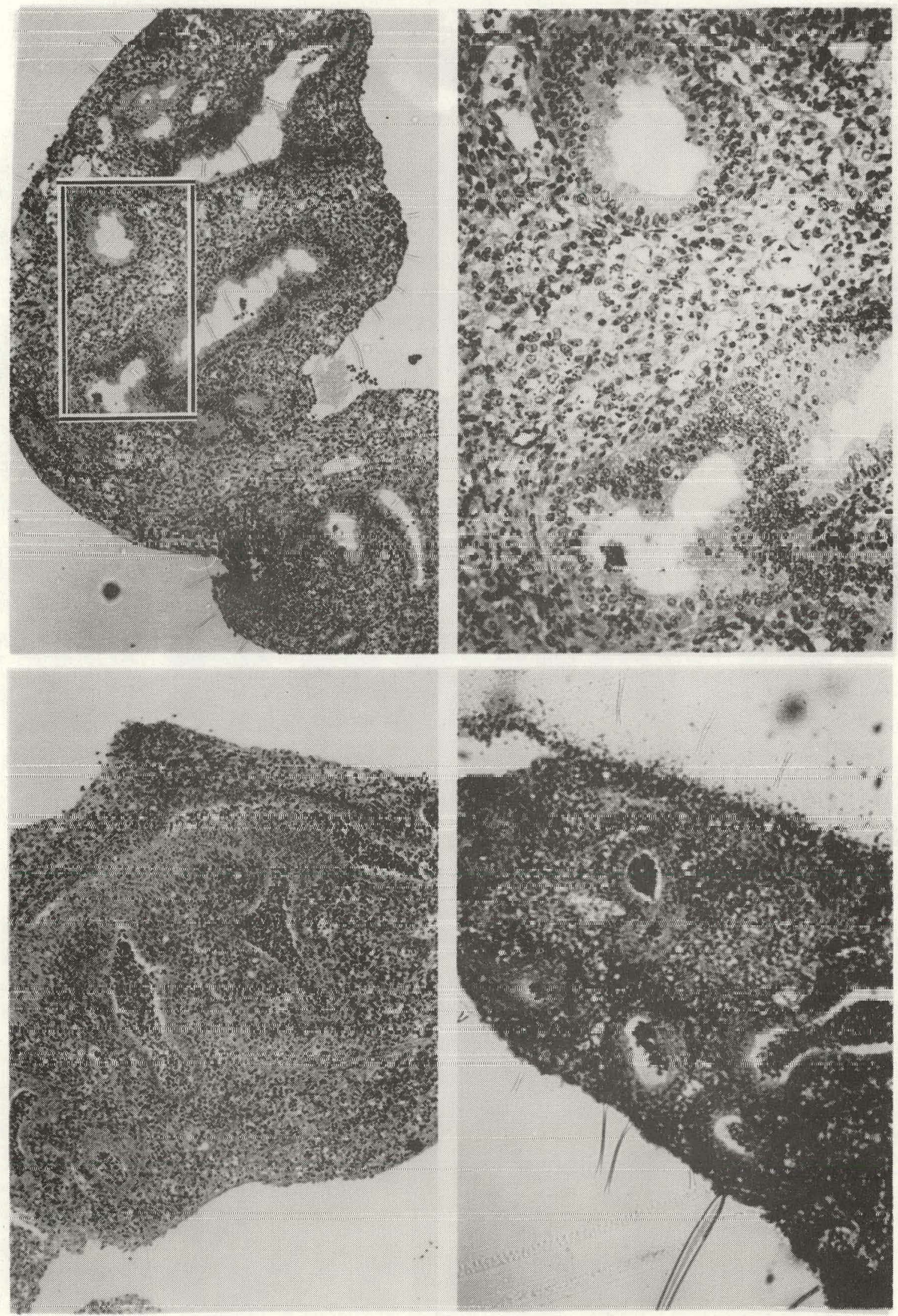
Figure 75a. (Upper left) Photomicrograph of a fetal lung which was sham irradiated and explanted at 15 days of gestation and cultured for three days. Progressive branching of the bronchial tree can be seen, although development does not keep pace with in vivo development. See Figure 50 (90x).

Figure 75b. (Upper right) Higher magnification of a rea outlined in Figure $75 \mathrm{a}$. Note the cytoplasmic vacuoles and mitotic figures in the epithelium $(225 \mathrm{x})$.

Figure 76. (Lower left) Photomicrograph of fetal lung explanted at 15 days of gestation, immediately ir radiated with $435 \mathrm{R}$ of $\mathrm{x}$-ray and cultured for three days. There is marked lysis and one degenerated lumen $(90 x)$.

Figure 77. (Lower right) Photomicrograph of lung explanted from fetus immediately after exposure to $435 \mathrm{R}$ at 15 days of gestation and cultured for three days. One lumen is surrounded by basophilic fibrous material. Note the fibroblasts in the central portion of the explant $(90 \mathrm{x})$. 
151
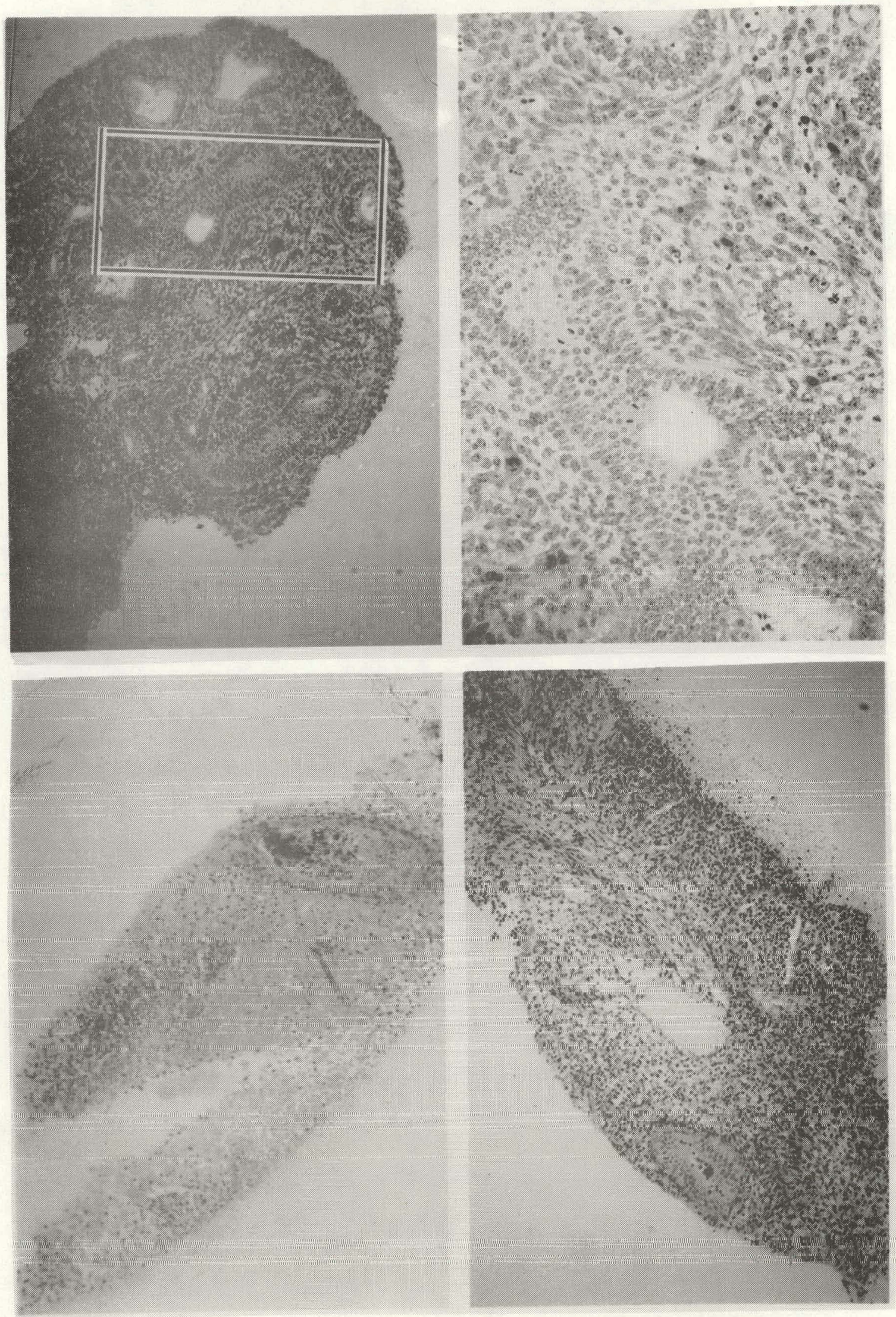
Figure 78. (Top) Photomicrograph of fetal lung which was sham irradiated at 15 days of gestation, explanted at 16 days of gestation and cultured for four hours. Fibroblasts are "streaming" around the developing bronchial tree $(225 \mathrm{x})$.

Figure 79a. (Lower left) Photomicrograph of fetal lung which was irradiated with $435 \mathrm{R}$ at 15 days of gestation, explanted at 16 days of gestation and cultured for four hours. Fibrous debris surrounds the acidophilic explant. See Figure $49(90 x)$.

Figure 79b. (Lower right) Higher magnification of area outlined in Figure 79a. Deterioration of the epithelial lining and its basement membrane as well as vascular engorgement, can be seen $(225 \mathrm{x})$. 

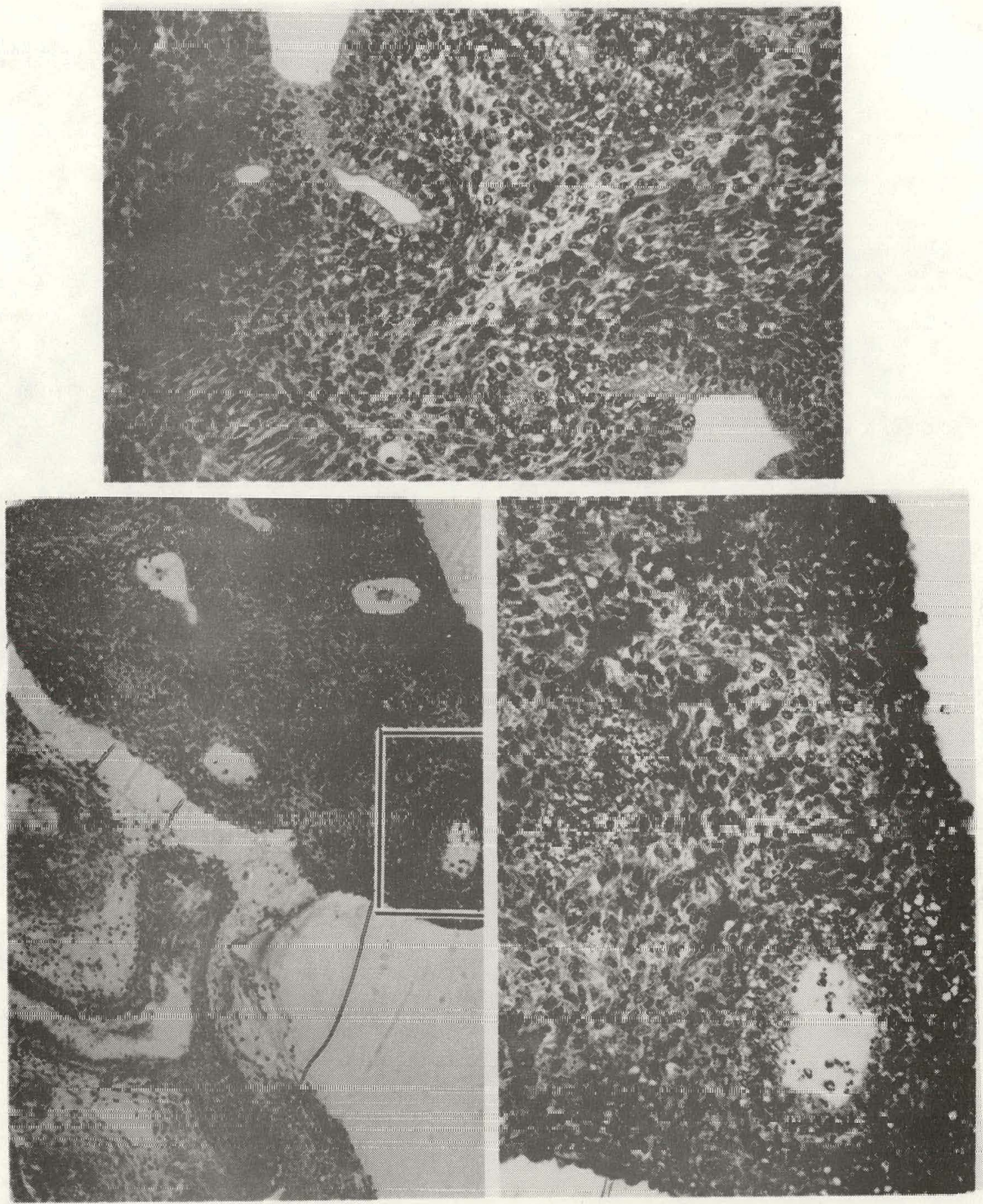
Figure 80. (Top) Photomicrograph of fetal lung which was sham irradiated at 15 days of gestation, explanted at 18 days of gestation and cultured for four hours. Note the numerous terminal bronchioles (tb) and the cytoplasmic vacuoles present in their epithelium $(225 \mathrm{x})$.

Figure 8 la. (Lower left) Photomicrograph of fetal lung which was irradiated with $435 \mathrm{R}$ of $\mathrm{x}$-ray, explanted at 18 days of gestation and cultured for four hours. Note the vascular engorgement, the presence of amorphous material in the lumina and slight retardation in the deg ree of development. See Figure 50 (90x).

Figure $8 \mathrm{lb}$. (Lower right) Higher magnification of a rea outlined in Figure $81 \mathrm{a}$. Note the distended terminal bronchioles, the increased mitotic frequency and the distinct zone of fibroblasts (f) $(225 \mathrm{x})$. 

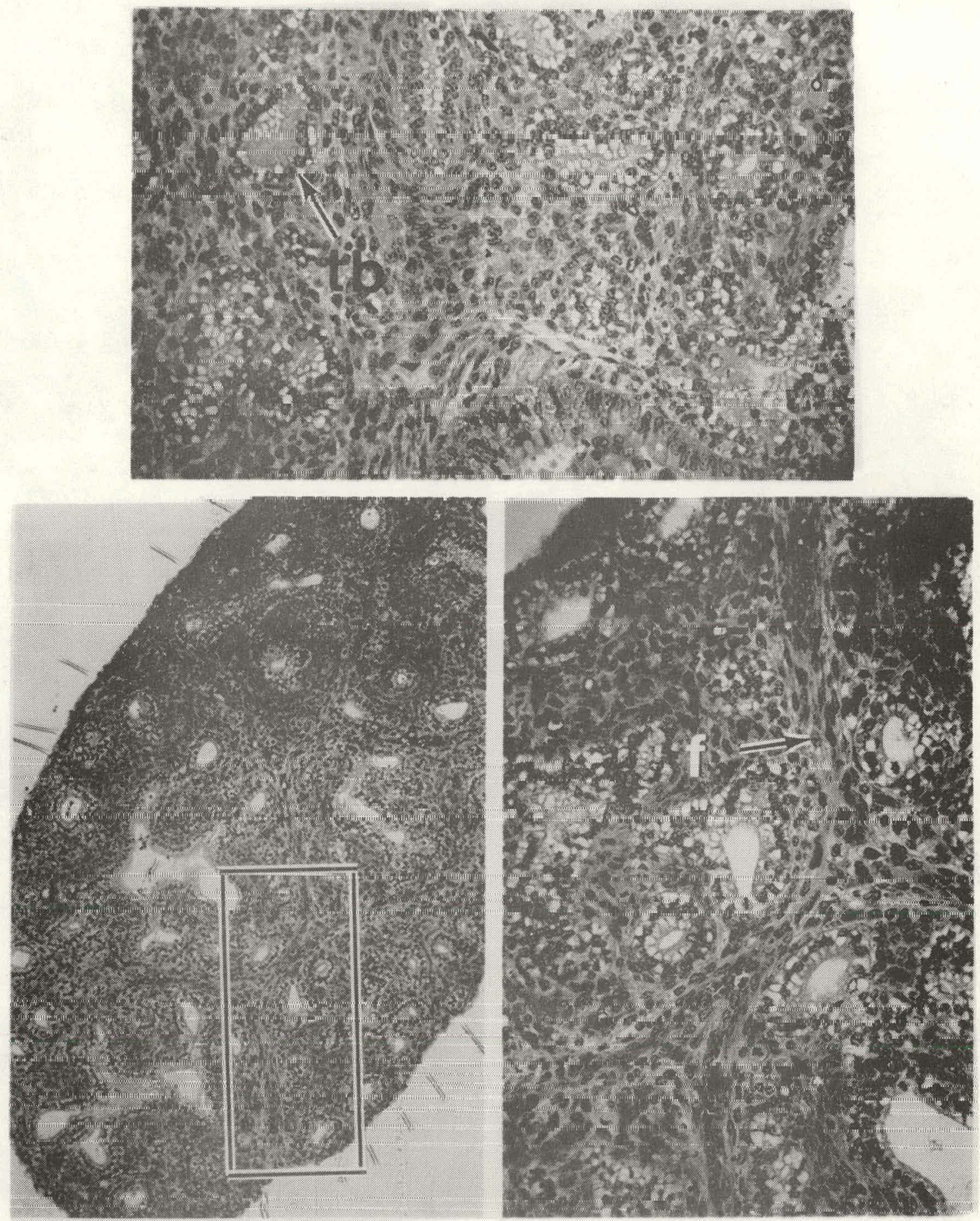
Results and Interpretation of Biochemical

Studies on Fifteen-Day Fetal Lung

The biochemical analysis expanded quantitatively what was ob-. served histologically in 15 -day fetal lung explants. The concentration of ${ }^{14} \mathrm{C}$-leu in the TCA precipitate is assumed to be a measure of the total protein synthesized during the labeling process. Since connective tissue has a high proline/hydroxyproline content, ${ }^{3} \mathrm{H}$-pro incorporation into TCA-precipitable material is indicative of connective tissue biosynthesis occurring in the four hours of incubation. The presence of ${ }^{3} \mathrm{H}$ and ${ }^{14} \mathrm{C}$ in the supernatant may be presumed to be due to the small peptides and free amino acids within the cell. Since it could not be determined gravimetrically, the protein analysis was performed as an index of tissue mass, both viable and nonviable; and an indication of the number of cells present was determined by the DNA content. The data are summarized in Tables 13 and 14.

Control lungs undergoing in vivo morphogenesis (Series "C") showed anincrease in the ratios of protein to DNA (Figure 83) and ${ }^{3} \mathrm{H}$ to ${ }^{14} \mathrm{C}$ in the supernatant as well as the precipitate (Figure 82 ). The increased ratio of ${ }^{3} \mathrm{H}$ to ${ }^{14} \mathrm{C}$ in the precipitate probably represents. an increase in the amount of connective tissue biosynthesis. In the control organs the ${ }^{14} \mathrm{C}$-leu per $\mu \mathrm{g}$ DNA showed an increase between four hours and one day but plateaued at three days while the ${ }^{14} \mathrm{C}$-leu 1. per $\mu g$ protein and the ratios of the supernatant to the precipitate of 
both ${ }^{3} \mathrm{H}$ and ${ }^{14} \mathrm{C}$ remained nearly constant over the three days. The ratios imply that the rate of total protein biosynthesis did not change significantly during the labeling periods in lung developing in vivo.

Non-irradiated lung explants developing in vitro (Series "B"), however, showed a progressive decrease in the incorporation of ${ }^{3} \mathrm{H}$ pro and ${ }^{14} \mathrm{C}$-leu per $\mu \mathrm{g}$ DNA and a slight decrease in the protein to DNA ratio (Figure 83 ), which are all indicative of cellular degeneration. There was a decrease in the incorporation of ${ }^{3} \mathrm{H}$-pro and ${ }^{14} \mathrm{C}$ leu per $\mu$ g protein after 24 hours with a slight increase after three days in culture. The following ratios inc reased with in vitro development; ${ }^{3} \mathrm{H}$ to ${ }^{14} \mathrm{C}$ in the precipitate and the supernatant, the supernatant to precipitate of ${ }^{3} \mathrm{H}$ and ${ }^{14} \mathrm{C}$. The ratios of the supernatant to precipitate, which showed a slight decrease between one and th ree days in culture, were higher than those of in vivo controls while the ratio of the ${ }^{3} \mathrm{H}$-pro to ${ }^{14} \mathrm{C}$-leu in the supernatant was decreased. This seems to indicate that' a smaller proportion of the incorporated amino acids, particularly the ${ }^{14} \mathrm{C}-1 \mathrm{eu}$, was enteringthe TCA-precipitable material as compared to the controls, for the ratio of ${ }^{3} \mathrm{H}$-pro to ${ }^{14} \mathrm{C}-$ leu in the precipitate was greater than the in vivo controls.

Irradiated lungs differentiạting in utero (Se ries "C") had a progressively increased ratio of protein to DNA (Figure 83 ); this ratio. was greater than in the corresponding controls. This is perhaps indicative of mitotic inhibition or increased extracellula $r$ protein 
synthesis. The incorporation of ${ }^{14} \mathrm{C}$-leu per $\mu \mathrm{g}$ protein and the supernatant to precipitate ratio of ${ }^{3} \mathrm{H}$-pro showed an increase at one day post-irradiation and leveled off two days later. The incorporation of ${ }^{14}$ ' -leu per $\mu g$ DNA and the supernatant to precipitate ratio of ${ }^{14} \mathrm{C}$-leu remained about the same in post-irradiation development in vivo. The ratios of the supernatant to the precipitate of both ${ }^{14} \mathrm{C}$ and ${ }^{3} \mathrm{H}$ were greater than the sham irradiated controls. The incorporation of ${ }^{14} \mathrm{C}-1$ eu on the basis of DNA and protein was slightly depressed compared to their respective controls at one and three days post-irradiation. The incorporation of ${ }^{3} \mathrm{H}$-pro per unit mass of DNA or protein and the ratio of ${ }^{3} \mathrm{H}$ to ${ }^{14} \mathrm{C}$ in both the supernatant and the precipitate (Figure 82 ) showed a decrease at 24 hours after irradiation and an increase at three days. The incorporation of ${ }^{3} \mathrm{H}$-pro on the basis of DNA was about the same in both the control and irradiated lungs developing in utero for the three days post-irradiation. The ratio of ${ }^{3} \mathrm{H}$-pro to ${ }^{14} \mathrm{C}$-leu incorporation in both the supernatant and the precipitate was lower than the non-irradiated controls at 24 hours after $\mathrm{x}$-irradiation, but two days later these ratios were greater than those of the control counterpart. Based on the mass (i. e. protein) of the irradiated tissues, total protein synthesis seems to be slightly depressed but constant. While the rate of connective tissue biosynthesis seems lower at one day post-irradiation, it is increased at three days after $\mathrm{x}$-ray exposure (Figure 82 ). 
Lung irradiated and incubated in vitro (Series "B") showed a progressive and marked depression of ${ }^{3} \mathrm{H}$-pro and ${ }^{14} \mathrm{C}-$ leu incorporation and a decreased protein to DNA ratio, which probably reflects cellular degeneration. In the in vitro development, which occurred after $x$-irradiation, the following ratios were increased in the first 76 hours; the supernatant to precipitate of both ${ }^{3} \mathrm{H}$ and ${ }^{14} \mathrm{C}$, the ${ }^{3} \mathrm{H}$ to ${ }^{14} \mathrm{C}$ in both the supernatant, and the precipitate (Figure 82). There seems to be an increase in degradation of protein, and while the metabolic rate of these irradiated lung explants is probably low, residual protein synthesis has shifted to connective tissue. In a limited number of autoradiographs, ${ }^{3} \mathrm{H}$-pro incorporation was concentrated around the larger lumina of the upper bronchial tree and the debris (if present) inside the lumina in all lungs, irradiated and non-irradiated, that were developing in vitro (Figure 84 and 85 ). Lungs which wereirradiated and allowed to remain in utero for one day 'had a small but even distribution of ${ }^{3}$ H-pro over the entire explant (Figure 86). After three days post-irradiation, explants from lungs developing in utero showed $a^{3} \mathrm{H}$ pro-pattern similar to that seen in lungs developing in vitro (Figure 87). The density of the grains observed in the above autoradiog raphs paralleled the chemical findings. 
Table 13. Effect cf X-Irradiation on the Irradiation on the Incorporation of ${ }^{3} \mathrm{H}$-Proline and ${ }^{14} \mathrm{C}$-Leucine into Protein by Explants of Fetal Rat Lung at 15 Days of Gestation.

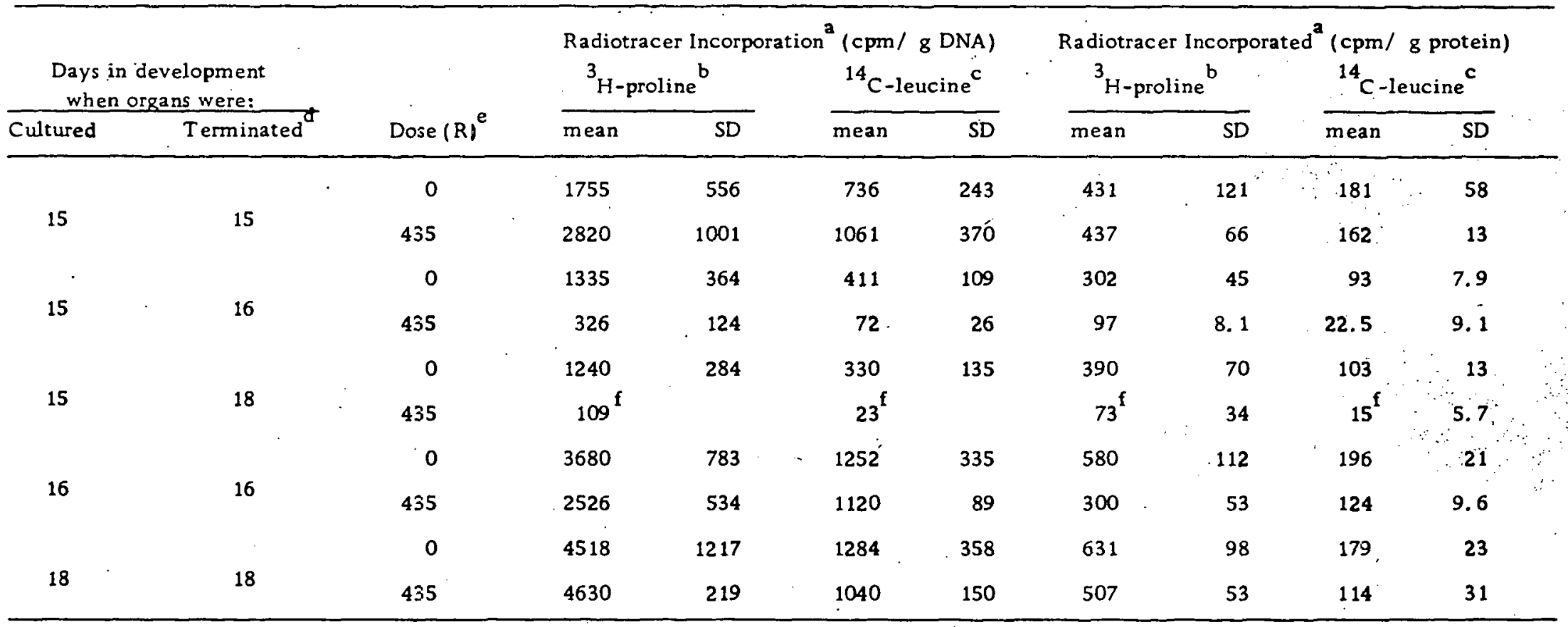

${ }^{a}$ Radiotracer incorporation was measured in the 5\% TCA (trichloroacetic acid) precipitate.

${ }^{t_{3}} \mathrm{H}$ was counted at $54 \%$ efficiency.

${ }^{c 14} \mathrm{C}$ was counted at $56 \%$ efficiency.

d All cultures were exposed to radiotracers four hours prior to termination.

eAll organs were iradiated in vivo on the fifte enth in gestation.

f Only two samples were analyzed. 
Table 14. Ratios of Biochemical Parameters Measured on Explants in Development of Fetal Rat Lung After X-Irradiation at 15 Days of Gestation:

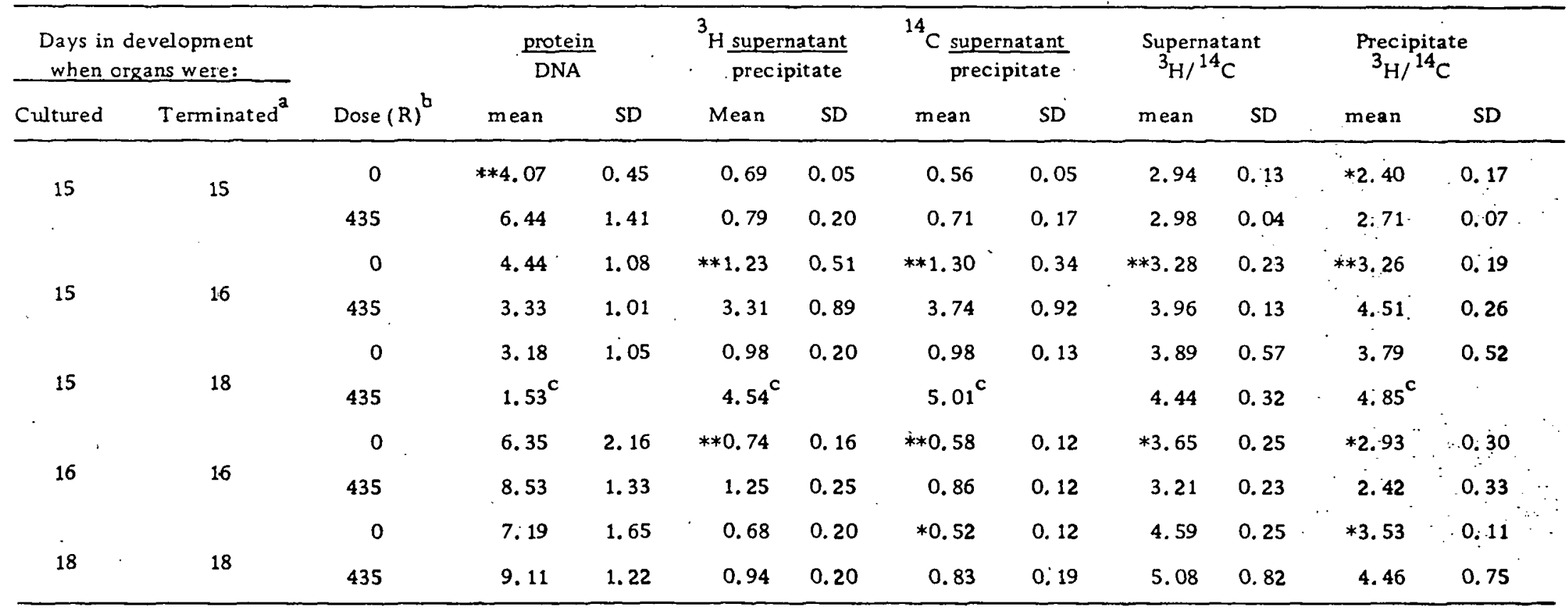

all explants were exposed to radiotracers four hours prior to termination.

b $\mathrm{All}$ organs were irradiated in vivo on the fifteenth day in gestation.

Only two sample values were averaged.

** Significant difference between means of irradiated and non-irradiated at $95 \%$ level using student's $t$ test.

* Significant difference between means of irradiated and non-irradiated at $90 \%$ level using student's $t$ test. 
Figure 82. Effects of x-irradiation at 15 days of gestation on the ratio of ${ }^{3} \mathrm{H}$-proline $/{ }^{14} \mathrm{C}$-leucine incorporation into the TCA-precipitable fraction by explants of fetal lung after development in vivo or in vitro. Labeled medium was introduced four hours prior to termination. 


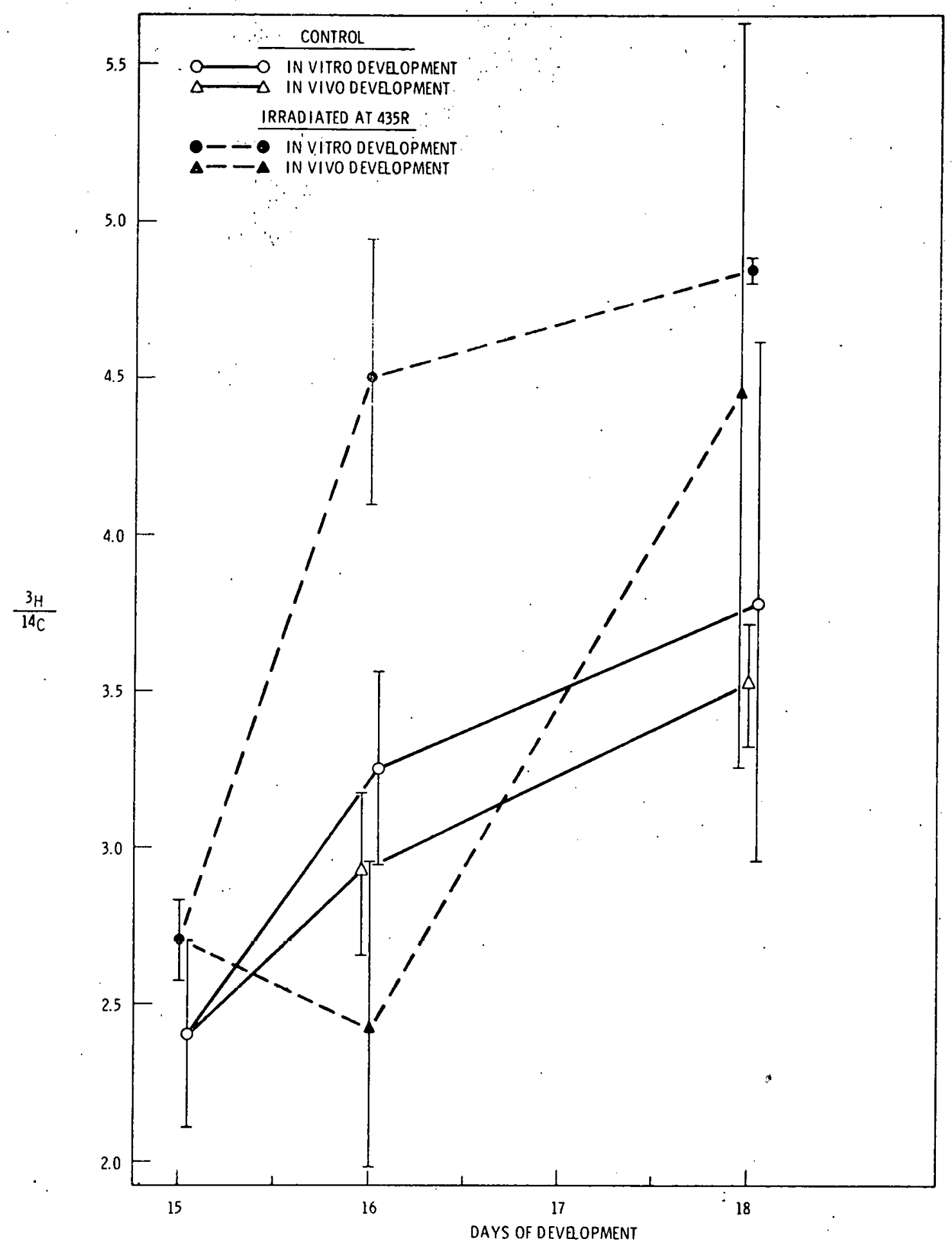


Figure 83. Effect of in vivo $x$-irradiation at 15 days of gestation on the ratio of protein to DNA in fetal lung developing in vivo or in vitro. In vivo lungs were explanted four hours prior to analysis. 


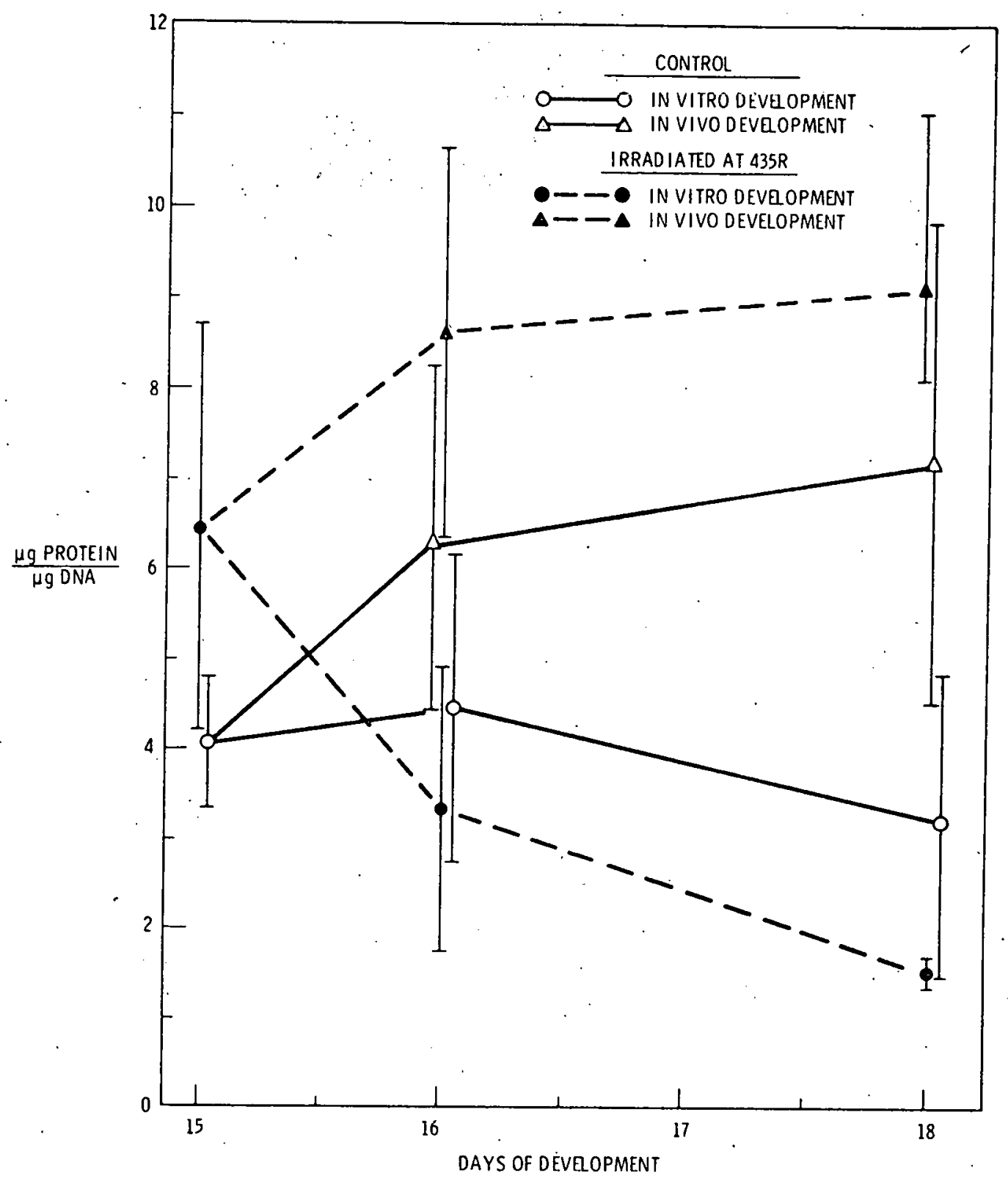


Figure 84. (Upper left) Autoradiog raph of lung which was sham irradiated and explanted at 15 days of gestation, incubated for three days and labeled with $50 \mu \mathrm{C} \mathrm{i}{ }^{3} \mathrm{H}$ proline/cc for four hours. The ${ }^{3} \mathrm{H}$ is concentrated in developing bronchial tree $(90 x)$.

Figure 85. (Upper right) Autoradiograph of lung explanted from fetus immediately after exposure to $435 \mathrm{R}$ at 15 days of gestation and cultured for four hours with media containing $50 \mu \mathrm{Ci}{ }^{3} \mathrm{H}$-proline/cc. The ${ }^{3} \mathrm{H}$ is above the upper bronchial tree (far right) and in the debris in the lumina $(90 x)$.

Figure 86. (Lower left) Autoradiograph of lung irradiated.with 435 $R$ at 15 days of gestation explanted at 16 days of gestation and cultured for four hours with media containing $50 \mu \mathrm{Ci} 3 \mathrm{H}$-proline/cc. There appears to be little incorporation of ${ }^{3} \mathrm{H}$ into the explant $(90 \mathrm{x})$.

Figure 87. (Lower right) Autoradiograph of lung irradiated with $435 \mathrm{R}$ at 15 days of gestation explanted at 18 days of gestation and cultured for four hours with media containing $50 \mu \mathrm{Ci}{ }^{3} \mathrm{H}$-proline/cc. The re is an increase in ${ }^{3} \mathrm{H}$ incorporation which is concentrated in the upper bronchial tree (centcr) $(90 x)$. 

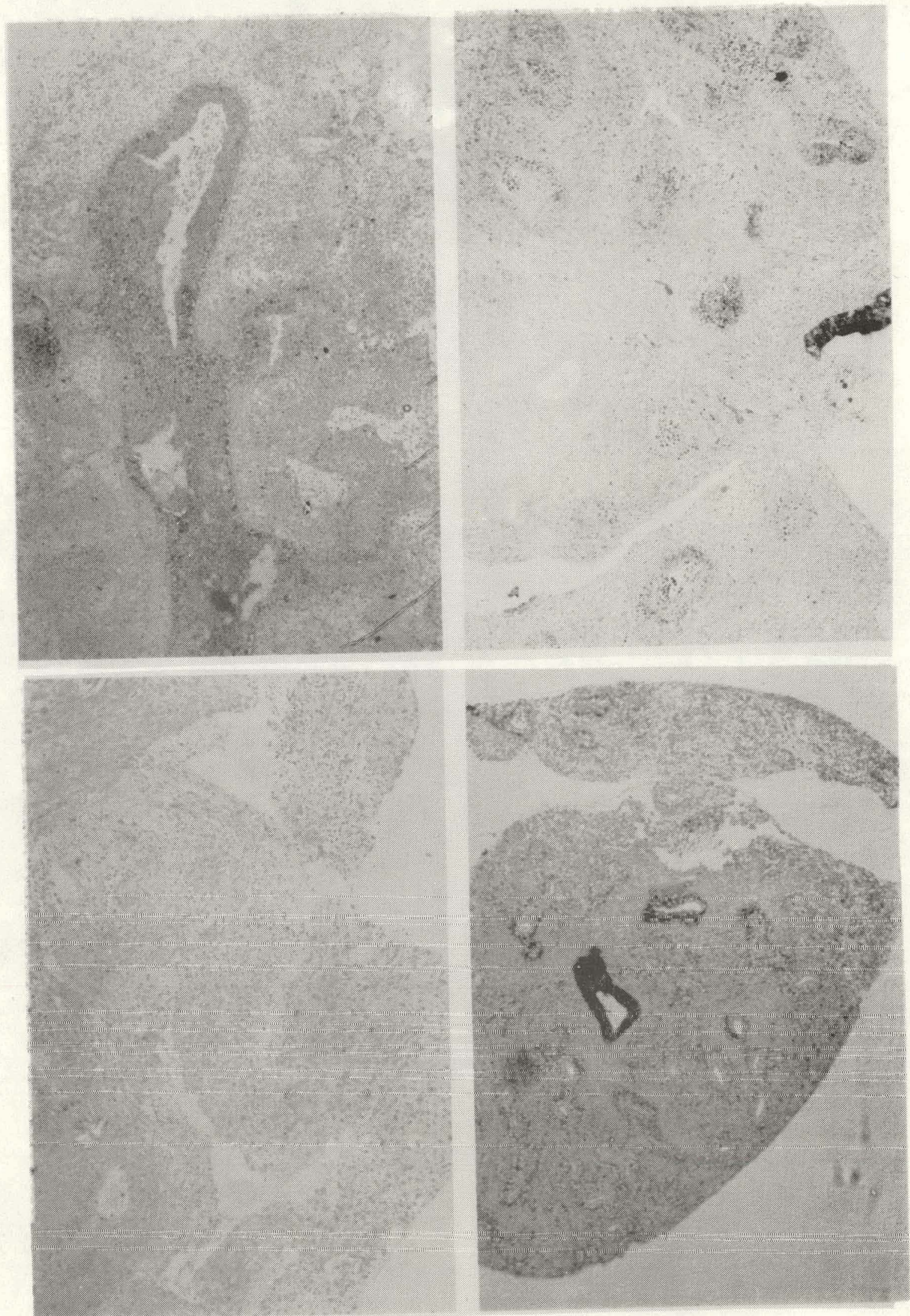


\section{Discussion}

In Vivo Development of Fetal Rat Lung

In the morphogenesis of lung, the laying down of connective tissue occurs with the arboreous expansion of the bronchial tree and the transformation of the mesenchyme (Sorokin, et al. 1959). The mesenchyme which is essential for epithelial morphogenesis, is a. major source of epithelial collagen (Kallman and Grobstein, 1955; Bernfield, 1970). The scoring of histological sections as used in this study provides a semiquantitative defipition of these and other morphological changes previously established by classical qualitative observations. The biochemical data on 15-day fetal lung provide further insight to the development of the histological pattern. Lungs developing in vivo did not have a substantially increased rate of total amino acid incorporation (based on ${ }^{14} \mathrm{C}-1 \mathrm{eu}$ ), but there was a progressive increase in the rate of ${ }^{3} \mathrm{H}$-pro incorporation between the 15 th, 16th, and 18th day in development. While the rate of total protein synthesis of the differentiating cell is not changed, there is increased incorporation of proline into the protein being synthesized, an indication of increased connective tissue biosynthesis. 
In Vitro Development of Fetal Rat. Lung

The lung lends itself well to in vitro study because of its flexible metabolic requirements (Sorokin, 1961) and the obvious morphogenic \%: events which facilitate analysis. In culture, 13- and 15-day lungs not only survived, but the $t$ issue mass increased and the organ underwent distinct differentiation. This maturation was seen in the progressive branching and "budding". of the bronchial tree, the increased number of terminal bronchioles and histological differentiation. In 15-day lungs an increase in connective tissue biosynthesis (as implied by increasing ${ }^{3} \mathrm{H}$-pro/ $/{ }^{14} \mathrm{C}$-leu ratios) paralleled the incubation time and morphological development. Sorokin (1961) reported abrupt "attenuation" (i.e. a shift from pseudostratified to cuboidal to squamous morphology) of the epithelium of the bronchial tree into "saccules" in 14-day fetal lung. Although this was not found in his 13day lung cultures, in the present studies, "saccules" were observed in 13-day lung after three days in culture. These "saccules" may represent disintegration; however, the resulting web-like pattern appears to be quite extensive and does not seem to be an artifact of histological manipulation. The 17-and 19-day lung explants did not survive as well in organ culture as those explanted earlier in gestation. This may be due to their more differentiated state and aerobic metabolism (Sorokin, 1965). 
In vitro studies of epithelio-mesenchymal interactions indicate that the mesenchyme and epithelium both incite collagen biosynthesis (Bernfield, 1970). The presence of epithelial collagen per se does not necessarily lead to morphogenesịs (Bernfield, 1970). Enzymic (Wessels and Cohen, 1968) and analog (Alescio, 1973) studies show that failure of the system to synthesize collagen will definitely inhibit "budding" of the bronchial tree. Protein biosynthesis (as ${ }^{14} \mathrm{C}$-leu incorporation) was seen to decrease with time in culture in the 15-day lung explants, and the protein which is synthesized appears to be predominantly connective tissue. In fact, the ratio of ${ }^{3} \mathrm{H}$-pro/ ${ }^{14} \mathrm{C}-\mathrm{leu}$ incorporation of the lungs developing in vitro never varies ma rkedly from the in vivo controls. One might speculate that while the rate of total protein biosynthesis is less in the organ culture, the proportion of the connective tissue protein being synthesized is the same as that in vivo. Of course, verification of this would requi re more refined quantitative studies.

The stress of culturing on lungs developing in vitro became evident in the degeneration of the epithelium, deterioration of the vascular system and the presence of pycnotic cells. Sorokin (1961) found that the epithelium of the bronchial tree became shorter as the branching proceeded in vitro. While the attenuation of the epithelial morphology occurs during normal differentiation, it may also signify degeneration of the epithelium since it occurred aber rantly in the 
larger, proximal lumina of the bronchial tree. There was some debris detected in the lumina, particularly with 15-day and older fetal lung explants. Although debris was not reported by Sorokin (1961), who cultured the lungs in agar, phagocytes were observed in the bronchial tree. His observed deterioration of the vasculature which may be a consequence of its disuse while in vitro (Sorokin, 1961).

Pycnosis was usually greater in the lungs grown in vitro for one or three days than for those retained in vivo and it was particularly obvious in the mesenchyme. The quantitative data seem to indicate cellular degeneration; the 15-day organ cultures showed a decreased rate of amino acid incorporation, increased ratio of supernatant/ppt. of ${ }^{3} \mathrm{H}$-pro and ${ }^{14} \mathrm{C}-1$ eu and a decreased protein mass per unit of DNA when compared to the in vivo controls. Morphologically the 13- and 15-day lungs appeared to have a resurgence between one and three days in vitro as evidenced by increased differentiation and mitosis. This is supported by the slight increase in amino acid incorporation per $\mu g$ of protein which was seen in the 15 -day fetal lung. Perhaps optimal growth and morphogenesis can proceed only after the explant has "adapted" to this in vitro environment. The restoration of growth, however, was not sufficient so that the rate of in vitro development equaled that found in vivo. Two detrimental effects which were visible following explantation may contribute to the retardation of the rate of development: (1) the decrease in the mitotic frequency, 
especially in the epithelium and (2) an increase in cell death, particularly in the mesenchyme. The presence of functional mesenchyme is mandatory if morphogenesis is to occur since the growth rate of the epithelium as a whole is dependent on the "activity" of the mesenchyme (Alescio, 1966).

Effects of X-Irradiation on the Development of Fetal Rat Lung

None of the lungs exposed to $x$-ray survived better in vitro than did their respective controls. For reasons stated previously, a comparison between the effects of radiation in vivo and in vitro is difficult to make. The patterns of the differential survival between cultures irradiated in vivo or in vitro were inconclusive, although the 13-day lung exposed in vitro seemed to exhibit less deterioration than those lungs irradiated in vivo. One can conclude that necrosis and lysis in the irradiated organ cultures, regardless of fetal age, was progressive and irreversible for the first three days. Whether the 15-day lung developed in organ culture or in vivo following ir radiation, there were increases in the supernatant/ppt. ratios of incorporated radioactive amino acids. This may indicate that a greater percentage of the amino acids and small peptides are not being assembled into precipitable proteins or that the protein turnover is greater than in the controls. In any case, a disruption of protein biosynthesis appears to occur after irradiation. 
The deleterious effects of $\mathrm{x}$-irradiation on development, whether in vivo or in vitro, parallel degene rative aspects of morphogenesis in vitro; i. e., sloughing of the epithelium into the lumina, pycnosis concentrated in the mesenchyme, deterioration of blood vessels, initial depression of mitosis and retardation of the rate of differentiation. Alescio and Ladu (1962) found that the first phase of radiation damage in organ culture of lung was in the epithelium, which became pycnotic and sloughed into the lumen within three hours. All irradiated lungs showed attenuated epithelium regardless of their postirradiation environment. In fact, 13-day lungs remaining in the uterus. one day after $\mathrm{x}$-ray exposure had a completely denuded tracheobronchialtree. The presence of hemorrhage and vascular dilation indicates a breakdown of the vascular system. Radiation causes the depolymerization of the hyaluronic acid which is a component of the extracellular tissue of the capillary wall. The basement membrane which has a different polymeric content, also appears to have an altered structure after $\mathrm{x}$-irradiation. The effect of radiation may be a dis ruption of the formed protein structure or an inter ruption in the process in the assembly of monomeric units.

Tissue often exhibits a decreased mitotic frequency following radiation treatment (Casarett, 1968) and division delay has been reported in $1 \mathrm{l}$-day mouse lung explants after irradiation (Alescio, 1966; Alescio and I-adu, 1962). Therewas a depresed mitotic 
frequency in all irradiated explants except for lungs which remained in the uterus for three days after $x$-ray exposure at 13 - and 15-days of gestation. In 15 -day lungs which had been irradiated and allowed to develop in utero, the amount of protein per unit mass of DNA increased with incubation time compared to the controls. This observation may reflect an inc rease in the average cell volume and/or depressed DNA synthesis since the rate of amino acid incorporation was slightly loiver than in the controls. In irradiated lungs developing in vitro, the absolute amounts of protein and DNA were diminished but the ratios between the two were not significantly different from the controls. This is probably a result of cellular degeneration in the irradiated lung cultures.

Radiation mày induce a shift towards connective tissue biosynthesis. All irradiated lung explants, except for the 13- and 15day lungs left in utero for three days after irradiation, appear to have a. greater amount of fibrous tissue than their respective controls. The biochemical data on the 15-day lungs do not entirely corroborate the microscopic observations. The ${ }^{3} \mathrm{H}$-pro $/{ }^{14} \mathrm{C}$-leu ratio indicates connective tissue biosynthesis in the four hours prior to termination, while the histological appearance indicates the net amount of connective tissue when development is terminated. Although the ${ }^{3} \mathrm{H}-\mathrm{pro} /{ }^{14} \mathrm{C}-\mathrm{leu}$ incorporation ratios were not significantly different between the control and irradiated cultures at four hours, this ratio was depressed at 
on'e day post-irradiation in utero and then was greatly elevated above the controls at three days. The rate of total protein biosynthesis was reduced after one or three days in culture, but a proportionally greater fraction of the protein which is synthesized is connective tissue. These quantitative data are substantiated by the autoradiog raphs visulaizing the site of ${ }^{3} \mathrm{H}$-pro incorporation.

The results consistently showed that radiation retards the rate of differentiation. Lung morphogenesis is dependent upon cellular proliferation as well as the ratio of mitotic frequencies of epithelium to stroma (Sorokin, et al., 1959). The decrease in the mitotic frequency seen after irradiation is a factor responsible for the retardation in the rate of differentiation. Even though the lungs which remained in utero for three days after $x$-ray exposure showed an elevated frequency of mitosis, they were unable to attain the level of development seen in the controls. Thus, ir radiated lungs that seem to recover from the insult of irradiation often do not rebound at a rate sufficient to keep pace with the non-irradiated organs (Alescio, 1966; Alescio and Ladu, 1962). In the younger organs, where mesenchymal cells predominate, there appears to be a greater incidence of pycnotic cells. Alescio and Ladu (1962) saw no recovery of the mesenchyme after 72 hours in vitro. Since viable mesenchymal tissue is a requisite for lung organogenesis, progress toward 
differentiation even after epithelial repair would not occur until after the mesenchyme recovers.

The progressive degeneration of irradiated lung cultures seen in this study conflicts with the results reported by Alescio (1966) and Alescio and Ladu (1962) on 11-day mouse lung. In their studies the 11 -day embryonic lung, which is about equivalent in development to 13-day rat lung, was exposed in vitro at doses up to $400 \mathrm{R}$ of $\mathrm{x}$-ray and $850 \mathrm{R}$ of $\gamma$-ray. Explants were submerged in Tyrode's solution and chick embryo extract during irradiation and were subsequently cultured in a chicken plasma-chick embryo extract clot. This submersion of the lung with its increased anaerobiosis during and after radiation exposure may have a protective effect; this perhaps explains the difference between their observations and the ones presented here. They observed that epithelial damage proceeded from the proximal to the distal portions of the tracheobronchial tree and that after 18 hours mesenchymal pycnosis was increased. Mitosis resumed after 12 hours and epithelial replacement occurred after 30 hours, although there was a change in epithelial morphology. Alescio (1966) reported that degenerated cells were removed from mesenchyme after 70 hours.

Alescio and Ladu's (1962) observations, made in vitro more closely resemble our in vivo studies with 13- and 15-day lungs. 
Following irradiation, the lung in utero exhibits degeneration particularly of the epithelial lining between four and 28 hours. Between 28 hours and 76 hours, there was a recovery as exemplified by increased mitotic activity and replacement of the epithelial tree, and in the 15-day lung, by a marked increase in proline incorporation.

It appears that radiation damage to the fetus is not due to indirect effects of ionizing radiation. Brent and McLaughlin (1960) shielded rat. fetuses and exposed the mothers or placentas to $400 \mathrm{R}$ and found that the fetuses incurred no radiation damage. The more primitive fetal cells have a greater DNA content than the adult cells (Schjeide and de Vellis, 1969) which may account in part for the greater radiosensitivity of the fetal tissue. On the other hand, the greater DNA content of fetal cells may provide for a greater degree of redundancy.

A number of factors may influence the differential survival between in vivo and in vitro development after exposure to $x$-ray. As discussed relative to liver, both oxygen tension during exposures as well as the trauma associated with explantation may influence the results. In addition, fetal cells are less committed (i. e. differentiated) than adult cells to a particular function or biochemical pattern of synthesis (Lehninger, 1970). Thus, if a mesenchymal cell survives radiation insult, it can respond in a variety of ways to compcnsatc for lost tissue. Particularly in vivo, phagocytosis removes 
cellular debris so that the mesenchyme can migrate within the fetus to compensate for focal degeneration (Schjeide and de Vellis, 1.969). On the other hand, repair mechanisms are less available under the in vitro conditions.

\section{Connective Tissue Biosynthesis}

The current theory of protein biosynthesis points to a mechanism whereby an initiator "derepresses" the DNA genome and allows the appropriate protein to be synthesized. While some-mediators have been identified, the initial mechanism by which the vast number of proteins are synthesized and as sembled is unknown. In these studies three examples of apparent shifts to connective tissue biosynthesis have been presented: (1) in the normal morphogenesis of lung; (2) during the in vitro development of lung explants; (3) as a response to injury by radiation. In the unaltered morphogenesis of the 15-day fetal lung, a progresive increase in the rate of connective tissue biosynthesis was found. In contrast, a diminution in the rate of connective tissue was noted with in vitro and post-irradiation development of 15 -day fetal lung. There was, however, a preferential shift to connective tissue (as measured by ${ }^{3}$ H-pro incorporation) in the proteins which were synthesized.

Previous studies indicate (Bernfield, 1970; Wessels, 1970) that the quality of fibril alignment, rather than the quantity of the collagen 
determine the morphology of lung tissue. While more definitive subcellular and chemical determinations would be required, it does appear that physico-chemical characteristics of the connective tissue in these three examples is not the same. In using the van de Grift stain, the connective tissue stained green in the four-hour-control cultures. In contrast, the irradiated tissues developing in vivo (especially at l day-post-radiation) were very acidophilic and stained a brilliant red, while those tissues which were irradiated and developed in vitro had a blue, basophilic connective tissue. The control lung explants lost thei $r$ affinity for stain after threedays inculture. To understand the significance of the shift to connective tissue formation observed here, more will have to be known about the ultrastructure and chemical makeup of the products, as well as the molecular mechanism which mediates the connective tissue synthesis in the normal and atypical environments. 


\section{CONCIUSIONS AND SUMMARY}

Three histological changes were observed when fetal liver was incubated in vitro: (1) increased necrosis; (2) increased fibrinogenesis; (3) decreased hematopoiesis. Failure to meet the oxygen requirement in the incubation atmosphere may be an important factor causing the increased necrosis. Since fetal liver metabolism is glycolytic in utero, it is not obvious why the parenchymal cells of the liver explants have a high oxygen requirement. It would seem that the insult of explantation has altered the cell metabolism, hence its nutritional requirements. Moreover, this method of culture selects for glycolytic cell types such as the fibroblastic-like cells and their ensuing fibrinogenesis. The decrease in hematopoietic elements may be due to the use of the liquid medium.

Histological changes in fetal liver, occurring after exposure to $435 \mathrm{R}$ of $\mathrm{x}$-rays, indicate a further alteration in the cellula $\mathrm{r}$ metabolism as seen by the increased size and frequency of cytoplasmic vacuoles and decreased granulation of the parenchymal cells. As with attempts by others to culture liver explants, the variability of the responses within a single treatment group was marked, thus masking the effects of radiation on hepatic organogenesis.

During normal morphogenesis of the lung, there is a progressive increase in the amount of connective tissue. Biochemical 
analysis of the lung during in vivo development (15 to 18 days of gestation) indicated that while the rate of total protein biosynthesis (as ${ }^{14} \mathrm{C}$-leucine incorporation) did not increase, the proportion of ${ }^{3} \mathrm{H}-\mathrm{proline}$ being incorporated into the protein did.

In the culture method used, fetal lungs, especially at 13 - and 15-days of gestation, developed and differentiated. Culturing did have some deleterious effects, however, as reflected by histological difference between organs developing in vitro and in vivo. These differences included the degeneration of the epithelia. and blood vessels, pycnosis especially in the mesenchyme, an initial decrease in mitosis and failure to keep pace with in vivo development. There appeared to be an "adaptation" to the in vitro envi ronment between one and three days post-explantation which was reflected by an increased mitotic frequency. These observations are further extended in the radiotracer studies of the 15 -day fetal lung, where the relative proportion of connective tissue (as ${ }^{3} \mathrm{H}-$ proline incorporation) increased with incubation, although the rate of total protein biosynthesis progressively decreased. Thus, while differentiation of the lings occurs in culture, it proceeds at a slower rate than it does in utero.

The radiation effects on the organogenesis of lung developing in vivo or in vitro observed in this study were: the sloughing of the epithelial lining, pycnosis, particula rly in the mesenchyme, 
deterioration of the blood vessels, an initial decrease in the mitotic frequency and a decreased rate of differentiation. Except for those lungs left in utero for three days, an increase in the amount of connective tissue relative to the controls could be seen histologically. The outstanding difference between the development patterns of irradiated lungs. was that those developing in vitro underwent progressive degeneration, whereas those remaining in utero showed a marked recovery between one and three days post-irradiation. It is concluded that the dynamic state of the fetus. and the undifferentiated state of the mesenchyme are able to compensate (at least partially) for the radiation damage incurred by the lung.

The histological observations were corroborated by the biochemical studies on the 15-day fetal ling. Post-irradiation development, like in vitro development, caused a decrease in the rate of overall protein synthesis in all but the 18 -day fetal lung (in utero 15-day lung, three days post-ixradiation). There was a relative increase in connective tissue in all irradiated lungs but the 16 -day fetal lung (in utero 15-day lung, one day post-irradiation) which was proportionally greater than that seen in the controls. In 15-day fetal lungs which were irradiated and developing in vitro, the re was a progressive decrease in the rate of total biosynthesis, but a greater proportion of the protein synthesized was connective tissue. Fifteenday fetal lungs which were irradiated and developing in utero showed 
a marked depression in the rate of connective tissue biosynthesis at one-day post-exposure compared to the control. At three-days postirradiation there was recovery as demonstrated by a ma rked elevation in the rate of connective tissue biosynthesis.

With time, lungs undergoing normal morphogenesis as well as differentiation inter rupted by in vitro incubation and/or $\mathrm{x}$-irradiation, all exhibted a relative increase in the proportion of connective tissue biosynthesis. The histological properties suggested that the nature of the connective tissue differed between the different. treatment groups. 


\section{BIBLIOGRAPHY}

Alescio, Tommaso. 1966. Response to $x$-irradiation of mouse embryonic lung cultured in vitro. Radiation effect on the epithelium growth rate. Experimental Cell Resea rch 43:459-473.

- 1973. Effect of a proline analog azetidine-2carboxylic acid on the morphogenesis of mouse embryonic lung. Journal of Embryology and Experimental Morphology 29:439-451.

Alescio, Tommaso and A. Cassini. 1962. Induction in vitro of tracheal buds by pulmonary mesenchyme g rafted on tracheal epithelium. Journal of Experimental Zoology 150:83-94.

Alescio, Tornmaso and E. Colombo Piperno. 1967. A quantitative assessment of mesenchymal contribution to epithelial growth rate in mouse embryonic lung developing in vitro. Journal of Embryology and Experimental Morphology 17:213-227.

Alescio Tommaso and A. M. Dani. 1971. The influence of mesenchyme on the epithelial glycogen and budding activity in mouse embryonic lung developing in vitro. Journal of Embryology and Experimental Morphology 25:131-140.

Alescio, Tommaso and M. di Michele. 1968. Relationship of epithelial growth to mitotic rate in mouse embryonic lung developing in vitro. Journal of Embryology and Experimental Morphology 19:227-237.

Alescio, Tommasco and Mario Ladu. 1962. Response to gammaradiation of mouse embryonic lung cultivated in vitro. Intero national Journal of Radiation Biology 5:579-589.

Alexander, R. W. and J. W. Grisham. 1970. Explant culture of rat liver. I. Method, morphology and cytogenesis. Laboratory Investigation 22:50-62.

Bacqe Z. M. and P. Alexander. 1961. Biochemical mechanisms for cellular efferts - the enzyme releasc hypothesis. In: Fundamentals of radiobiology. $2 \mathrm{~d}$ ed., New York, Pergamon Press, p. 263-279.

Bang, F. B. and A.:C. Warwick. 1965. I iver. In: Cells and tissues in culture: Methods in biology and physiology. ed. by E. N. Williner. Vol. 2. New York, Academic Press. p. 607-630. 
Bailey, A. J. 1968. Effect of ionizing radiation on connective tissue components. In: International review of connective tissue research, ed. by David A. Hall, Vol. 4. New York, Academic Press. p. 233-281.

Bernfield, M. R. 1970. Collagen synthesis during epitheliomesenchymal interactions. Developmental Biology 22:213-231.

Bloom, William and D. W. Fawcett. 1968. A textbook of histology. 9 th ed. Philadelphia, W. B. Saunders. 858 p.

Borghese, Elio. 1961. The effect of ionizing radiation on mouse embryonic lungs developing in vitro. Annals of the New York Academy of Sciences 95:866-872.

Brent; R. L. and M. M. M̀cLaughlin. 1960. The indirect effect of irradiation on embryonic development. I. Ir radiation of the mother while shielding the embryonic site. American Medical Association Journal of Diseases of Children 100:94-102.

Burch, H. B., O. H. Lowry, A. M. Kuhlman, Jeanette Skerjance, E. J. Diamant, S. R. Low ry and Patricia von Dippe. 1963. Changes in patterns of carbohydrate metabolism in developing rat liver. Journal of Biological Chemistry $238: 2267-2273$.

Campbell, A. K. and C. N. Hales. 1971. Maintenance of viable cells in an organ culture of mature rats. Experimental Cell Research 68:33-42.

Casarett,'A. P. 1968. Radiation Biology. Englewood Cliffs, New Jersey, Prentice Hall. 365 p.

Chen, J. M. 1954. The cultivation in fluid medium of organized liver, pancreas and other tissues of fetal rats. Experimental Cell Research 7:518-529.

Chvapil, M. and J. Hurych. 1968. Control of collagen biosynthesis. In: International review of connective tissue research, ed. by D. A. Hall. Vol. 4. New York, Academic Press. p. 68-196.

Croisille, Y. and N. M. LeDouarin. 1965. Development and regeneration of the liver. In: Organogenesis, ed. by $R$. L. De Haan and Helnrich Ursprung. San Francisco, Holt, Rinehart and Winston. p. $421-466$. 
Dameron, Florence. 1961. L'influence de divers mesenchymes sur la differenciation de l'epithelium pulmonaire de l'embryon de Poulet en culture in vitro. Journal of Embryology and Experimental Morphology 9:628 -633 (Abstracted in Biological Abstracts 37: no. $23014 .(1962$.)

de Belle, R., A. Brown, N. R. Blacklow, R. M. Donaldson and R. Lester. 1973. Organ-culture of fetal liver - new model system. (Abstract) Petiatric Research 7:292.

Ehrmann, R. I. and G. O. Gey. 1956. The growth of cells on a transparent gel of reconstituted rat-tail collagen. Journal of National Cancer Institute 16:1375-1403. (Abstracted in Biological Abstracts 31: no. 1490. 1957).

Eisen, H. J., W. H. Glinsman and P. Sherline. 1973. Effect of insulin on glycogen synthesis in fetal rat-liver in organ culture. Endoc rinology 92:584-588.

Fell, H. B. 1951. Histogenesis in tissue culture. In: Cytology and cell physiology, ed. by G. H. Bourne. 2d ed. Oxford, England, Cla redon Press. p. 419-440.

Fitton Jackson, Sylvia. 1953. Fibrinogenesis in vivo and in vitro. In: Nature and structure of collagen, ed. by J. T. Randall and Sylvia Fitton Jackson. New York, Academic Press. p. 140151.

. 1954. Connective tissue cells. In: The cell, ed. by Jean Brachet and A. E. Mirsky. Vol. VI. New York, Academic Press. p. 387-520.

Grobstein, Clifford. 1967. Mechanism of organogenetic tissue interaction. Journal of National Cancer Institute Monograph 26: 279-299.

Hagen, Ulrich. 1963. Viscosity of single-stranded deoxyribonucleic acid after $x$-irradiation in the native state. Nature 197:10041005.

Hazzard, D. G. and R. A. Budd. 1969. Effect of in utero x-irradiation on the peripheral blood of the newborn rat. In: Radiation biology of the fetal and juvenile mammal: Proceedings of the Ninth Annual Hanford Biology Symposia at Richland, Washington, er. by M. R. Sikov and D. D. Mahlum. (U. S. Atomic Energy Commission CONF-690501). p. 357-364. 
Hicks, S. P. and C. J. D'Amato. 1966. Effects of ionizing radiations on mammalian development. In: Advances in teratology, ed. by D. H: M. Woolam. Vol. 1. London, Logos Press. p. $106-243$.

Hillis, W. D. and F. B. Bang. 1962. The cultivation of human embryonic liver cells. Experimental Cell Research 26:9-36.

Izadian, H. and J. F: Duplan. 1957. Etude des depots de fer dans le foie des foetus de soures, normaux et irradies. Comptes Rendus Helidomadaries des Seance de l'Academies des Science 245:1756.

Kallman, F. and Clifford Grobstein. 1965. Source of collagen at epitheliomesenchymal interfaces during inductive interaction. Developmental Biology 11:169-183.

Kefalides, N. A. 1973. Structure and biosynthesis in basement membranes. In: International review of connective tissue research, ed. by D. A. Hall and D. S. Jackson. Vol. 6. New York, Academic Pres. p. 63-104.

Le Douarin, N.M. 1968. Synthese du glycogene dans les hepatocytes in voie de differentiation role des mesenchymes homologue et heterologue. Developmental Biology 17:101-114.

Leeson, C. R. and T. S. Leeson. 1966. Histology. Philadelphia, W. B. Saunders. 492 p.

Lehninger, A. L. 1970. Biochemistry; the molecular basis of cell structure and function. New York, Worth Publishers. 833 p.

Lowry, O. H. , N. J. Rosebrough, A. I. Farr and R. H. Randall. 1951. Protein measurement with the Folin phenol reagent. Journal of Biological Chemistry 193:265-275.

Maximow, A. A. and William Bloom. 1957. A textbook of histology. 7th ed. Philadelphia, W. B. Saunders. 628 p.

McManus, J. F. A. and Mowry, R. W. 1960. Staining methods, histological and histochemical. New York, Hoeber Medical Division, Harper and Rnw Publishers. p. 74; 235-236. 
Paul, J. and E. S. Pearson. 1957. Metabolism of chick embryonic liver explants during the transition from in vivo to in vitro conditions. Experimental Cell Research $\overline{12} \overline{2223}-23 \overline{0}$.

Pitot, H. C., Carl Peraino, Sam. Lesher and Carlos Lamar, Jr. 1965. Effect of gamma radiation on dietary and hormonal induction of enzymes in rat liver. Science 150:901-903.

Pollard, E. C. 1964. Ionizing radiation: effect on genetic transcription. Science 146:927-929.

Puck, T. T., D. Morkovin, P. I. Marcus and S. J. Ciecuira. 1957. Action of, $\mathrm{x}$-rays on mammalian cells. II. Survival curves of cells from normal human tissue. Journal of Experimental Medicine 106:485-500.

Rabes, Hartmut and Barbara Jantsch. 1971. Proliferationskinetik der Hepatocyten in primären Liberkulturen. Zeitzschrift fur Zelforsch und Mikrokopische Anatomie 112:414-429.

Räiha, N. C. R., A. I. Schwartz and M. C. Lindroos. 1971. Induction of tyrosine- $\alpha$-ketoglutarate transaminase in fetal rat and fetal human liver in organ culture. Pediatric Research $5: 70-76$.

Resnick, J. S., D. M. B rown and R. L. Venier. 1973. Oxygen toxicity on fetal kidney and lung in organ culture. (Abstract) Pediatric Research 7:315.

Rose, G. G., M. Kumegawa and M. Catoni. 1968. The circumfusion system for multipurpose culture chambers. II. The protracted malntenance of differentiation of fetal and newborn mouse liver in vitro. Journal of Cell Biology 39:430-450.

Rugh, Roberts. 1968. The mouse: its reproduction and development. Minneapolis, Burgess Publishing. $430 \mathrm{p}$.

- 1969. Chairman's remarks. In: Radiation biology of the fetal and juvenile mammal: Proceedings of the Ninth Annual Hanford Biology Symposia at Richland, Washington, ed. by M. R. Sikov and D. D. Mahlum. (U.S. Atomic Energy Commission CONF-690501) p. 381-391. 
Sandström, B. 1965. Studies on cells from liver tis sue cultivated in vitro. I. Influence of the culture method on cell morphology and growth patterns. II. The origin and mutual relationships of the cells. Experimental Cell Research 37:552-568.

Schjeide; O. A. and J. de Vellis. 1969. Mechanisms of radiation damage in the mammalian fetus and neonate. In: Radiation biology of the fetal and juvenile mammal: Proceedings of the Ninth Annual Hanford Symposia at Richland, Washington, ed. by M. R.' Sikov and D. D. Mahlum. (U. S. Atomic Energy Commission CONF-690501) p. 919-942.

Schneider, W.: C. 1957. Determination of nucleic acids in tissues by pentoseanalysis. In: Methods in enzymology, ed. by S. P. Colowick and N. O. Kaplan. vol. III. New York, Academic Press, p. 680-684.

Smith, C. H. and M. L. Shore: 1966. Impaired development of the rat liver enzyme activities at birth after irradiation in utero. Radiation Research 29:499-504.

Sorokin, Sergei. 1961. A study of the development in organ cultures of mammalian lungs. Development Biology 3:60-83.

- 1965. Recent work on developing lungs. In:

Organogenesis, ed. by D. L. De Haan and Heinrich Ursprung. San Francisco, Holt, Rinehart and Winston. p. 467-491.

Sorokin, Sergei, H. A. Padykula and Edith Herman. 1959. Comparative histochemical patterns in developing mammalian lungs. Developmental Biology 1:125-151.

Stevens, K. M. 1965. Oxygen requirements for liver cells in vitro. Nature 206:4980.

Taderera, J. V. 1967. Control of lung differentiation in vitro. Developmental Biology 16:489-512.

Trowell, O. A. 1966. Tissue culture in radiobiology. In: Cells and tissues in culture: methods in biology and physiology, ed. by E. N. Willmer. Vol. 3. New York, Academic Press. p. 64149.

Watanabe, H. 1966. A fine structure study of liver culture. Experimental Cell Research 42:685-699. 
Wessels, N. K. 1967. Avian and mammalian organ culture. In: Methods in developmental biology, ed. by F. H. Wilt and N. K. Wessels. New York, Tomas Y. C rowell. p. 445-456.

. 1970. Mammalian lung development: interactions in formation and morphogenesis of tracheal buds. Journal of Experimental Zoology $175: 455-466$.

Wessels, N. K. and Julia Cohen. 1968. Effects of collagenase on epithelia developing in vitro in lung, uteric bud and pancreas. Developmental Biology 15:294-309.

Wicks, W. D. 1968. Induction of ty rosine- $\alpha$-ketogluta rate transaminase in fetal rat liver. Journal of Biological Chemistry 243:900906.

- 1969. Induction of hepatic enzymes by adenosine $3^{\prime}, 5^{\prime}$-monophosphate in organ culture. Journal of Biological Chemistry 244:3941-3950.

Wilson, J. A. 1972. Principles of animal physiology. New York, MacMillan. p. 842 .

Wilson, J. G. and J. W. Karr. 1951. Effects of irradiation on embryonic development. I. X-rays on the loth day of gestation in the rat. American Journal of Anatomy 88:1-34.

Wilson, J. W.,.C. S. Groat and E. H. Leduc. 1963. Histogenesis of the liver. Annals of the New York Academy of Sciences 3: $8-24$.

Wolff, Etienne. 1968. Specific interactions between tissues during organogenesis. In: Current topics in developmental biology, ed. by A. A. Moscona and Alberto Monroy. Vol. 3. New York, Academic Press. p. 65-94.

Zirkle, R. E. 1957. Partial-cell radiation. In: Advances in Biological and Medical Physics 5:103-146. (Abstracted in Nuclear Science Abstracts 12: no. 8931. 1958) 


\section{A PPENDIX I}

\section{Contents of I-15 (Leibovitz) Medium}

The contents of L-15 medium, as specified by Crand Island Biologics (Crand Island, Ill.) catalog;

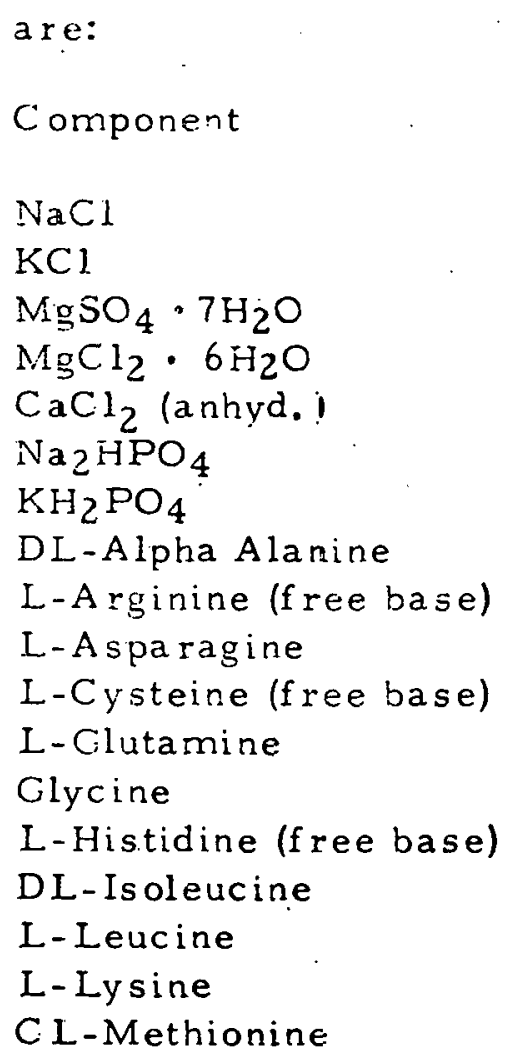

4:0.00

200.00

200.00

140.00

190.00

50.00

450.00

500.00

250.00

120.00

300.00

200.00

250.00

250.00

125.00

75.00

150.00
Component

$\mathrm{mg} / \mathrm{L}$

DL-Phenylalanine

L-Serine

DL-Threonine

L-T ryptophain

L-Ty rosine

DL-Valine

Choline

Folic acid

Inositol

Nicotinamide

DL-Ca panthothenate

Pyridoxine $\mathrm{HCl}$

Riboflavin-5-phosphate, Sodium

Thiamin monophosphate

Sodium py ruvate

$D(+)$ Galactose

Phenol red

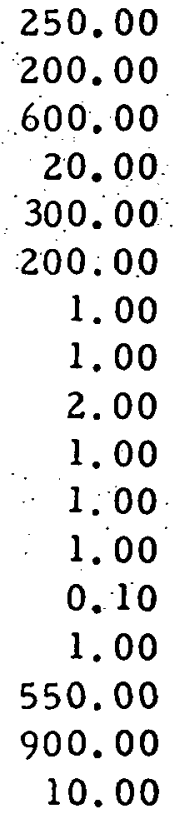

1.00

2.00

1.00

1.00

1.00

0.10

1.00 550.00 900.00 10.00 


\section{APPENDIX II}

\section{Contents of Bouin's Fixative}

Saturated picric acid

$1000 \mathrm{cc}$

Formalin

$333 \mathrm{cc}$

Glacial acetic acid

$66 \mathrm{cc}$ 


\section{APPENDIX III}

\section{Procedure for: Paraffin Embedding}

The tissue holders containing the organ cultures were placed in the following solutions for $15 \mathrm{~min}$. each: $80 \%$ alcohol, $95 \%$ alcohol, $95 \%$ alcohol, $100 \%$ alcohol, $100 \%$ alcohol, xylene, xylene. The tissues were placed in a paraffin bath (maintained at $56-61{ }^{\circ} \mathrm{C}$ ) for $30 \mathrm{~min}$. before being embedded into paraffin blocks using a Tissue Tek II Embedding Center (Technicon). 


\section{APPENDIX IV}

\section{Procedurefor Van de Grift's Stain}

The procedure for Van de Grift!s stain is discussed in McManus and Mow ry (1960).., The following solutions a.re required for the stain: Harris hematoxylin

$\begin{array}{lrl}\text { Hematoxylin } & 1 & \mathrm{~g} \\ \text { Absolute alcohol } & 10 \mathrm{cc} \\ \text { Ammonium alum } & 20 & \mathrm{~g} \\ \text { Distilled water } & 200 & \mathrm{cc} \\ \text { Mercuric oxide } & 0.5 \mathrm{~g}\end{array}$

Dissolve hematoxylin in the alcohol and the alum in the water with heat. Mix and boil quickly. Add mercuric oxide and cool rapidly. It is ready for use.

Ponceau fuchsin

Ponceau de Xylidine

Acid fuchsin

Glacial acid acid

Distilled water
$0.7 \mathrm{~g}$
$0.3 \mathrm{~g}$
1. $0 . \mathrm{g}$
$100 \quad \mathrm{CC}$

$1 \%$ aqueous phosphomolybdic acid

Light green solution

$\begin{array}{ll}\text { Light green S. F. yellowish } & 1.0 \mathrm{~g} \\ \text { Glacial acetic acid } & 1.0 \mathrm{~g} \\ \text { Distilled water } & 100 \mathrm{cc}\end{array}$

ITI a queous glacial acetic acid 


\section{Procedure for Paraffin Sections}

1. Slides with the cooled paraffin sections were placed in the follow ing solutions for 5 min each: xylene, xylene, $100 \%$ alcohol, $95 \%$ alcohol, $80 \%$ alcohol.

2. Slides were placed in Haris' hematoxylin for $10 \mathrm{~min}$.

3. Slides were rinsed in $1 \%$ hydrochloric acid in $95 \%$ alcohol.

4. Slides were rinsed in $1 \%$ ammonia in $95 \%$ alcohol.

5. Slides were washed for 5-10 min in running tap water.

6. Slides were placed into Ponceau fuchsin for 5-10 min.

7. Slides were dipped 3-5 times in the phosphomolybdic acid.

8. Slides were transferred directly into the light green solution for 10 min (until sections were a dark green).

9. Slides were washed briefly in tap water and placed in the glacial acetic acid solution for $3 \mathrm{~min}$ and dehydrated $w$ ith alcohols and xylene.

10. Slides were coverslipped using Histoclad mounting media.

\section{Procedure for Methacrylate Sections}

1. Methacrylate sections, which had been thoroughly dried were warmed to $60^{\circ} \mathrm{C}$.

2. The slide was covered with Delafield's hematoxylin (Carolina Biological Supply Co., Gladstone, Oregon) for $15-30 \mathrm{sec}$ and rinsed gently. 
3. Slides were placed into ponceau fuchsin for $10 \mathrm{~min}$.

4. Slides were dipped 3-5 times in the phosphomolybdic acid.

5. Slides were transferred directly into the light green solution for $20 \mathrm{~min}$

6. Slides were washed briefly and placed in the glacial acetic acid solution for $3 \mathrm{~min}$ :

7. Slides were washed thoroughly and air dried.

8. Slides were coverslipped using Histoclad mounting media.

Results after Staining

Erythrocytes - red to orange

Conrective tissue - green

Nuclei - blue

Cytoplasmi - pink 


\section{APPENDIX V}

\section{Procedure for Methacrylate Embedding}

The tissue holders containing the organ cultures were placed in the following solutions for 10 min each: $70 \%$ ethanol; $80 \%$ ethanol; $95 \%$ ethanol; $95 \%$ ethanol; $100 \%$ ethanol and then placed in a fresh solution of $100 \%$ ethanol for one hour. The tissues were individually placed in small vials containing $1 \mathrm{cc}$ of methac rylate solution " $\mathrm{A}$ ". (Glycol methacrylate, butoxyethanol and benzoyl peroxide, Ivan Sorvall, Inc., Newtown, CT). The vials were sealed and placed in a $5^{\circ} \mathrm{C}$ refrigerator overnight. The pieces of tissue were transferred into plastic embedding cups 1 OMNI-cups $6 \times 12 \times 5 \mathrm{~mm}$, Ivan Sorvall, Inc.) containing $2 \mathrm{cc}$ of solution "A". Plastic block holders (Ivan Sorvall, Inc.) were placed over the cups and sealed with melted paraffin. The methacrylate and tissues were exposed to $\gamma$-radiation from a ${ }^{60} \mathrm{Co}$ source for 1 hour. The hardened plastic blocks were removed immediately after exposure to $\gamma$-rays. 


\section{APPENDIX VI}

\section{Preparation of Autoradiog raphs}

Autoradiog raphs were prepared in a darkroom using Watten Series I filtered as safe lights. Ilford K-5 nuclear track emulsion (Ilford Ltd., Ilford, England) in the gel form was.mixed 1:1 with distilled water in a vial. The vial was placed in light-tight container and then into a $45^{\circ}$ oven for $30 \mathrm{~min}$. The emulsion was mixed thoroughly and rewarmed to $32^{\circ}$ in dipping container. Slides, warmed to $32^{\circ} \mathrm{C}$, were dipped one at a time in the emulsion and were drained on end until dry. Then slides were placed in light-tight boxes, sealed with photog raphic tape and placed into a $5{ }^{\circ} \mathrm{C}$ refrigerator for 6 weeks. The slides were developed in the dark room by placing them in following solutions:

$\begin{array}{lr}\text { D-19 developer } & 3 \mathrm{~min} \\ \text { Stop bath } & 30 \mathrm{sec} \\ \text { Fixer (Rapid-Fix) } & 5 \mathrm{~min} \\ \text { Running water } & 5 \mathrm{~min} \\ \text { Photo-Flo } & 30 \mathrm{sec}\end{array}$

(All solutions were purchased from Eastman Kodak Co.)

Slides were allowed to dry thoroughly. Then the slides were stained at $60^{\circ} \mathrm{C}$.with Delafield's hematoxylin (Carolina Biological Supply Co., Gladstone, Oregon) for $15 \mathrm{sec}$ and gently washed in water. 
Eosin, containing $10 \mathrm{~g}$ eosin " $\mathrm{Y}$ ", $50 \mathrm{cc}$ of distilled water and $940 \mathrm{cc}$ of $95 \%$ ethanol, was placed on warmed slides for $3-5$ sec. The slides were coverslipped using Histoclad (Clay-Adams, Parsippany, N.J.). 


\section{APPENDIX VII \\ Procedure for the Determination of DNA}

Schneider (1957) originally outlined the procedures for separation of the nucleic acids from protein and the DNA determination. The diphenylamine reagent was made fresh prior to each determination:

$\begin{array}{lrr}\text { Diphenylamine } & 1 & \mathrm{~g} \\ \text { Glacial acetic acid } & 100 & \mathrm{cc} \\ \text { Conc. Sulfuric acid } & 2.75 \mathrm{cc}\end{array}$

Procedure for standard curve:

1. A highly polymerized DNA from Sigma Lot D7951 was prepared at a concentration of $0.1 \mathrm{~g}$ in $200 \mathrm{cc}$ wate $\mathrm{r}$ containing $0.7 \mathrm{cc}$ conc. hyd rochloric acid.

2. Aliquots of $0.1,0.2,0.3$ and $0.4 \mathrm{cc}$ of the standard were removed and brought to $0.5 \mathrm{cc}$ total volume witi distilled water.

3. One cc of $7.5 \%$ trichloracetic acid (TCA) was added and the standards were hydrolyzed for $20 \mathrm{~min}$ at $90^{\circ} \mathrm{C}$.

4. The standards were cooled and $1.5 \mathrm{cc}$ of diphenylamine reagent was added.

5. The tubes were heated for $10 \mathrm{~min}$ in a boining water bath.

6. The tubes were cooled and read at $600 \mathrm{~nm}$ on a Gilford Spectrophotorneter.

Procedurefor samples:

1. 2. 0 ce of diphenylamine reagent was adoré to a color tube. 
2. $1.0 \mathrm{cc}$ of the supernatant was added and mixed.

3. The tube was heated for $10 \mathrm{~min}$ in a boiling water bath.

4. The tube was cooled and read at $600 \mathrm{~nm}$ on a Gilford spectrophotometer. 


\section{APPENDIX VIII}

\section{Procedure for the Determination of Protein}

The Low ry et al. (1951) method of proteinanalysis was used on the dissolved precipitates. Three solutions are required for this protein determination:

"A" $2 \%$ sodium carbonate (anhydrous) in $0.1 \mathrm{~N}$ sodium hydroxide

"B" $2 \%$ potassium - sodium tartrate and $1 \%$ cupric sulfate crystals in $0.1 \mathrm{~N}$ sodium hydroxide

Fifty $c c$ of " $A$ " and one $c c$ of " $B$ " were mixed just before the determination.

Folin and Ciocatteu phenol reagent (Harleco, Philadelphia, PA) mixed $1: 1$

Purified bovine plasma, Grade "A" (Calbiochem Lot \#72104) was dissolved aseptically in distilled water at concentrations of $50 \mu \mathrm{g} / \mathrm{cc}$, $100 \mu \mathrm{g} / \mathrm{cc}, 150 \mu \mathrm{g} / \mathrm{cc}, 200 \mu \mathrm{g} / \mathrm{cc}$. An aliquot of $0.5 \mathrm{cc}$ was removed from each standard concentration and the protein content was de: termined by the following procedure.

Procedure:

1. The dissolved precipitate volumes were $0.1,0 . ?$ or 0.5 cc depending on the protein concentration.

2. Water was added until the final volume is $0.5 \mathrm{cc}$. 
3. Five $c c$ of the "A"-"B" mixture was added to the protein solution.

4. One-half $\mathrm{cc}$ of diluted Folin phenol reagent was added and the mixture was shaken vigorously.

5.: The color was allowed to develop for $30 \mathrm{~min}$ and read at $660 \mathrm{nn}$ on a Gilford spectrophotometer (Oberlin, Ohio). 
APPENDIX IX

Contents of Packard Naphthalene PPO

Dioxane Scintillation Fluid

Naphthalene

$100 \mathrm{~g}$

PPO

$3 \mathrm{~g}$

POPOP

$0.2 \mathrm{~g}$

Dioxane

$730 \quad \mathrm{cc}$

Toluene

$135 \quad c c$

Absolute Methanol

$35 \mathrm{cc}$ 


\section{DISTRIBUTION}

No. of

Copies

OFFSITE

1

22
No. of

Copies

OFFSITE (continued)

AEC Division of Biomedical and Environmental Research

N. F. Barr

W. W. Burr

C. E. Carter

R. D. Cooper

G. Duda

C. W. Edington

R. J. Engelmann

D. Grahn

E. B. Harvey

H. Hollister

J. S. Kirby-Smith

J. L. Liverman

K. E. Lockridge

S. Marks

M. L. Minthorn

C. Osterberg

R. L. Persing

M. Schulman

B. 0. Stuart

J. Swinebroad

B. W. Wachholz

R. L. Watters

W. W. H. Weyzen

R. W. Wood

M. W. Wrenn

2 AEC Division of Space Nuclear Systems

G. P. Dix

T. J. Dobry

1 AEC Bethesda Technical

Library

1 AEC Library Washington
2

AEC Patent Office-Hdqts

Air Force School of Aerospace Medicine

$1 \quad$ Air Force Surgeon General

Argonne National Laboratory (AEC)

Army Environmental Hygiene Agency

1 Army Letterman Inst. of Research

2 Army Medical Field Service School

1 Army Natick Laboratories

1. Army Walter Reed Medical Center

1 Atomics International (AEC)

1 Battelle Memorial Institute, Davidson (AEC)

$2 !$ Battelle Memorial Institute, Davis (AEC)

$4 \quad$ Brookhaven National Laboratory (AEC)

1. California Inst. of Tech. AT(04-3)-767 (AEC)

1 Case Western Reserve University (AEC)

1 Department of Commerce, NBS (COMM)

1 Dept. of Agriculture National Library (AGR) 
No. of

\section{Copies}

\section{OFFSITE (continued)}

1 Dept. of Agr. Animal and Plant Health Service

1 Dept. of Interior, Water Resources Res.

1 - DNA Radiobiology Research Institute

1 DNA Washington

2 Du Pont Company Aiken (AEC)

1 Du Pont Company Wilmington (AEC)

1 Eastern Environmental Radiation Lab (HEW)

1 EG and G Incorporated, Las Vegas $\overline{(A E C)}$

1 EG and G Incorporated, Santa Barbara (AEC)

1 Environmental Protection Agency/ DAP (HEW)

1 Environmental Protection Agency/ DAP (AEC)

1 Environmental Protection Agency, NERC (AEC)

2 Franklin Mclean Memorial Research Inst. (AEC)

1 General Electric Company Pleasanton (AEC)

1 Jet Propulsion Laboratory (NASA)

1 Kent State University. (AEC)
No: of

Copies

OFFSITE (continued)

3

Lawrence Berkeley Laboratory (AEC)

3 Lawrence Livermore Laboratory (AEC)

1 Library of Congress

1 Lockheed-Georgia Company (AF)

3 Los Alamos Scientific Laboratory. (AEC)

1 Lovelace Found for Med. Ed. and Res. (AEC)

NASA John F Kennedy Space Center

1 National Bureau of Standards (COMM)

1 National Library of Medicine (HEW)

National Technical Information ? Service (COMM)

1 New York State Dept of Health (HEW)

1 New York University Medical Center $\underline{(\mathrm{AEC})}$

2 Oak Ridge Associated Universities (AEC)

4 Oak Ridge National Laboratory (AEC)

2 Public Health Service Rockville (HEW)

1 Public Health Service Winchester: (HEW)

1 Puerto Rico Nucl Cntr., AT-(40-1)-1833, (AEC)

Savannah River Ecology Laboratory (AEC) 
No. of

Copies.

1 Systems Group of Trw, Inc. (AEC)

1 University of Chicago (Army)

1 University of Tennessee, Oak Ridge (AEC)

$1 \quad$ University of Utah (AEC)

1 University of Washington (AEC)

$1 \quad$ Virginia Associated Research Center (NASA)

1. Washington State University (AEC)

1 William Beaumont Army Medical Center (Army)

ONSITE-HANFORD

1

AEC/RL Patent Attorney

R. M. Poteat

2 AEC Richland Operations Office
P. Holstead

B. J. Melton

3 Atlantic Richfield Hanford Company

G. E. Backman

A. E. Barber

B. J. McMurray

1 Douglas United Nuclear, Inc. C. D. Corbit

2 Hanford Environmental Health

Foundation

P. A. Fuqua

W. D. Norwood
No. of

Copies

ONSITE-HANFORD (continued)

1

U.S. Testing

W. V. Baumgartner

51 Battelle-Northwest

Technical Information (3)

R. R. Adee

E. L: Alpen

W. J. Bair

J. E. Ballou

R. L. Buschbom

A. C. Case

D. K. Craig

F. T. Cross

G. E. Dagle

H. Drucker

R. F. Foster

M. E. Frazier

J. J. Fuquay

M. F. Gillis

P. L. Hackett

J. C. Hampton

V. G. Horstman

F. P. Hungate

E. L. Klepper

J. E. Lund

D. D. Mahlum (5)

B. J. McClanahan

K. E. McDonald

J. M. Nielsen

J. F. Park

H. M. Parker

H. A. Ragan

C. L. Sanders

M. R. Sikov (5)

V. H. Smith

J. K. Soldat

M. F. Sullivan

K. L. Swinth

J. M. Thomas

R. C. Thompson

C. M. Unruh 
No. of

Copies

ONSITE-HANFORD (continued)

Battelle-Northwest (continued)

B. E. Vaughan

A. P. Wehner

W. R. Wiley

G. M. 'Zwicker

1 Battelle Columbus Laboratory

W. J. Clarke 